University of Louisville

ThinkIR: The University of Louisville's Institutional Repository

Electronic Theses and Dissertations

$12-2019$

\title{
Meta-engagement: an examination of employee engagement antecedant variable interactions and the impact on engagement outcomes.
}

Joshua Branden Jordan

University of Louisville

Follow this and additional works at: https://ir.library.louisville.edu/etd

Part of the Organizational Behavior and Theory Commons

\section{Recommended Citation}

Jordan, Joshua Branden, "Meta-engagement: an examination of employee engagement antecedant variable interactions and the impact on engagement outcomes." (2019). Electronic Theses and Dissertations. Paper 3338.

https://doi.org/10.18297/etd/3338

This Doctoral Dissertation is brought to you for free and open access by ThinkIR: The University of Louisville's Institutional Repository. It has been accepted for inclusion in Electronic Theses and Dissertations by an authorized administrator of ThinkIR: The University of Louisville's Institutional Repository. This title appears here courtesy of the author, who has retained all other copyrights. For more information, please contact thinkir@louisville.edu. 


\title{
META-ENGAGEMENT: AN EXAMINATION OF EMPLOYEE ENGAGEMENT ANTECEDANT VARIABLE INTERACTIONS AND THE IMPACT ON ENGAGEMENT OUTCOMES
}

\author{
By \\ Joshua Branden Jordan \\ B.A., Purdue University, 2002 \\ M.S.M., Troy University, 2004
}

\begin{abstract}
A Dissertation
Submitted to the faculty of the

College of Education and Human Development of the University of Louisville in Partial Fulfillment of the Requirements

for the Degree of
\end{abstract}

Doctor of Philosophy

In Educational Leadership and Organizational Development

Department of Educational Leadership, Evaluation, and Organizational Development University of Louisville

Louisville, Kentucky

December 2019 
C Copyright 2019 by Joshua Branden Jordan

All rights reserved 

META-ENGAGEMENT: AN EXAMINATION OF EMPLOYEE ENGAGEMENT ANTECEDANT VARIABLE INTERACTIONS AND THE IMPACT ON ENGAGEMENT OUTCOMES

\section{By}

Joshua Branden Jordan

B.A., Purdue University, 2002

M.S.M., Troy University, 2004

A Dissertation Approved on

September 26, 2019

Dr. Brad Shuck, Dissertation Director

Dr. Jeff Valentine

Dr. Jacob Gross

Dr. Kevin Rose 


\section{DEDICATION}

To Megan Walendzik, the strongest person I know. 


\section{ACKNOWLEDGEMENTS}

I would like to thank my fiancé Kelly, who has been a fierce supporter of mine with this study. Her support, knowledge, wisdom and love are immeasurable and appreciated. Her daughter Megan has been a source of inspiration. Together they inspire me to do more and to be the best I can before God. To my sons Alex and Brayden, who kept me full of cheer during this journey, I send love and appreciation. To friends, family, work colleagues and fellow social scientists who have aided me in this journey, I give thanks.

To my committee, thank you for the mentorship through this process. I appreciate all that you have done to make this dream become a reality. To Dr. Valentine I send appreciation for making statistics as easy as $2+2$ (well, the hand written ANOVA formula is a bit more than that, but once you get the hang of it...). Thank you for introducing me to $\mathrm{R}$. Thank you to Dr. Rose for giving me a deeper and better appreciation of constructs and the underlying construct measurement. This was critical to understanding issues discovered during this dissertation. To Dr. Gross, thank you for the encouraging words, especially at the beginning of my journey when I was feeling much like a fish out of water. Thank you for swimming along!

Finally, thank you Dr. Shuck. He understood right away that I was talking about engagement. He saw my passion as a seed and watered it immensely. Thank you for all your support during this journey. I look forward to tackling engagement and inspiring employees and leaders to get the most out of their own engagement journeys. 


\title{
ABSTRACT \\ META-ENGAGEMENT: AN EXAMINATION OF EMPLOYEE ENGAGEMENT ANTECEDANT VARIABLE INTERACTIONS AND THE IMPACT ON ENGAGEMENT OUTCOMES
}

\author{
Joshua B. Jordan
}

September 26, 2019

This dissertation is a meta-analysis of employee engagement, employee engagement antecedent variable relationships, and the impact on engagement outcomes. Specifically, this analysis excluded the use of the Utrecht Work Engagement Scale (UWES) as a measure for employee engagement. Using the model proposed by Shuck and Wollard (2011) to understand relationship magnitude, this study examined the relationship of employee engagement antecedents (work-family conflict and supportive organizational culture), antecedents in relation to employee engagement and intent to turnover, and the relationship between employee engagement and intent to turnover. The results suggest a significant effect size for the pairing work family conflict/intent to turnover $(r=.316, \mathrm{~N}$ $=39104, k=57)$ and employee engagement/intent to turnover $(r=-.325, \mathrm{~N}=35962, k=$ 12). No studies were found that included other pairings. These findings suggest that despite previous research detailing the inadequacy of the UWES as a measure for employee engagement, the empirical exploration of antecedent variables and outcomes with employee engagement measures other than the UWES is still lacking. Implications to research, theory, and practice are discussed. 


\section{TABLE OF CONTENTS}

PAGE

ACKNOWLEDGEMENTS..............................................................

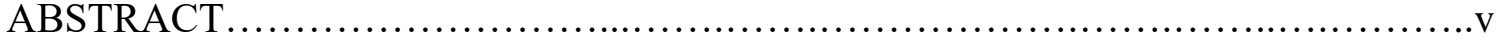

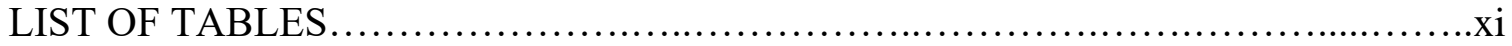

LIST OF FIGURES....................................................................

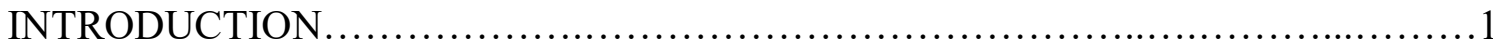

Background to the Problem...................................................

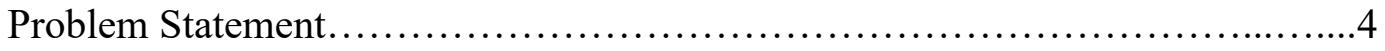

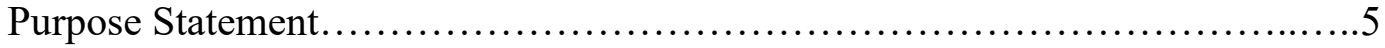

Research Questions..................................................6

Conceptual Framework.....................................................

Work-Family Conflict...........................................

Supportive Organizational Culture .................................... 8

Employee Engagement............................................. 8

Intention to Turnover.................................................. 10

Significance of the Study................................................... 10

Definition of Key Terms................................................12

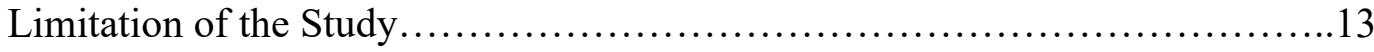

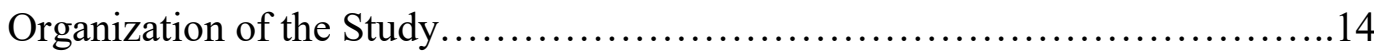

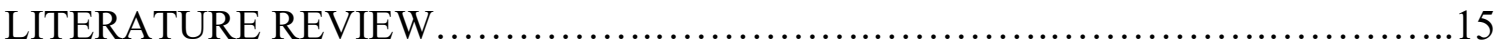

Employee Engagement: Foundational Roots..................................15 
Need-satisfying: Kahn............................................. 15

Work Engagement/burnout antithesis..............................17

Satisfaction-engagement framework................................ 18

Multidimensional approach to engagement............................19

The Current State of Employee Engagement...................................20

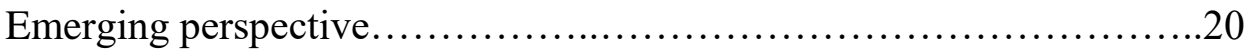

Redefining the employee engagement construct......................20

Further employee engagement refinement: Management literature........21

Tying research together: Human Resource Development.................23

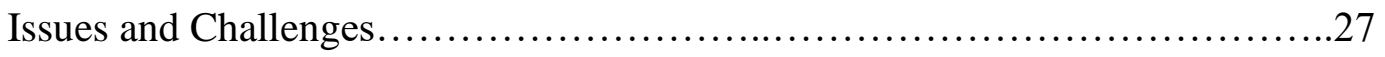

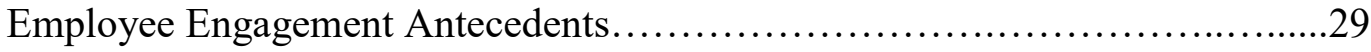

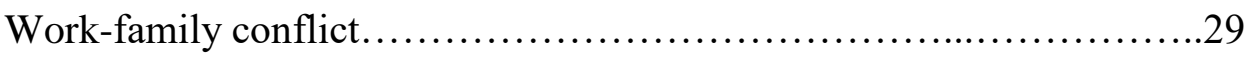

Supportive organizational culture ....................................32

Employee Engagements Outcomes: Intent to Turnover...........................34

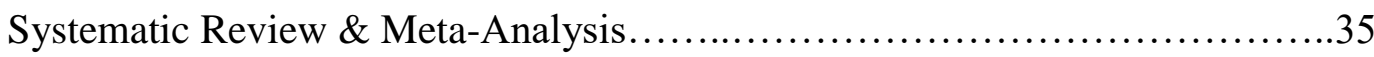

Conclusion and Study Organization...........................................

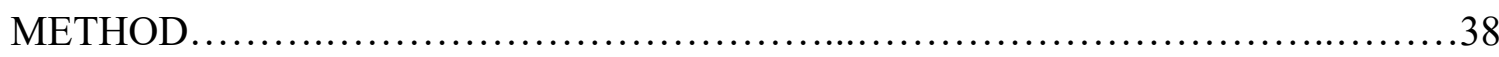

Conceptual Framework.................................................... 38

Study Inclusion and Exclusion Criteria....................................40

Search strategies................................................... 40

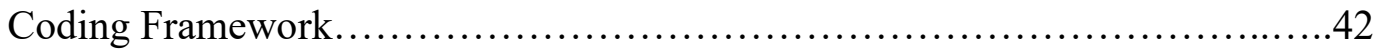

Study coding procedures..........................................42

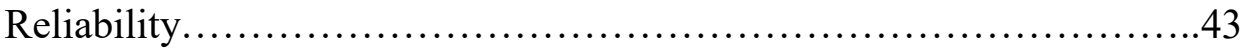


Assessment of study quality...................................43

Statistical Procedures and Conventions Used................................44

Selection of effect size.........................................44

Power analysis................................................46

Handling of non-independent effects...........................46

Data Analysis Framework..............................................47

Fixed vs. random effects model.................................47

Homogeneity analysis..........................................48

Moderator effects................................................48

Publication Bias................................................49

Summary .......................................................49

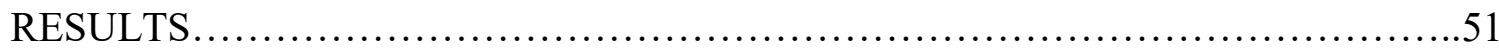

Search Results....................................................51

Screening results................................................. 51

Coding results...............................................52

Descriptive Statistics.................................................53

Variable pair distribution......................................54

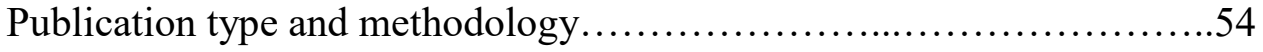

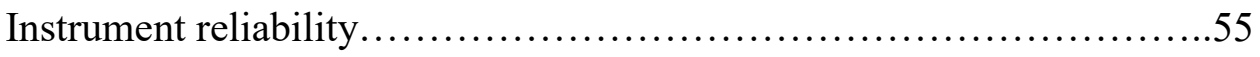

Use of employee engagement instruments.........................56

Effect size and Fisher's Z transformation............................57

Random-Effects Model Results......................................60

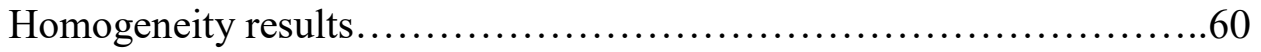


Confidence intervals............................................62

Mean effect size conversion......................................64

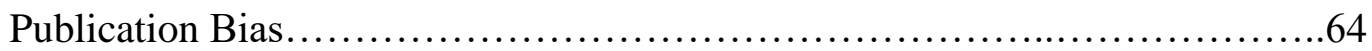

Funnel plots................................................65

Trim-and-fill results..........................................67

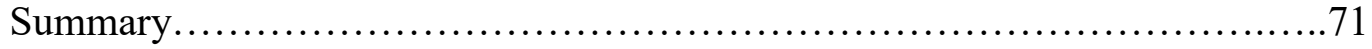

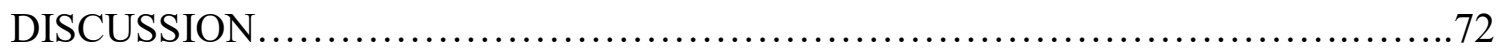

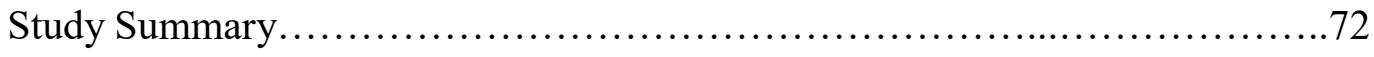

Study Synopsis.................................................. 75

Findings........................................................... 76

Research questions Q1, Q2a, Q3a, and Q3b.........................76

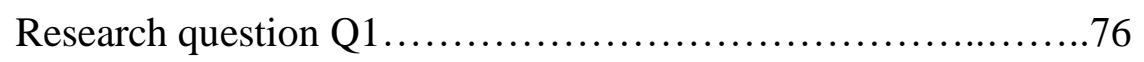

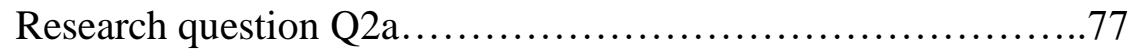

Research question Q3a..................................79

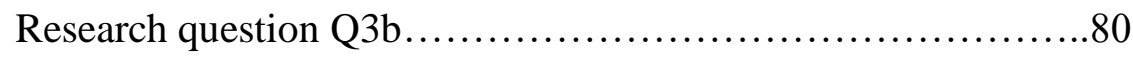

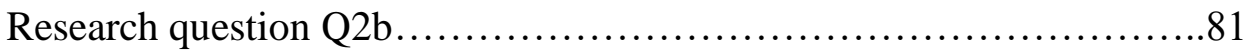

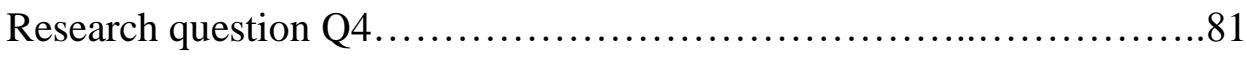

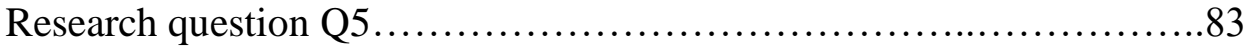

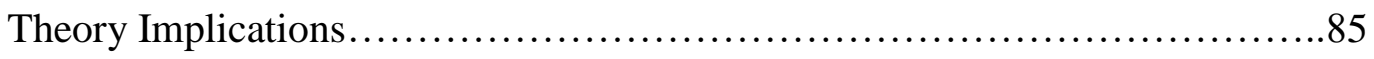

Research Implications...........................................87

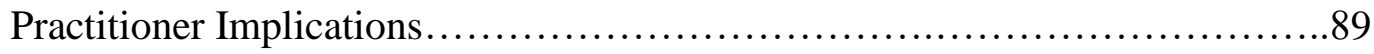

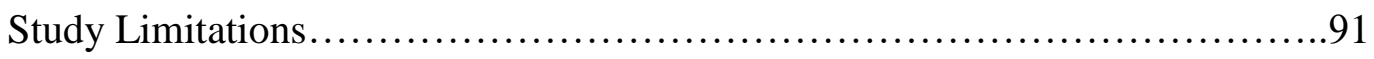

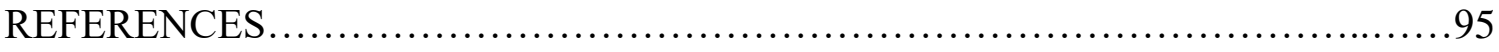




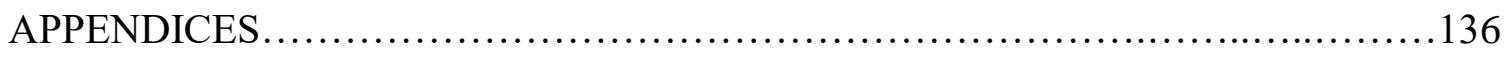

Appendix A - Screening Guide.............................................136

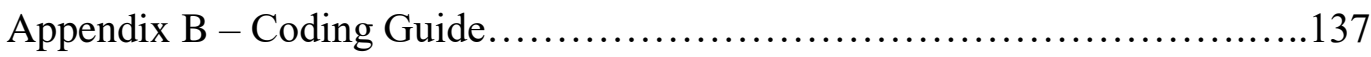

Appendix C - Instrument Inclusion/Exclusion Criteria.........................139

Appendix D - Random Effects Table .....................................147

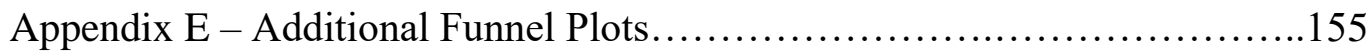

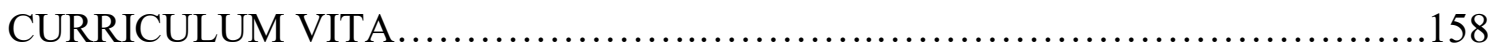




\section{LIST OF TABLES}

$\begin{array}{ll}\text { TABLE } & \text { PAGE }\end{array}$

4.1. Screening Results..............................................................

4.2. Coding Results.......................................................... 53

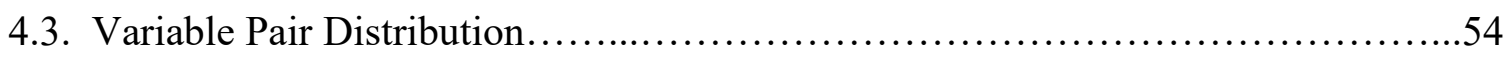

4.4. Publication Type by Variable Pairing........................................55

4.5. Study Methodology by Variable Pairing...................................55

4.6. Instrument Reliability Statistics......................................56

4.7. Employee Engagement Instrument Use.................................57

4.8. Correlations and Fisher's Z Transformation.................................57

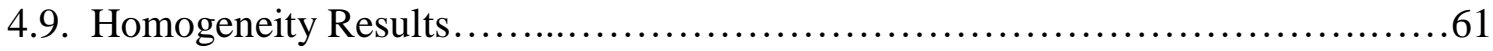

4.10. Heterogeneity Results..................................................62

4.11a. Work-Family Conflict/Intent to Turnover Confidence Intervals.................63

4.11b. Employee Engagement/Intent to Turnover Confidence Intervals...............63

4.12. Conversion of Mean Effect Sizes to Correlations...................................64

4.13. Trim-and-Fill Model Results...............................................68

4.14. Mean Effect - Correlation Model Comparison...............................69

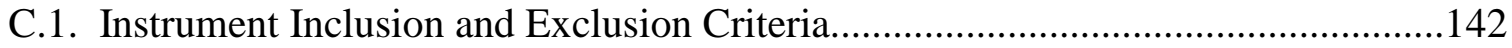

D.1 Work-Family Conflict/Intent to Turnover Study Information....................148

D.2 Employee Engagement/Intent to Turnover Study Information..................153

E.1 Work-Family Conflict/Intent to Turnover Funnel Plots......................156 
E.2 Employee Engagement/Intent to Turnover Funnel Plots......................157 


\section{LIST OF FIGURES}

FIGURE

PAGE

2.1. Wollard \& Shuck (2011) Employee Engagement Model...........................36

3.1. The Conceptual Framework of the Research Design.............................38

4.1. Funnel plot for pairing work-family conflict/intent to turnover..................66

4.2. Funnel plot for pairing employee engagement/intent to turnover.................67

4.3. Trim-and-Fill funnel plot for pairing work-family conflict/intent to turnover.......70

4.4. Trim-and-Fill funnel plot for pairing employee engagement/intent to turnover.....71 


\section{CHAPTER 1}

\section{INTRODUCTION}

This chapter begins with a background of the current study and is followed by both the problem as well as the purpose statements. Research questions are then presented, which are followed by an introduction of the theoretical background of the variables. Definition of terms, significance of this study, and limitations close this chapter.

\section{Background to the Problem}

Recent estimates place the cost of low levels of employee engagement at close to $\$ 400$ billion per year (Byrne, 2015). Employee engagement is defined as "an individual employee's cognitive, emotional, and behavioral state directed toward desired organizational outcomes" (Shuck \& Wollard, 2010, p. 103). Research has reliably shown that organizations with higher levels of employee engagement outperform their counterparts by $22 \%$, and earn $28 \%$ more in earnings-per-share than organizations with low levels of employee engagement (Harter, Agrawal, Plowman \& Asplund, 2010). Research has further indicated that organizational practices influence employee engagement to a great extent (Ghosh, Rai, \& Sinha, 2014; Ludwig \& Frazier, 2012). For example, organizations that placed an emphasis on safety management processes experienced $48 \%$ less safety incidents, saved $\$ 1.7$ million in related costs, and had increased levels of employee engagement (Harter, Schmidt, Agrawal \& Plowman, 2012; 
Lockwood, 2007; Wachter \& Yarlo, 2014). Building high levels of employee engagement increases individual motivation, deepens the meaningfulness of work to individuals, and reduces undesirable organization outcomes (Fairlie, 2011; Kumar \& Pansari, 2014).

One of the more connected outcomes to employee engagement is an employee's intention to turnover (Shuck, Reio, \& Rocco, 2011; Shuck, Twyford, Reio, \& Shuck, 2014). Intention to turnover occurs when an individual has "a conscious and deliberate desire to leave the organization within the near future" (Carmeli \& Weisberg, 2006, p. 193). Research has suggested that engagement significantly influences individual turnover intentions (Andrew \& Sofian, 2014). Estimated costs of retraining and replacing an employee lost to turnover often exceed the cost of the original employee, and it also negatively impacts organizational performance outcomes (Hancock, Allen, Bosco, McDaniel, \& Pierce, 2011; MacLeod \& Clarke, 2009). However, when employees maintain positive perceptions of organizational practices, engagement and performance both increase while turnover decreases (Shuck et al., 2014). According to the research, organizations stand to gain appreciably from an engaged workforce.

One factor shown to influence both employee engagement as well as turnover is an individual's ability to manage the struggle between the responsibilities of work and the responsibilities an individual has to their family (MacLeod \& Clarke, 2009; Shankar \& Bhatnagar, 2010). Scholars have identified this struggle as work-family conflict. Work-family conflict is defined as:

[A] form of inter-role conflict in which the role pressures from the work and family domains are mutually incompatible in some respect. That is, participation 
in the work (family) role is made more difficult by virtue of participation in the family (work) role. (Greenhaus \& Beutell, 1985, p. 77)

Further research into work-family conflict has separated the nature of conflict into work interfering with family (WIF) and family interfering with work (FIW) (Frome, Russell \& Cooper, 1992a). Research has suggested that employees who are able to successfully manage work-family conflict report higher levels of engagement than those of their peers struggling to manage the relations between work and home (Halbesleben, Harvey, \& Bolino, 2009). Organizations that support employees in managing this conflict - and those workers who perceive higher levels of organizational support in terms of managing this conflict-report higher levels of overall engagement (Matthews, Mills, Trout \& English, 2014; Prottas, 2013).

One resource for mitigating work-family conflict while increasing employee engagement and decreasing an employee's intention to turnover is a supportive organizational culture (Bedarkar \& Pandita, 2014). A supportive organizational culture "represents and protects its core values by trying to use the flexibility of operational procedures to meet the employees' needs, maintaining human relations and showing concern for people" (Sok, Bloome, \& Tromp, 2014, p. 460). Research into corporate culture has suggested a positive link between a supportive organizational culture and organizational outcomes such as financial performance, as well as performance-related attitudinal outcomes such as job satisfaction and intent to turnover (Allen \& Shanock, 2013; Han, 2012). Moreover, employees who work for an organization that creates a supportive organizational culture experience decreased levels of work-family conflict 
than employees where support is not an organizational priority (Byron, 2005; Sok et al., 2014). In short, several streams of research have suggested that the presence of a supportive organizational culture positively influences employee engagement while reducing work-family conflict and individual intention to turnover (Timms et al., 2015) — however, this evidence is disparate and connected by little.

\section{Problem Statement}

Recent research on employee engagement has attracted scholars from various fields to produce a voluminous record (Saks \& Gruman, 2014). This has resulted in numerous studies providing empirical evidence on the benefits of employee engagement (Anitha, 2014; Ghosh, Rai, \& Signa, 2014; Wachter \& Yurio, 2014). However, the quantity of employee engagement research has also provided many frameworks, perspectives, and measures of employee engagement (Byrne, 2015). Despite a growing record of scholarship, there is an increasing lack of consensus across the field about what actually defines employee engagement (Saks \& Gruman, 2014). Thus, researchers have, at times, proceeded without an agreed upon framework (Halbesleben, 2011; Saks \& Gruman, 2014). In fact, scholars have developed so many differing frameworks about engagement (e.g., see Andrew \& Sofian, 2014; Bakker, 2011; Fearon, McLaughlin, \& Morris, 2013; Halbesleben, 2011) that academics have recently suggested an "almost total lack of context in most studies of employee engagement" (Purcell, 2014, p. 242). Therefore, due to the lack of context surrounding most employee engagement research, organizations struggle to understand and capture the reported competitive advantage of engagement, which includes meeting an individual's most basic needs — such as the 
struggle between an employee's work and family_ - whilst at work (Wollard \& Shuck, 2011).

Connected, Wollard and Shuck (2011) suggest that, although current research around organizational and individual antecedents of engagement showed little theoretical overlap or connection, a "connection seem[ed] quite plausible" (p.433). Such plausibility opens the space for new research to explore a potential relation between employee engagement, individual and organizational antecedents (such as work-family conflict and supportive organizational culture), and employee intent to turnover. Exploring and understanding the connection between antecedents, employee engagement, and organizational outcomes more fully could not only enable organizations to create an environment where employee engagement flourishes, but it could also add clarity to the still emerging employee engagement construct. Moreover, no meta-analysis into the interaction between employee engagement antecedents (e.g., work-family conflict and supportive organizational culture), employee engagement, and turnover intentions has been undertaken using the term "employee engagement", specifically. While researchers have used meta-analytic procedures in previous research (c.f., Christian, Garza, Slaughter, 2011; and Cole, Walter, Bedeian, \& O’Boyle, 2012), most have conflated the terms work engagement, organizational engagement, job engagement, and employee engagement, despite calls for conceptual clarity among terms. Moving forward without conceptual clarity adds to the potential conflation of employee engagement across frameworks, definitions, and measurement tools, as well as confounds the construct in practice. This knowledge gap in understanding the interaction of employee engagement antecedents - such as work-family conflict and supportive organizational culture, the 
mediating role of employee engagement, and the influence on turnover intentionsleaves both scholars as well as practitioners grasping for the demonstrated value and meaning of employee engagement in both research and practice.

\section{Purpose Statement}

The purpose of this analysis is to investigate the relation between work-family conflict, supportive organizational culture, employee engagement, and intent to turnover. Specifically, by employing the Wollard and Shuck (2011) employee engagement “conceptual model of relationships" (p. 432), this inquiry shall—using a meta-analytic review of the research — explore the potential relation of individual and organizational antecedents pertaining to employee engagement, the effect of those antecedents on employee engagement, and the relation regarding intent to turnover. Additionally, this research will investigate whether or not employee engagement mediates the relationship between employee engagement antecedents and organizational outcomes.

\section{Research Questions}

$\mathrm{Q}_{1}$ : To what extent does work-family conflict and a supportive organizational culture affect each other?

Q2a: To what extent does work-family conflict have an effect on an individual's level of employee engagement?

$\mathrm{Q}_{2 \mathrm{~b}}$ : To what extent does work-family conflict have an effect on an individual's turnover intentions?

$\mathrm{Q}_{3 \mathrm{a}}$ : To what extent does a supportive organizational culture have an effect on an individual's level of employee engagement? 
$\mathrm{Q}_{3 \mathrm{~b}}$ : To what extent does a supportive organizational culture have an effect on an individual's turnover intentions?

Q4: To what extent does employee engagement have an effect on an individual's turnover intentions?

Q5: To what extent does employee engagement mediate the effects of workfamily conflict and a supportive organizational culture on individual turnover intentions?

\section{Conceptual Framework}

The following section presents the theoretical frameworks used to understand the variables that are work-family conflict, supportive organizational culture, employee engagement, and intention to turnover.

Work-family conflict. Byron's (2005) meta-analysis suggested that the empirical results of work-family conflict measures reinforce the Greenhaus and Beutell (1985) theoretical conceptualization. Greenhaus and Beutell (1985) define work-family conflict (WFC) as:

[A] form of inter-role conflict in which the role pressures from the work and family domains are mutually incompatible in some respect. That is, participation in the work (family) role is made more difficult by virtue of participation in the family (work) role. (p. 77).

It is a well-established construct within the literature (Byron, 2005) that precedes engagement and has been shown to have a direct impact on individuals' attitudes as well as turnover intentions (Shankar \& Bhatnagar, 2010; Spell et al., 2014). Work-family conflict was first explored by Greenhaus \& Beutell (1985), and was further broken down 
into components of work interfering with family (WIF) and family interfering with work (FIW) (Byron, 2005; Frome et al., 1992a). Frome et al. (1992a) explored a model in which antecedent variables could affect and predict both the nature as well as the directionality of the work-family conflict.

Supportive organizational culture. A supportive organizational culture is one in which management provides a psychologically safe environment wherein employees can fail at tasks without fear of negative repercussions (Kahn, 1990). When an organization is not supportive of the employee - or inconsistencies exist in the treatment of the employee(s) - the amount of employee engagement decreases (Kahn, 1990), resulting in a decreased performance that is negatively related to organizational outcomes (Brown \& Leigh, 1996). In contrast, Positive Organization Support is the degree of perception that an individual believes their organization both supports and shows a concern for them as a person (Eisenburger, Huntington, Hutchinson, \& Sowa, 1986; Matthew, Mills, Trout \& English, 2014). Work-family conflict research indicates a negative interaction between low levels of perceived organizational support and high levels of work-family conflict; organizations that strive to increase an individual's perception of a supportive organizational culture facilitate an overall decrease of workfamily conflict amongst employees (Mesmer-Magnus \& Viswesvaren, 2006). Positive perceptions of an organization's culture can lead to increased employee engagement and lower turnover (Shuck, et al., 2014).

Employee engagement. Employee engagement is an organizational behavior construct that gets theoretical and philosophical grounding from social science communities such as psychology (Kahn, 1990), management (Harter, Schmidt, and 
Hayes, 2002; Macey \& Schneider, 2008; Saks, 2006), and training/development (Czarnowsky, 2008; Ketter, 2008). This construct has generated much interest and implementation from the practitioner community who initially set the research agenda (Shuck \& Wollard, 2010). Consultants and practitioners alike saw engagement as a measure that employers could use as a yardstick for the bottom line (Harter et al., 2002) and, also, as a means for assessing leadership and talent (Li \& Liao, 2014; Tuckey, Bakker \& Dollard, 2012) in order to prevent costly employee turnover (Shuck et al., 2014; Spell, Eby, \& Vandenberg, 2014). However, employee engagement lacks cohesion within the scholarly community, so further research is needed to provide clarity to its nomological, theoretical, and conceptual roots (Christian, et al., 2011; Purcell, 2014; Saks \& Gruman, 2014). This examination of employee engagement will employ Shuck and Wollard's (2010) definition as well as the conceptual framework the two (2011) laid out, which is grounded in the theoretical framework advanced by Shuck (2010).

The Wollard and Shuck (2010) definition was chosen as the guiding definition for this study due to several factors. First, the definition is theoretically grounded in the operationalization — produced by Kahn (1990) — of an individual investing their one true self when engaging in the organizational setting. That is, the individual makes a conscious choice to engage. This definition contrasts with the operationalization of engagement by Harter, Schmidt, and Hayes (2002), which focuses on one's satisfaction with work as a basis for engagement. Secondly, the Wollard and Shuck (2010) definition focuses on an individual dedicating cognitive, behavioral, and emotional resources toward the attainment of organizational goals. By contrast, the operationalization of employee engagement by Schuafeli et al. (2002) is characterized by the individuals' 
engagement vis a vis their relationship — through vigor, absorption, and dedication - to the work performed and not through individual choice. Similarly, the Wollard and Shuck (2011) framework is theoretically grounded in the engagement theory of Kahn (1990). In essence, scholars generally agree that Kahn is the root for engagement theory (Saks, 2006; Shuck \& Wollard, 2010; Christian et al, 2011; Saks and Gruman, 2014; Byrne, 2015) - therefore, by focusing on a framework rooted in Kahn (1990); this meta-analysis seeks to provide clarity amongst frameworks.

Intention to turnover. Intention to turnover is an employee's cognitive decision to "to leave the organization within the near future" (Carmeli \& Weisberg, 2006, p. 193). This decision can lead to voluntary turnover-defined as "an employee's decision to terminate the employment relationship" (Dess \& Shaw, 2001 p. 446)—as opposed to involuntary turnover, which is defined as "an employer's decision to terminate the employment relationship" (Dess \& Shaw, 2001 p. 446). Recent turnover meta-analysis reveals the negative impact turnover relationships have on organizational performances and outcomes (Park \& Shaw, 2013). These negative relationships cause organizations to suffer costs in both financial and performance outcomes with the loss of employees (Park \& Shaw, 2013). The cost of turnover, in terms of how turnover affects the individual, center around an individual's degradation of trust in the organization's intentions relating to shared individual and organizational outcomes (Leana \& Van Buren, 1999; Park \& Shaw, 2013).

The research is clear that the negative relationship of turnover, even when positive or helpful for the organization, has a negative impact on the individual. Research suggested that employee engagement impacts an individual's desire to turnover (e.g., 
Alfes, Shantz, Truss \& Soane, 2013; Timms et al, 2014). This review, by examining the summary effect of engagement on turnover intentions, has the potential to give organizations a competitive advantage and increase performance outcomes.

\section{Significance of the Study}

This study will contribute new knowledge to the field around theory building by exploring the conceptual link between individual and organizational antecedents, and how those antecedents interact. This new knowledge will provide a new understanding of how individual and organization variables interact with one another, their relation with employee engagement, and how each variable influences organizational outcomes (Purcell, 2014). Armed with this knowledge, individuals and organizations can make informed decisions about employee engagement initiatives.

Moreover, this review shall contribute new knowledge to the field around research by exploring employee engagement as a mediation variable (Saks \& Gruman, 2014). Additionally, this research provides an examination of effect sizes related to employee engagement, such as the effect size between individual employee engagement antecedents (i.e. work-family conflict) and employee engagement, which might enable future research to more clearly understand the practical significance of the employee engagement construct. This examination, using the meta-analytic methodology lacking within the HRD community, provides tools for future HRD researchers to conduct future HRD focused systematic reviews (Newman, Hitchcock, \& Newman, 2015; Reio, Nimon, \& Shuck, 2015).

This examination deepens understanding of the impact of antecedent variables on employee engagement as well as engagement outcomes where "little research has 
purposely focused" on antecedent impact on employee engagement and employee engagement outcomes (Wollard \& Shuck, 2011). In essence, intent to turnover is a primary outcome that organizations focus efforts to curb due to decreased performance and increased costs (Shaw, 2011). Moreover, individuals make a cognitive choice to disengage and foster turnover intentions (Madden, Rivera, Madden, 2015). Therefore, this survey of employee engagement seeks to explore antecedent and engagement impact on turnover intentions.

This research will contribute new knowledge to the field around practice, that is, how employee engagement practitioners develop organizational employee engagement strategies, by demonstrating how organizations might best influence certain aspects of culture as an antecedent to employee engagement. This new knowledge has the potential to impact an organization's bottom line as well as increase their firm's competitive advantage. By using the framework established by Wollard and Shuck to produce a metaanalytical correlation matrix, this examination seeks to aid scholars and practitioners in employee engagement efforts as well as provide a base that provides clarity for future scholars to build upon. This matrix shall provide effect size direction and impact that will enable scholars to infer conclusions about employee engagement antecedents of workfamily conflict and supportive organizational culture as well as employee engagement and the outcome of intent to turnover.

\section{Definition of Key Terms}

The following section presents definitions to key terms used throughout this investigation. These terms and concepts have been discussed in the sections above, and are presented here for reference. 
Work-family conflict. This term was previously defined on page 7 using the Greenhaus and Beutell (1985) definition wherein involvement in work roles precludes full participation and effort in the execution of family roles and responsibilities ultimately leading to conflict. The bi-directional nature of work-family conflict as dependent construct will be operationally defined as work interfering with family (WIF) and family interfering with work (FIW) (Frome et al., 1992; Greenhaus \& Beutell, 1985).

Supportive Organizational Culture. This term defines an organization culture that "represents and protects its core values by trying to use the flexibility of operational procedures to meet the employees' needs, maintaining human relations and showing concern for people" (Sok et al., 2014, p. 460).

Employee engagement. This term is defined as "an individual employee's cognitive, emotional, and behavioral state directed toward desired organizational outcomes" (Shuck \& Wollard, 2010, p. 103).

Intent to Turnover. The definition of this term is a "conscious and deliberate desire" by an employee "to leave the organization within the near future" (Carmeli \& Weisberg, 2006, p. 193).

\section{Limitations to the Study}

The methods section will cover in detail my efforts to include all relevant research of the variables in question. This analysis will only include one organizational and one individual antecedent of engagement while, as a whole, the employee engagement construct has forty-two individual and organizational antecedents (Wollard \& Shuck, 2011). The reason behind choosing a pair of antecedents versus multiple antecedents rests with the longevity and consistency of measure of work-family conflict relative to the 
other antecedent variables, as well as research examining the interaction between workfamily conflict supportive organizational cultures (Byron, 2005). The limitation is also mitigated due to meta-analytic works on organization outcomes that explore employee engagement (see e.g., Halbesleben, 2006; Halbesleben et al., 2009) as well as workfamily conflict (Chen, Powell \& Cui, 2014), which suggested these variables are well researched. No known meta-analytic studies of employee engagement-specifically, using the Wollard and Shuck (2011) framework or model—currently exist. Understanding how the interplay between work-family conflict and a supportive organizational culture effects engagement provides a starting point for understanding how overlapping engagement efforts impact the choices individuals and organizations make when choosing how to direct resources in decisions that influence individual engagement.

\section{Organization of the Study}

Chapter two will cover the current literature of employee engagement, supportive organizational culture, work-family conflict, and intention to turnover. Chapter three will detail the meta-analytic methodology used to examine variable interactions, and chapter four discusses the findings. Chapter five discusses research implications as well as the future directions of employee engagement research. 


\section{CHAPTER 2}

\section{LITERATURE REVIEW}

This chapter begins, first, with an introduction to the foundational roots of employee engagement. Second, the current state of employee engagement is reviewed and, third, literature around both antecedents and outcome variables are explored. Lastly, this chapter concludes with a hypothesized meta-analytic path model, chapter summary, and overview of chapters three through five.

\section{Employee Engagement: The Foundational Roots}

Research suggested that employee engagement rests on four major theoretical frameworks: needs-satisfying (Khan, 1990); burnout (Maslach, et al., (2001); satisfaction-engagement framework (Harter, et al., 2002); and the multidimensional approach to engagement (Saks, 2006; Shuck, 2011). These four foundations are explained below. The Wollard and Shuck (2010) conceptual framework - that is theoretically rooted in Kahn's “needs satisfying approach”-is my conceptual grounding. I shall introduce the other foundations for background and context, but the focus will be on Kahn's approach as conceptualized by Wollard and Shuck (2010). Employee engagement scholars reliably identify Kahn's (1990) ethnographic research as the first study to 
explore engagement theory and its application to the workplace (Christian et al., 2011; Gruman \& Saks, 2014; May, Gilson \& Harter, 2004; Saks, 2006; Shuck, 2011).

Needs-satisfying: Kahn. Kahn defined the idea of personal engagement as "the simultaneous employment and expression of a person's 'preferred self' in task behaviors that promote connections to work and to others, personal presence, and active full role performances" (Kahn, 1990, p. 700). Through his work, Kahn sought to determine if individuals behaved the same inside and outside the organizational environment and what types of fluctuations in their behavior occurred, if any. Results suggested that three psychological conditions were prerequisites for influencing positive levels of personal engagement: meaningfulness, safety, and availability (Kahn, 1990).

Psychological meaningfulness occurred when there was a positive "return on investment" for individual exertions, physical efforts, and emotional effort during job execution (Kahn, 1990, pp. 703-704). An individual derived a feeling of meaningfulness from their work by the nature of the task, their work role, and their work interactions (Kahn, 1990). Meaningfulness was absent when employees did not feel part of the organization due to not reaching their true potential during task performance (Kahn, 1990; Fairlie, 2011). Work viewed as not meaningful led to lower levels of engagement (Britt, Adler \& Bartone, 2001). For example, Britt et al. (2001) suggested that meaningful work leads to increased levels of personal hardiness — allowing individuals to handle stressful situations better, which leads to higher levels of engagement—while lack of meaningful work inversely impacts hardiness and, ultimately, leads to lower levels of engagement. 
The second condition for engagement, psychological safety, developed when an individual could express and operate in a safe environment as "one's true self without fear of negative consequences to self-image, status, or career" (Kahn, 1990, p. 708). Kahn's safe environment consisted of four factors: interpersonal relationships, group and intergroup dynamics, management style and process, and organizational norms (Kahn, 1990). Interpersonal relationships were seen as those that developed out of both positive and negative work interactions (Kahn, 1990). Positive work interactions between individuals and groups resulted from interactions that were free of fear over loss of status or influence (Kahn, 1990; Reio, Jr., \& Sanders-Reio, 2011). Kahn theorized that management styles and processes prevented individual withdrawal from the work environment by providing a safe environment where management enforcement of organizational norms was a key facet that facilitated individual trust as well as engagement. Individuals instinctually withdrew from unsafe environments by not expending personal resources or engaging with their preferred self in the work environment (Halbesleben, 2010; Kahn, 1990).

The final dimension of Kahn's notion of personal engagement was psychological availability. Psychological availability emerged from an individual's "sense of having the physical, emotional, or psychological resources to personally engage at a particular moment” (Kahn, 1990, p. 714). Individuals brought these personal resources (e.g., behaviors, energy) — in addition to resources provided by the organization (e.g., a supportive organization culture) - toward organizational goals (Halbesleben, 2011; Wollard \& Shuck, 2011). The study's findings suggested that resource expenditure occurred when engaging in relationships both inside and outside the organization (Kahn, 
1990). Social support provided individuals additional resources to bolster psychological availability and prevented individual instincts to conserve resources (Halbesleben, 2006; Halbesleben, 2011).

Work engagement/burnout antithesis. Following Kahn, the second engagement framework emerged from the burnout literature of Maslach, Schaufeli, and Leiter (2001). Employee engagement was conceptualized as work engagement - that is, work engagement focused solely on the individual and their work while employee engagement added organizational inputs and influences on individual engagement levels (Schaufeli, 2014, Shuck, 2011). Although these terms were and still are used interchangeably, Schaufeli (2014) notes the two terms are vastly different constructs. Work engagement was defined "as a persistent, positive affective-motivational state of fulfillment in employees that is characterized by vigor, dedication, and absorption" (Maslach et al., 2001, pg. 417). This conceptualization was based on burnout literature wherein the absence of burnout indicated a state of engagement (Maslach \& Leiter, 1997; Maslach et al., 2001). Scores for engagement were obtained by reverse scoring the Maslach Burnout Inventory (MBI) creating a new instrument: The Utrecht Work Engagement Scale (UWES) (Cole et al., 2011; Maslach et al., 2001). Researchers using this scale explored work engagement antecedents (Dollard \& Bakker, 2010; Mauno, Kinnunen, \& Ruokolainen, 2007), work engagement as a mediating variable (Tuckey, Bakker \& Dollard, 2012), and the impact of work engagement on performance outcomes (Alacron, Lyons \& Tartaglia, 2010; Rurkkhum \& Bartlett, 2012). The UWES has remained the most frequently used engagement measurement scale to date (Byrne, 2015; Christian et al., 2011; Cole et al., 2011; Saks \& Gruman, 2014) 
Satisfaction-engagement framework. A concurrent framework to work engagement emerged from the literature linking employee engagement to desired organizational outcomes. Research into this linkage was spurred by claims that close to $75 \%$ of the United States-based workforce were not engaged and, thus, negatively impacting organizations' ability to reach maximum performance outcomes (Bates, 2004). James Harter of Gallup led a practitioner-focused study on the impact of employee engagement on organizational outcomes (Harter et al., 2002). The Gallup Work Audit (GWA) was used to measure employee engagement, and it considered influences such as workplace environment and supervision (Buckingham \& Coffman, 1999; Harter et al, 2002, p. 269). The results indicated that employee engagement had a statistically significant positive correlation to organizational outcomes such as profit and productivity.

Multidimensional approach to engagement. Adding to previous research, scholars examined a framework focused on the impacts of variables on employee engagement and the antecedent impact on outcomes. Saks (2006) examined employee engagement from a viewpoint that included both Kahn's (1990) framework as well as the Schaufeli and Bakker (2004) burnout-engagement framework. Saks's (2006) study examined individual and organizational antecedent effects on employee engagement as well as the impact of employee engagement on individual and organizational outcomes. The research model offered by Saks (2006) broke employee engagement into two distinct states: job engagement (JE) and organizational engagement (OE). The state of job engagement measured individual immersion into the job, and the state of organization engagement measured how individuals saw themselves as a part of the organization 
(Saks, 2006). The study results suggested that employee engagement antecedents—such as perceived organizational support—positively impacted employee engagement.

Furthermore, Saks concluded that employee engagement influenced outcomes such as organizational commitment and organizational citizenship behaviors. Findings also suggested that management must provide the resources, support, and commitment to facilitate individual investment of cognitive, emotional, and behavioral energies for engagement (Saks, 2006). After the publishing of Saks (2006), scholarly exploration of the employee engagement grew exponentially (Saks \& Gruman, 2014).

\section{The Current State of Employee Engagement Research}

Emerging perspective. Beginning in 2005, the number of scholarly articles on employee engagement began to multiply year after year (Oswick, 2015; Saks \& Gruman, 2014; Schaufeli, 2014). This research was not restricted to one field or subfield, but rather expanded into a multitude of fields to include industrial and organizational psychology, human resource management (HRM), and HRD. In the following sections, I will explore the refinement of employee engagement from psychological and management literature. After doing so, I shall then tie up these threads with an exploration of employee engagement situated in HRD literature. The current state of employee engagement follows with exploration of antecedent variables.

Refining the employee engagement construct. Drawing from the work by Saks (2006), Macey and Schneider (2008) furthered the employee engagement construct refinement with a three-point conceptual model: state engagement, trait engagement, and behavior engagement. Macey and Schneider (2008) theorized that the employee engagement construct—as positioned by previous researchers (e.g., Maslach et al., 2001; 
Harter et al., 2002)—related to specific conditions (i.e., antecedents), and that those conditions were believed to impact employee engagement and organizational outcomes. State engagement was a form of engagement that encompassed "some form of absorption, attachment, and/or enthusiasm," and was operationally defined as having components of satisfaction, commitment, job involvement, and psychological empowerment (Macey \& Schneider, 2008, p. 6). Moreover, behavior engagement was viewed as behaviors that place the organization above one's self-for instance, organizational citizenship behavior or "discretionary effort" (Macey \& Schneider, 2008, p. 14). Lastly, trait engagement was personality-based, during which an individual's "positive, active and energetic ways to behave adaptively" impacted both state and behavioral engagement (Macey \& Schneider, 2008, p. 14). In essence, individual and organizational antecedents were believed to interact with an individual's overall level of employee engagement (Macey \& Schneider, 2008). The study findings suggested that, in turn, individual engagement levels had both a positive and negative influence on individual and organization outcomes.

Further employee engagement refinement: Management literature. Research by scholars in other fields such as management, occupational health, and psychology followed previous research — particularly, in measurement of engagement as well as the mediating impact of engagement on antecedent and outcome variables. Rich, Lepine, and Crawford (2010) developed an alternate instrument to the UWES instrument. The 18question instrument measured three aspects of job engagement: physical, emotional, and cognitive, which are grounded in Khan's (1990) engagement theory. Rich et al. (2010) suggested that engagement was significantly correlated to other antecedent and outcome 
measures reported (e.g., job satisfaction, organizational citizenship), and that engagement had a significant impact on relationships between engagement antecedents and outcomes (e.g., core self-evaluations and organizational citizenship). Additionally, findings suggested little impact of other possible mediation variables such as job involvement, job satisfaction, and intrinsic motivation (Rich, et al., 2010). The key is for organizations to develop human resource management practices that facilitate employee engagement.

Exploring the links between policy, employee engagement, and organizational outcomes, the link between human resource management (HRM) practices and employee engagement was examined by Alfes, Shantz, Truss, and Soane (2013) by using a refined version of the Rich, et al. (2010) scale. The findings suggested that HRM practices were significantly correlated to employee engagement as well as employee engagement antecedent and outcome variables (e.g., antecedent: perceived organizational support; outcome: turnover intentions) (Alfes, et al., 2013). Additionally, the study's findings suggested that HRM practices influence employee engagement, and that this influence mediated relationships to desired organizational outcomes such as lower turnover intentions. These findings infer a hypothesized overlap between individual and organizational employee engagement antecedent variables (Wollard \& Shuck, 2011). However, although the reporting of one study and just two employee engagement antecedents severely limits generalization, it does bolster further overlap plausibility between other antecedents. Further research into organization impacts on employee engagement explored how a supportive organization culture fostered employee engagement. 
Organizations that foster information sharing and communication created a culture of inclusion that enabled employee engagement (Downey, VanDerWerff, Thomas, \& Plaut, 2014). For example, Downey et al. examined diversity practices and inclusion effect on employee engagement. Drawing upon a sample of 4,597 healthcare employees from a large corporation, the findings suggested significant correlations between employee engagement, diversity practices, inclusion, and trust climate (Downey et al., 2014). Downey et al (2014) results give the impression that organizational efforts to foster employee engagement seems to empirically support the theory that organizational antecedents influenced employee engagement (Wollard \& Shuck, 2010). For example, Wachter and Yurio (2014) adapted items from the Rich et al. (2010) scale to explore the impact of employee engagement on safety management practices and reducing accidents. The research suggested that more engaged workers are more supportive of organizational safety initiatives, more likely to place resources towards workplace safety management practices, and less likely to have lost time due to accidents (Wachter \& Yurio, 2014).

Tying research together: Human Resource Development (HRD). One field that has benefited immensely from the various debates (e.g., scholar vs. practitioner; individual vs. organization engagement) was the field of HRD. HRD is defined as "a process of developing and unleashing expertise for the purpose of improving individual, team, work process, and organizational system performance" (Swanson \& Holton, 2009, p.4). HRD's focus on both the individual and the organization allowed for a holistic approach (i.e., individual and organizational) to employee engagement, which work engagement lacked (Schaufeli, 2014). 
Drawing on previous research, in addition to the conceptual refinement offered by Macey and Schneider (2008), Shuck and Wollard (2010) furthered employee engagement research in HRD. The study identified the popularity of the term "employee engagement" from a variety of scholarly and practitioner sources, and then researched the roots of employee engagement by conducting a seminal review of the literature. Specifically, Shuck and Wollard (2010) sought to understand the conceptual foundations, evolution, and definitions of employee engagement up to that point. Results from their work suggested employee engagement was a highly researched and emerging construct. Findings also suggested employee engagement was an individual construct, impacted by organizational and individual variables, which could be used to measure and predict both individual and organizational outcomes (Shuck \& Wollard, 2010).

A follow-up study by Wollard and Shuck (2011) explored the suggested organizational and individual impacts on employee engagement by examining employee engagement antecedent variables at both the individual and organizational level. A structured literature review yielded 265 articles in 10 databases containing the term "employee engagement" with findings that indicated 42 antecedent variables to employee engagement were present and, also, evenly divided between 21 individual and 21 organizational antecedents (Wollard \& Shuck, 2011). Additionally, the study's findings indicated that only half of the antecedent variables had studies that published quantitative results. A gap Wollard and Shuck (2011) identified in the literature involved "naturalseeming links" between individual and organization antecedents (p. 438). The interactions between individual and organizational antecedent variables are theorized to influence individual employee engagement levels (Wollard \& Shuck, 2011). 
Further HRD research focused on employee engagement antecedent and outcome variables, variable causality, and experimental studies (Shuck, Reio \& Rocco, 2011). For example, Shuck et al. (2011) conducted a correlational study examining the links between antecedent variables (e.g., affective commitment), employee engagement, and organizational outcomes (e.g., intent to turnover). The research findings suggested the links between antecedents, employee engagement, and organizational outcomes were statistically significant. Employee discretionary efforts, for instance, are influenced by a supportive organizational culture, and this supportive culture fosters meaningfulness that facilitates employee engagement in ways that lower employee turnover intentions (Shuck et al., 2011). Cultural influence seems to indicate that leadership (through a supportive organizational culture) has an impact on engagement (Rose, 2016; Shuck et al., 2011). Additionally, leaders influence the engagement environment and create a climate where employees feel safe to engage in pursuit of meaningful work (Fairlie, 2011; Kahn, 1990). Furthermore, Fairlie (2011) found that meaningful work was a significant predictor of employee engagement. Taken together, leadership and the culture driven by leadership influences individual engagement levels.

Recent HRD research has continued to focus on theory development, organizational policies, and the organizations engagement culture. Valentin (2014) suggested government and consulting firms claim that employee engagement-inducing programs give organizations a competitive advantage, which drove organizational engagement efforts. This resulted in organizational pressures to meet unrealistic organization expectations that engagement would deliver desired organizational outcomes (Valentin, 2014). Instead, Valentin suggested that, rather than creating a hyper 
engagement driven environment, HRD policies are needed along with procedures that allow for issues that create a better work environment. Godkin (2015) argued that the driving force behind employee engagement organizational practices is the leadership of mid-level management facilitating "strong employee relations" to obtain desired organizational outcomes such as increased corporate social responsibility amongst employees.

Despite this focus on leadership and organizational engagement policies, recent research suggests that empirical examination of the links between engagement and leadership styles has focused on transformational leadership with "little empirical examination on leadership styles such as ethical leadership," or other styles such as authentic or charismatic leadership (Saul, Kim \& Kim, 2015). Indeed, organizations that empower leaders to facilitate engagement with focused organizational policies and procedures designed to support the individual—namely, align individual skills with the right job-will foster higher levels of engagement as both the desired outcomes of employees and the desired organizational outcomes are met (Alagaraja \& Shuck, 2015). Additionally, a dysfunctional leader at the wrong place at the wrong time can negate the best organizational HRD efforts to foster engagement as well as other desired organizational outcomes (Rose, 2016; Rose, Shuck, Twyford, \& Bergman, 2015). Recent HRD scholarship suggests that organizations "encourage and enable" employee engagement through the selection of the right leaders as well as by driving engagement via HRD and HRM policies, not through direct organizational control (Oswick, 2015, p. 14). This push for organizations to foster-not control—employee engagement is central to creating the type of culture wherein employees find meaning, feel safe, and are willing 
to expend individual resources toward the pursuit of desired organization outcomes (Fairlie, 2010; Halbesleben, 2011; Kahn, 1990).

Beginning in 2008, scholars sought to gain a critical perspective of employee engagement. Research suggested that employee engagement did have an impact on desired organizational outcomes, as found by practitioners such as Gallup, government studies, and other consultancies (Saks \& Gruman, 2014). Researchers began a scholastic exploration of relationships amongst employee engagement antecedents, employee engagement, and employee engagement outcomes (Byrne, 2015). The antecedent variable exploration included both organizational and individual inputs that, as research suggested, influence one another in the creation of an engagement-inducing environment (Wollard \& Shuck, 2011).

\section{Issues and Challenges}

Despite twenty-five years of research, there is no unifying framework where scholars agree (Saks \& Gruman, 2014). For example, Purcell's (2014) criticism has suggested that past engagement research "focused on work engagement" and suffers from a "lack of context" (p. 242). Even though there are multiple measures, studies, and theories that examine the impact employee engagement has, there is still difficulty "showing conclusive and casual evidence between engagement and performance" (Purcell, 2014, p. 248). Despite a solid foundation from Kahn (1990), Saks (2006), Macey and Schneider (2008), as well as Wollard and Shuck (2011), employee engagement still has "no universally accepted definition” (Meyer, Gagne, and Parfyonova, 2010, p. 63). Indeed, the terms and definitions for job engagement, work engagement, and employee engagement are often confused and interchanged, leaving "no 
generally accepted theory of employee engagement” (Saks \& Gruman, 2014, p. 156).

Aside from the prolific employment of the UWES to measure employee engagement, research has suggested that the UWES was "empirically redundant" with similar scales measuring job burnout (i.e., the MBI; Cole, et al., 2011, p. 28). Additionally, the use of the term "employee engagement" with work engagement has further exacerbated confusion among scholars as to which construct is being measured (Cole et al., 2011). Conceptually, work engagement is understood as the opposite of burnout - that is, if an individual is not experiencing high levels of burnout, then that individual must be engaged (Maslach et al., 2001). However, research suggested that the high inter-collinearity of the underlying dimensions of burnout and work engagementas well as confusing interchangeability of the work engagement construct with employee engagement - make it difficult to use the UWES as a viable measure of employee engagement (Saks \& Gruman, 2014).

Following up on an examination by Albrecht (2010), Byrne (2015) suggested employee engagement still exists "as a relatively novel concept in both the popular and academic press" that requires more "theory, debate and empirical studies for clarifying its uniqueness and validity" (Byrne, 2015, p.2). Byrne (2015) stated that Albrecht's (2010) “10 key issues or questions" about employee engagement were not satisfactorily answered, so she set a research agenda that focuses on developing an organizational culture where employee engagement is contagious from one employee to the next. In her research, Byrne (2015) goes to great lengths to show how employee engagement is a unique construct whilst offering her own definition of employee engagement: 
[A] moment to moment state of motivation, wherein one is psychologically present (i.e., in the moment) and psycho-physiologically aroused, is focused on and aligned with the goals of the job and organization, and channels his or her emotional and cognitive self to transform work into meaningful and purposeful accomplishment.” (Byrne, 2015, p.15)

Though this definition follows the same path as previous research (c.f., Kahn, 1990, Macey \& Schneider, 2008, Maslach et al., 2001, Saks, 2006, and Schaufeli et al., 2002), there is much less parsimony than the direct definition given by Shuck and Wollard (2010). The current research agenda calls for study into engagement measures to gain "accumulated validity to support their use" (Byrne, 2015, p.196).

The future path of employee engagement research is to get beyond the debate on a unifying framework. Research into employee engagement should attempt to examine "factors and intervening variables" (Oswick, 2015, p. 14) that influence employee engagement, which is viewed as "a relatively broad and poorly understood phenomenon" (Oswick, 2015, p. 14). Indeed, the call to HRD researchers is to employ more sophisticated quantitative techniques such as meta-analysis to improve "theory, guide empirical research, and inform organizational practice" (Reio, Nimon, \& Shuck, 2015, p.3). A method such as meta-analysis enables employee engagement researchers to better understand the actual impact of the many measures of engagement that "should inform practice as much as theory" (Newman, Hitchcock, \& Newman, 2015, p.129). Consequently, I seek to explore the theorized influence between the individual and organization antecedents of work-family conflict and supportive organizational culture on employee engagement as well as the meditational role of employee engagement on 
turnover intentions - as an outcome measure - using the meta-analytic technique. The following sections review, in detail, the proposed antecedents and outcomes.

\section{Employee Engagement Antecedents}

Work-family conflict. In the literature, Greenhaus and Beutell (1985) were the first to explore work-family conflict (WFC) as a separate and autonomous variable. Building on the research of Kahn, Wolfe, Quinn, Snoek, and Rosenthal (1964), Greenhaus and Beutell (1985) expanded this conflict type specifically to examine the conflict that arises from a person's attempt to balance workplace roles as well as the demands pertaining to familial responsibilities. Work-family conflict was previously defined in chapter one as a conflict between an individual attempting to fulfill separate roles involving work and family. Early research into WFC examined the conflict created by the interplay of work and family demands. A 1977 study — published after the Greenhaus and Beutell (1985) study_examined WFC married men and women (Voydanoff, 1998). Voydanoff (1998) explored the characteristics of a subject's work as well as the impact of family and work demands on the subject's ability to manage the interaction between demands. Additionally, this research examined an individual's perceived control over demands versus the actual measured conflict emanating from those demands (Voydanoff, 1988). The findings suggest that an individual's perceived control is tied to their ability to control their schedules (Voydanoff, 1998). An interesting finding was that the family structure (e.g., number of children) did have a significant correlation to the amount of conflict. In essence, women experience more conflict when the youngest child is below the age of five, and men experience the same correlative level 
for all children (Voydanoff, 1998). Overall, men experience more WFC from work roles while women experience more WFC from family roles (Voydanoff, 1998).

Subsequent WFC studies focused on expanding the understanding of both antecedents of WFC as well as the impact of a variety of organizational outcomes such as turnover intentions and performance. For instance, Kossek and Ozeki’s (1999) research increased the number of outcomes impacted by WFC. Their findings suggested that not all outcomes were affected evenly across both directions of WFC — as originally proposed by Frome et al. (1992a) — but it did show how WFC in the direction of family to work conflict could have greater impacts on organizational outcomes rather than individual outcomes (Kossek \& Ozeki, 1999). In a similar study, Thompson, Beauvis, and Lyness (1999) examined the effects of work culture on WFC and whether or not culture could somehow assist in measuring WFC. Work-family culture was defined as "the shared assumption, beliefs, and values regarding the extent to which an organization supports and values the integration of employees' work and family lives" (Thompson et al., 1999, p. 394). Moreover, it is operationally defined by three components: work prioritized before family, family first priorities have negative career effects, and positive organizational support. The study's findings suggest that only the last component of managerial support has any significance.

Work-family researchers also used quantitative data-analytic techniques (i.e., meta-analysis [Reio et al., 2015]) to examine antecedent variable effects on WFC outcomes. For example, research suggested that employee engagement was connected to job satisfaction as an outcome with culture (Michel, Mitchelson, Kotrbra, Lebreton, \& Baltes, 2009; Rivera \& Flinck, 2011). Thirteen antecedents-including organizational 
support and demands from both family and work — were measured along with their impact outcomes regarding satisfaction with life, job, and family. The results suggest that there is a negative correlation in the relationship between WFC and satisfaction outcomes (Michel et al., 2009). An earlier meta-analysis found similar results between conflict and culture (i.e., "work support") that suggested the influence of culture on WFC mitigates impact on organizational outcomes (Byron, 2005).

Lastly, research suggested that WFC has a significant impact on organizational outcomes such as employee engagement and turnover. Work-life balance, a connected construct to WFC, was linked to organizational support policies that allowed individuals more flexibility in performing work roles, which thus facilitated higher levels of employee engagement (Bedarkar \& Pandita, 2014). Similarly, Prottas's (2013) findings indicated a positive correlation between WFC and turnover, and a negative correlation between WFC and employee engagement. In other words, as the amount of conflict rises, individuals are more apt to become disengaged and, subsequently, more likely to turnover than are individuals who experience lower levels of WFC (Prottas, 2013). Prottas's (2013) findings suggest that the level of trust (i.e., supportive culture) an individual perceives increases the likelihood that particular individual is to engage.

Supportive organizational culture. An organization's culture is defined by shared norms, values, customs, or beliefs between members of an organization or group (Bolman \& Deal, 2008; Brown and Starkey, 1994; Erkutlu, 2010; Schein, 2010). Culture serves as a foundation for both individuals and organizations in the pursuit of organizational goals (Pool, 2000). A supportive organizational culture (SOC) is a culture that presents employees with "challenging work, open communication, trust, [and] 
innovation" (Pool, 2000, p. 374). A supportive organizational culture fosters a sense of teamwork between individuals, management, and those outside of the organization who have a vested interest in the organization's success (Pool, 2000; Sambasvian \& Yen, 2010).

Research suggested that SOC is an organizational variable that facilitates employee engagement (Byrne, 2015). Research also alludes to the relationship between supportive organizational culture and several employee engagement antecedent variables, such as organizational citizenship behaviors (Erkutlu, 2010), work-family conflict (MacDermid, Hertzog, Kensinger, \& Zipp, 2001), job satisfaction (Burke, Burgess, \& Oberrlaid 2003; Lok \& Crawford, 2004), turnover intentions (Burke et al., 2004) and job fit (Silverthorne, 2004). For example, Macey et al. (2008) describe trust as a variable that directly impacts SOC. Additionally, SOC serves as a mediating variable that influences individual employee engagement and organizational engagement efforts (Macey et al., 2008).

Taken further, trust underlies the relationship between management and employees to the extent that a lack of trust between employees and management could foster low levels of engagement (Alfes et al., 2013). Additionally, trust must be present for positive engagement interactions as well as for boosting engagement levels, and can be seen to foster a pro-diversity environment (Downey et al., 2014). Although this specific example of trust inducing engagement suggested the link between supportive organizational culture and employee engagement exists, the links between these two variables is disconnected given the amount of possible shared variables impacting both constructs (Lok \& Crawford, 2004; Matthews et al., 2014; Silverthorne, 2004). Lastly, 
research suggested that an individual's perception of the presence of a supporting culture has an impact on the level of individual employee engagement (Rich et al., 2010). Tying together organizational culture, employee engagement, and organizational outcomes, Shuck et al. (2014) examined the links between organizational support, employee engagement, and a desired organizational outcome: less turnover intent. The results indicated that all variables were significantly correlated and that employee engagement significantly mediated the relationship between organizational support of proactive employee engagement practices and turnover intention (Shuck et al., 2014).

\section{Employee Engagement Outcomes - Intent to Turnover}

Turnover is a costly organizational outcome of interest to both practitioners as well as academic communities. Research suggested that turnover intention was the single best indicator of actual turnover (Madden, Mathais, \& Madden, 2015). Knowing the turnover intentions of the workforce affords organizations the opportunity to invest in programs to prevent unwanted turnover-such as flexible work programs (Timms et. al., 2014) — instead of absorbing the costs associated with turnover (Guilding, Lamminmaki, \& McManus, 2014; Madden et al. 2015). By understanding individual turnover intentions, organizations can attempt to adjust the culture to foster reengagement (Downey, et al., 2014). These programs foster a supportive organizational culture that reinforces an individual's level of trust, which research suggested impacts turnover intention (Park \& Shaw, 2013).

Similarly, a supportive organization culture addresses turnover intention factorssuch as work-family conflict - that can influence employee engagement. For example, turnover researchers suggest cultural forces such as positive working relationships 
(Madden et al., 2015), availability to resources to perform tasks (Crawford, LePine, \& Rich 2010), and the creation/implementation of policies that reduce the amount of workfamily conflict an employee experienced (Nohe \& Sonntag, 2014) mitigated individual pressures impacting work-family roles, which thus influences individual withdrawalnamely, increased turnover intention (Zhang, Griffeth, \& Fried, 2012). While this withdrawal state is not predictive of a future decrease in performance and engagement antecedents — such as job performance and citizenship behaviors - it can have a negative influence that ultimately decreases individual engagement (Hom, Mitchell, Lee \& Griffeth, 2012, Swinder \& Zimmerman, 2014). Connected, work-family conflict scholars suggest that setting firm boundaries between one's work and one's home life can not only influence turnover intention, but also lessen work-family conflict (Wu, Kawn, Liu, \& Resnick, 2012). Additionally, research suggested that individuals experiencing higher levels of employee engagement are less likely to turnover, and that the mediation effect on turnover by higher levels of engagement is significant (Andrew \& Sofian, 2012).

Further research revealed turnover at moderate to low levels did have an impact on organizational outcomes - however, at higher turnover rates, the effect on organizational outcomes was found not to have as much of a significant impact (Park \& Shaw, 2013; Shaw et al., 2005). Lastly, from a cost-benefit perspective, low to moderate turnover can be seen as a positive influence on both performance and financial metrics (Abelson \& Baysinger, 1984; Shaw et al., 2005; Staw, 1990). The benefit, specific to the organization, is that organizations cut personnel who do not meet organizational norms and older employees that come with fixed benefit costs (Alexander, Bloom \& Nuchols, 1994; Dalton \& Toder, 1979; Park \& Shaw, 2013; Shaw, Gupta, \& Delery, 2005). 


\section{Systematic Review \& Meta-Analysis}

A meta-analysis, or systematic review, of the linkage in the Wollard and Shuck (2011) model is both timely and appropriate. To date, there has been no systematic review examining the "naturally seeming links" between individual and organizational employee engagement antecedents. Although, as described above, there are many studies that examine parts of the model proposed in Figure 2.1, none have measured the sum. By examining the linkages of the model in Figure 2.1, I address several issues related to the measurement and theory of engagement.

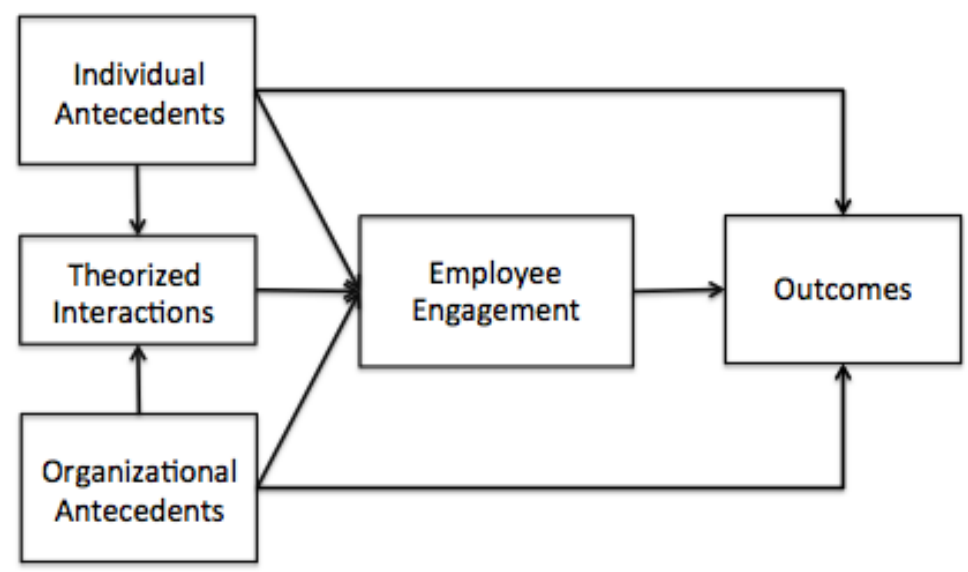

Figure 2.1. Wollard \& Shuck (2011) Employee Engagement model

First, by extracting the UWES, we can discover what the impact of employee engagement is on organizational outcomes - such as turnover intentions-without all the entanglement that comes with the UWES (Christian et al., 2011). Second, this review will focus on translating the remaining measures of engagement into an effect size that is less likely to suffer from the bias of individual correlational studies due to sample size, reliability, and other artifacts (Breugh, 2003). Lastly, employee engagement scholars 
suggest that meta-analysis is needed to move forward the measure to better understand and refine employee engagement measurement (Byrne, 2015). Taken as a whole, this review will allow examination of the gap addressed by Wollard and Shuck (2011): links between engagement antecedents, the mediating impact of employee engagement, and the linkage between employee engagement on organizational outcomes such as turnover intentions.

\section{Conclusion and Study Organization}

This chapter began with introduction to the foundational roots of employee engagement. Second, the current state of employee engagement was reviewed. Third, literature around both antecedents and outcome variables were explored. Lastly, this chapter concluded with a hypothesized meta-analytic path model, chapter summary, and overview of chapters three through five. Following this literature review, the study methodology is explained. Methodology is followed by the results, and a discussion on research findings. 


\section{CHAPTER 3}

\section{METHOD}

This chapter presents the methods used to collect, describe, correlate, and interpret sets of scholarly works that relate to the measure of work-family conflict, employee engagement, and intention to turnover. The research questions examined in this meta-analytic exploration of employee engagement studies encompass all studies since Kahn (1990) to 2015. HRD researchers have identified the use of meta-analysis as a technique to better understand the factors that influence individuals within the workplace (Gubbins \& Rousseau, 2015).

This chapter begins by reviewing research design, meta-analytic paths tested, and search strategies used to explore work-family conflict, supportive organizational culture, employee engagement, and intention to turnover. Study inclusion and coding procedures are presented followed by statistical procedures and conventions used to extract effect sizes. In an effort to be fully transparent, I followed best practices in systematic reviewing and meta-analysis (e.g., as set out by Aytung, Rothstein, Zhou, \& Kern, 2012) regarding the use of explicit inclusion and exclusion criteria as well as studying the coding procedures.

\section{Conceptual Framework}


The purpose of this study is to synthesize the results from previous research of work-family conflict, supportive organizational culture, employee engagement, and intention to turnover. Exploration will focus on the plausibility of overlap in individual and organizational antecedent variables, the effect this relationship has on employee engagement, and the size and effect of employee engagement on organization outcomes (Saks \& Gruman, 2014; Wollard \& Shuck, 2011). To date, there is no synthesis that looks at the path between individual and organizational employee engagement antecedents, employee engagement, and organization outcomes. Figure 3.1 maps the six paths explored.

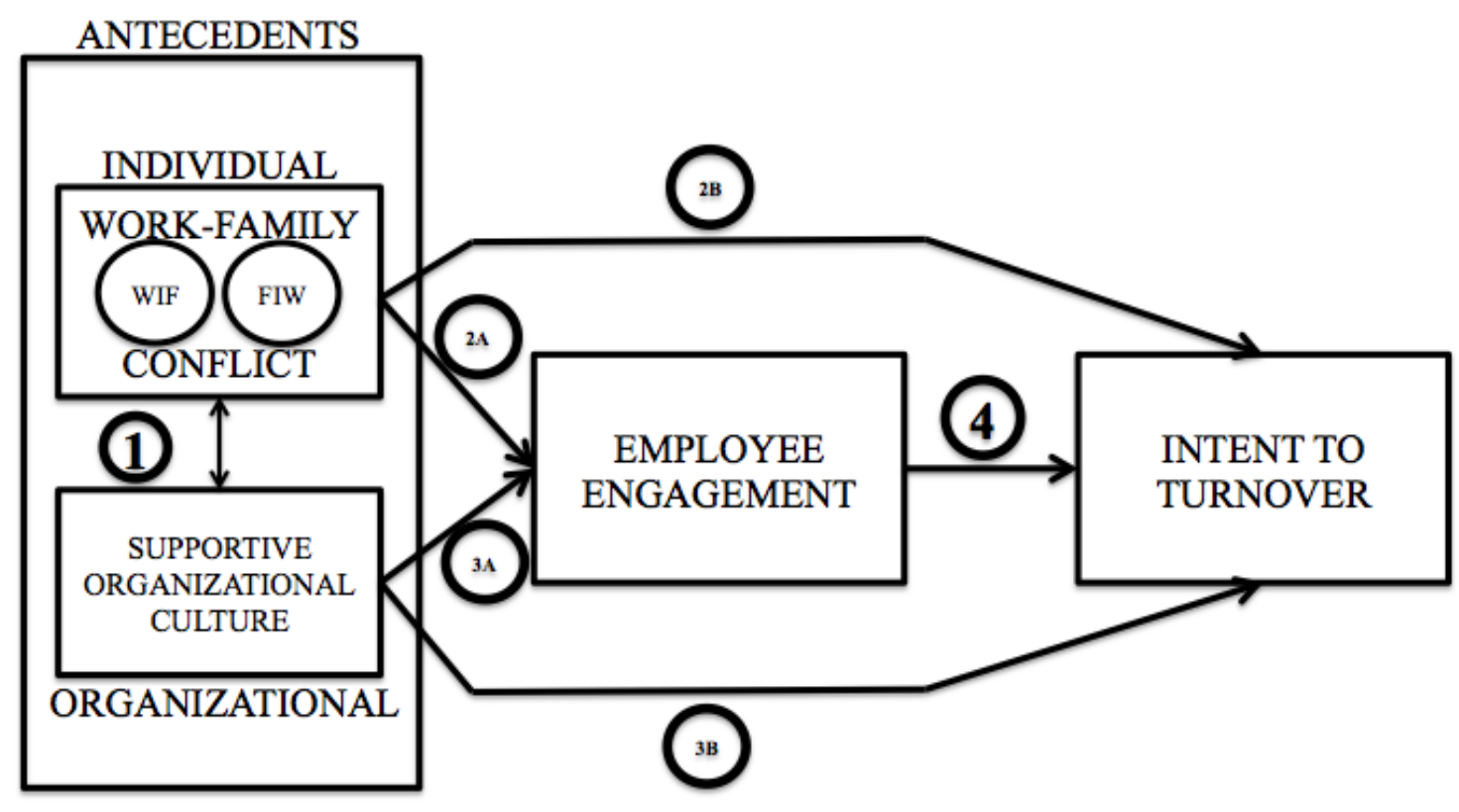

Figure 3.1. The Conceptual Framework of the Research Design.

This figure illustrates a model relating employee engagement toward intent to turnover. The numbers in the figure refer to the following paths: 
1: The overlap between individual (work-family conflict) and organizational (supportive organizational culture) employee engagement antecedents.

2a: The impact of work-family conflict on employee engagement.

$2 \mathrm{~b}$ : The impact of work-family conflict on intent to turnover.

3a: The impact of supportive organizational culture on employee engagement.

3b: The impact of supportive organizational culture on intent to turnover.

4: The impact of employee engagement on intent to turnover.

\section{Study Inclusion and Exclusion Criteria}

Studies were included in this meta-analysis based on four criteria. First, the study had to include quantitative results (i.e., no conceptual or opinion pieces, and no qualitative studies were included). Secondly, studies that included at least two of the variables of interest and reported the correlation between these were included (if a study appeared to meet other inclusion criteria without reporting a correlation of interest-

provided the study was conducted after 2005 - the study authors were contacted). Third, employee engagement was measured with a scale other than the UWES - in other words, the studies using the UWES as the only employee engagement measure were excluded. Recent research suggests that the work engagement measure is too closely correlated to exiting measures of burnout and may not be a good measure of employee engagement (Christian et al., 2012; Cole et al., 2011). Finally, studies reporting a survey instrument reliability lower than $\alpha=.6$ were excluded. This exclusion is based on the "general accepted value for Cronbach's $\alpha$ " as being between .7 to .8 (Field, Miles, \& Field, 2012, p. 799). In addition, Cortina (1993) suggests that the number of items could impact the inter-collinearity between items yet have no impact on the overall alpha (Field et al, 
2012). Therefore, a threshold of .6 was established to account for both the variance of scale and scale size, as well as the "generally accepted" reliability values.

Search strategies. I focused my review on primary studies that included correlations of at least two of the variables under question. Multiple overlapping strategies were used to ensure the initial inclusion of all potentially relevant studies, and to address the multi-disciplinary nature of employee engagement as well as to mitigate publication bias, or in other words the exclusion of studies due to such circumstances as language, statistical significance, or source of study (Borenstein et al., 2009;

Hammerstørm, Wade, \& Jørgensen, 2010). First, the following databases were searched: ABI/INFORM, Academic Source Premier, Business Source Premier, EBSCO, ERIC, Google Scholar, Proquest Library, Proquest Dissertation and Thesis, PsycINFO, Social Science Citation Index, and Web of Science. These databases were searched for any record that contained at least two of the variables in the keywords, title, or abstract. An initial search was used with the terms employee engagement, job engagement, workfamily conflict, WIF, FIW, supportive organizational culture, SOC, were included with the terms "intent to turnover", "turnover", "intent to quit", "quit" along with the specific search terms of "correlate", "correlates", "correlated", and "study", or "studies". Using multiple terms for engagement and turnover, this ambitious search yielded over 500,000 hits. After comparing search terminology used in other meta-analysis of both employee engagement and work engagement — as well as consultation with employee engagement and meta-analysis subject matter experts (SME) — search terms were narrowed to "employee engagement", "work-family conflict", "supportive organizational culture" and "intent to turnover" along with "correlate", "correlates", and "correlated". A 
comparison of results between initial search term yield and refined search term yield was done purposefully to ensure that the use of the refined search terms did not introduce bias. The results of the refined search strategy generated 653 articles.

The second strategy focused on relevant seminal articles in the development and theoretical grounding of employee engagement. The seminal articles were: Kahn (1990), Saks (2006), Macey and Schneider, (2008) as well as Wollard and Shuck (2011). Forward citations, meaning an exploration of the reference sections of cited references within the seminal articles listed above for any articles relevant to this review, was examined for any research that could answer the questions of this investigation. If the search identified relevant literature reviews, these were reviewed for studies not obtained through the initial search. Finally, I contacted an SME (subject matter expert) on employee engagement for assistance in finding any unpublished studies.

\section{Coding Framework}

Study coding procedures. I completed coding with any coding questions forwarded to an employee engagement SME as well as a meta-analysis SME for opinions on how best to resolve the issues brought forth by questions. The opinions of these experts were taken into consideration and then used as input from which to make an inclusion/exclusion decision. The screening guide consisted of publication type, the language of the study, research type (i.e., quantitative vs. qualitative study), inclusion of at least two variables of interest covered by the study, and the instrument used to measure employee engagement. In the first phase, I screened the title and the abstract of each study identified by the search process, using the screening guide located in Appendix A). Full-text studies were obtained the study in question met or appeared to meet the 
screening guidelines inclusion criterion. I read each full-text study. The study was included in the review if it contained empirical data (e.g., correlation matrix, reported correlations) on at least two variables of interest and, specific to employee engagement studies, inclusion occurred when the employee engagement measure used was a measure other than the UWES.

The studies' effect sizes (correlations), variables, design type, employee engagement measure, and an assessment of study quality were coded. Using the coding guide located in Appendix B, each record (article) was examined and the results recorded in a spreadsheet.

Reliability. A pilot study was conducted to test the reliability of the coding guide and process. The pilot study identified relevant issues relating to the preciseness of keywords, the relevance of databases used, and the relevance of the coding procedure. During coding, if an issue arose that prevented coding, a meta-analysis SME was consulted to adjudicate. Example of a coding issues is missing instrument reliability (no Cronbach's alpha reported). Each instance was reviewed with the meta-analysis SME and a determination was made for inclusion or exclusion.

Assessment of study quality. Due to the nature of the research question, the primary indicators of the study's quality were indicators of score reliability and validity. Score reliability is an estimate of the consistency of scores obtained from an instrument (Pryczak \& Bruce, 2011). Karras (1997a) provides an excellent example to understand reliability and validity. A sphygmomanometer that measures a patient's blood pressure consistently over time is both reliable and valid - however, if the measures have a wide variance, the findings are still valid, but unreliable (Karras, 1997a). Trying to measure 
blood pressure with a thermometer would be invalid (Karras, 1997a). Taken further, Karras (1997a) posits that a thermometer giving incorrect measures consistently is reliable_-but not valid. Low reliability scores, as measured by Cronbach's alpha, can reduce the relationships (i.e., the observed correlation) between study variables (Shadish, Cook, \& Campbell, 2002).

On the other hand, validity is defined as the "degree to which the measurement represents a true value" (Greenfield, Kuhn, \& Wojtys, 1998). There are three types of validity: criterion-related, construct, and content (Karras, 1997b). Validity measures attempt to assess the consistency of a measure using an external criterion-such as correlation—with similar instruments measuring the same characteristics (Karras, 1997b). Assessing validity requires a reference standard to assess the study's validitythat is, if no such reference exists, measuring validity becomes difficult. Measuring reliability is an "inherently quantifiable" method while testing validity is "often unmeasurable" (Karras, 1997a). As a result, I only examined score reliability, but I attempted to code information about validity presented in the articles. Reliability estimates from other sources (e.g., Kuder-Richardson) were reviewed on a case-by-case basis. If reliability coefficients were deficient or missing, attempts were made to contact the author to obtain coefficient alphas. The source of the coefficient was noted in the coding guide located in appendix B. No studies were excluded for missing coefficient alphas.

\section{Statistical Procedures and Conventions Used}

Selection of effect size. The Pearson correlation coefficient ( $r$ ) was the primary effect size (the size and nature of the relationship between two variables). Comparisons 
using raw correlation coefficients make analysis difficult. The difficulty stems from limitations based on coefficient range (bounded at -1 to 1) and the strength of correlation impacts the size of the correlation's variance (Shavelson, 1996). Due these limitations I created effect sizes by transforming the bivariate correlations $(r)$ into Fisher's $z$ scores, which allowed the correlations to be modeled using a normal distribution centered at zero (Shavelson, 1996; Cohen, 2008). The effect sizes were then weighted by the inverse of their variance — as recommended by Borenstein, Hedges, Higgins, and Rothstein (2009) — to account for study sample size. The formula (see below) creates effect sizes from correlation into Fisher's $z$, where "ln" is the natural $\log$ and $r$ is the study correlation coefficient.

$$
z=0.5 \ln \left[\frac{1+r}{1-r}\right]
$$

The variance for Fisher's $z\left(V_{z}\right)$ is calculated by dividing one by the total sample size minus three. Standard error is calculated by taking the square root of the Fishers $z$ variance (see below), where $n$ is the total number of participants, $V_{z}$ is the $z$-score variance, and $S E_{z}$ is the standard error.

$$
\begin{aligned}
& V_{z}=\frac{1}{n-3} \\
& S E_{z}=\sqrt{V_{z}}
\end{aligned}
$$

Once the analysis is complete, the correlations are transformed from their Fisher $z$ scores back into their original coefficients to facilitate interpretation (see below), where the value $e$ is approximately $2.718, z$ is the transformed Fisher's $z$, and $r$ is the computed correlation coefficient.

$$
r=\frac{e^{2 z}-1}{e^{2 z}+1}
$$


The upper and lower limits of the summary effect are calculated for the weighted effect sizes. An interval not containing zero allows for rejection of the hypothesis that the population relationship was equal to zero. The weighted mean effect size was calculated (see below), where $W$ is the inverse of the variance for study $i, Y$ is the within study variance for study $i, M$ is the weighted mean, and $S E_{M}$ is the weighted mean standard error.

$$
\begin{gathered}
M=\frac{\sum_{i=1}^{k} W_{i} Y_{i}}{\sum_{i=1}^{k} W_{i}} \\
L L / U L_{M}=M \pm 1.96 \times S E_{M}
\end{gathered}
$$

Power analysis. Due to the multi-discipline nature of employee engagement, the current study includes studies from the fields of psychology, management, human resource development, and business. The combined lifespan of the variables under research covers close to a 30-plus year span. The result is a variety of studies that are both vast and rich in amount. A power analysis was conducted to determine exactly how many studies would be required to meet statistical power requirements in order to draw inference. Valentine, Pigott, and Rothstein (2010) describe the process for establishing the minimum power threshold in meta-analysis. Valentine et al. (2010) suggested the minimal amount of studies needed for this examination to achieve both a statistical power near .8 to detect and an effect size of .15 is 40 studies. Additionally, Borenstein et al. (2009) recommend at least 25 studies to detect an effect size of $.2-.4$ with a power of nearly 1 .

Handling of non-independent effects. Non-independent effects, such as multiple time points and multiple employee engagement construct measures, were examined. Effect sizes for studies reporting multiple time point measure as well as 
multiple construct measures were calculated using the Borenstein, Hedges, Higgins, and Rothstein (2009) method. The mean effect size and variance across time points is calculated using the formula (see below), where $m$ is the number of time points, $Y_{j}$ is the outcome of study $j, v$ is the variance, and $r$ is the correlation coefficient. The summary effect size was then calculated using the procedures outlined in the "selection of effect size" section.

$$
\begin{gathered}
Y=\frac{1}{m}\left(\sum_{j}^{m} Y_{j}\right) \\
V_{y}=\frac{1}{m} V(1+(m-1) r)
\end{gathered}
$$

\section{Data Analysis Framework}

Fixed vs. random-effects model. Researchers conducting a meta-analysis must determine which statistical model they shall employ to analyze results. The fixed-effect model is used when the assumption is that all studies have one true effect size and that sampling error is responsible for any differences among the observed effects. Borenstein et al. (2009) recommend two criteria be met in order to use a fixed-effect model: a) belief that all studies are functionally identical, and b) the desire to compute a common effect size for a specific population that will not generalize to other populations. Random-effects models are more appropriate when: a) researchers studying the variables under consideration operated independently, and b) the assumption that studies are not functionally identical. A random-effects model does not make the true effect size assumption and allows that the true effects can vary between studies (Borenstein et al., 2009). This meta-analysis uses random-effects modeling due to the plurality of measures used to measure employee engagement, interest in the overall effect of employee 
engagement on different populations, and the desire to negate impacts of sampling error resulting from the use of multiple employee engagement instruments (Hedges \& Vevea, 1998).

Homogeneity analysis. Using the random-effects model allows the true effect size to vary between studies. A homogeneity test determines whether or not variation is due to sampling error, which is expected in estimating the true effect size, or the result of other factors besides sampling error. The statistic to determine homogeneity, $Q$, calculates a value by computing each individual effect size, subtracting the weighted mean effect size, squaring that sum, and multiplying by the individual weight of the individual study. The resulting values are then summed and provide the value of $Q$. Degrees of freedom are calculated by taking the number of studies included minus one. The formulas for $Q$ and the degrees of freedom (see below) are where wi is study weight, $E S$ is the effect size, $d f$ is the degrees of freedom, and $k$ is the number of studies.

$$
\begin{aligned}
& Q=\sum_{i=1}^{k} W_{i}\left(Y_{i}-M\right)^{2} \\
& d f=k-1
\end{aligned}
$$

The homogeneity analysis null hypothesis was that studies are estimating the same true effect. A chi-square distribution of $Q$ compared to the degrees of freedom is used to determine statistical significance. A significant result would suggest that the studies are not estimating the same true effect and are, therefore, heterogeneous. A statistically significant result suggests further testing to determine how other factors between studies are contributing to true effect variance.

Moderator effects. There are two related tests to understand variability between studies: tau-squared $\left(\tau^{2}\right)$ and $I^{2}$. In essence, $\tau^{2}$ is the "variance of true effect sizes" 
(Borenstein et al., 2009, pg. 114), and is determined by the formula for $\mathrm{T}^{2}$, which is an estimation of the observed effects (see below), where $Q$ is the $Q$ statistic, $d f$ are the degrees of freedom, and $C$ is a quantity that is calculated by taking the sum of the study weight for study $i$ minus the sum of the squared study weights minus sum of the study weights.

$$
T^{2}=\frac{Q-d f}{C}
$$

Where tau-squared is examined on the same scale as the true effect, the use of $I^{2}$ examines true effect variance independent of scale (Borenstein et al., 2009). The use of this statistic allows speculation on variation range and source. This statistic is calculated using the formula (see below) where $Q$ is the $Q$ statistic, and $d f$ are the degrees of freedom.

$$
I^{2}=\left(\frac{Q-d f}{Q}\right) \times 100 \%
$$

Publication Bias. Publication bias is defined as "the selective submission or acceptance of research for publication based on the attainment of statistically significant results" (Preston, Ashby, \& Smyth, 2004, p. 313), and it occurs when studies are not published due to a variety of reasons. These reasons include: Language bias: only studies in English are included in meta-anaylsis; Field bias: researchers only include studies from a singular field, usually the one the researchers belong too and publishing in a journal restricted to that field; Availability bias, wherein studies are included due to ease of access, usually to a certain database, while studies harder to access are left excluded; and finally Significance bias: Only studies that yield statistically significant results are published and therefore non-significant studies are not included (also impacted by 
availability). A funnel plot and a trim-and-fill method funnel plot were used to address publication bias.

A funnel plot distributes the mean standard error of effect sizes, and then calculates a risk ratio to determine whether or not a publication bias exists (Borenstein et al., 2009). The trim and fill method was used to examine funnel plot asymmetry (Duval \& Tweedie, 2000). A symmetrical graph suggests that there is little evidence of publication bias, as larger studies will tend to group tightly towards the top of the graph with smaller studies spreading out to create the bottom of an inverted funnel. In essence, asymmetry indicates the possibility of bias (Ferguson \& Brannick, 2012; Preston et al., 2004).

\section{Summary}

This chapter presented how the meta-analysis was performed. The conceptual framework of this meta-analysis presented six variable pairings. Study inclusion and exclusion frameworks were presented along with a detailed search strategy. The coding framework presented a plan to ensure reliability, inclusion of quality studies, as well as procedures to allow coders to work out differences and make judgment calls. The statistical procedures were then explained in detail, to include a power analysis and a plan for handling non-independent effects. Effect sizes were generated from reported correlations, transformed into Fischer's z scores, and then weighted using the inverse weighted method. The data analysis explained the choosing of the meta-analytic model, homogeneity analysis, and a plan to minimize publication bias. 


\section{CHAPTER 4}

\section{RESULTS}

This chapter includes the study results broken down into five sections. Section one covers the search, screening, and coding results. Section two reports the descriptive statistics of studies for inclusion. Section three details the results of the random-effects model for the resultant variable pairings. Section four examines detection results for publication bias, presenting both statistics and resultant plots. Finally, section five summarizes this chapter and outlines the next chapter.

\section{Search Results}

Screening results. The database search using the variable combinations outlined in chapter three yielded 687 returns. Endnote 8.1 was used to sort and screen these returns. Three hundred and fifteen duplicates were removed, which left a total of 372 candidates for screening. If any screening criteria were not explicitly yes/no, then the screening question was answered as don't know/can't tell and was kept for further screening/inclusion. Many candidates - 209 in number-were excluded due to not measuring two variables of interest together, often only measuring one or none. For example, an abstract would suggest that the study measured or examined employee engagement. A full-text examination would reveal that work engagement was the construct under review, not employee engagement, and the UWES was the survey instrument (e.g., Amah, 2016). Nineteen candidates were excluded due to the article not being in the English language. Five studies that did mention employee engagement and 
not work engagement were excluded due to mentioning of the UWES as the measurement instrument (Ballard, 2012; Holsten-Okae, 2017; Louison, 2007; van Schalkwyk, du Toit, Bothma, \& Rothmann, 2010; Watts, 2017). Three qualitative studies were also excluded (Aburge, 2017; Rana, Ardichvili, \& Tkachenko, 2014, Shankar \& Bhatnagar, 2010). Candidates were screened using the screening guide located in appendix A. Table 4.1 details the reasons and numbers for screening results and coding inclusion.

Screening results produced 136 candidates for coding. The University of Louisville library and interlibrary loan apparatus was used to locate full text or PDF versions. Ultimately, 16 candidates were deemed unavailable (nine of which were in a foreign language). This left 120 studies to be coded using the coding guide located in Appendix B.

Table 4.1

Screening Results

\begin{tabular}{lll}
\hline Screening Reason & Total Screened & Excluded \\
\hline Not in English & 372 & 19 \\
Two Variables Not Measured & 353 & 209 \\
UWES Used & 144 & 5 \\
Qualitative & 139 & 3 \\
Report Correlations & 136 & 0 \\
Total for Coding & 136 & - \\
\hline
\end{tabular}

Coding results. Coding procedures revealed that 17 studies did not report correlations, which was either due to the articles format (i.e., literature review or meta- 
analysis). Further examination revealed 14 studies that did not actually measure the variables in question, but the title, abstract, and keywords suggested the studies in question measured those variables. An example is a study abstract claiming to measure employee engagement or supportive organizational culture that measures work engagement and perceived organizational support, respectively. Appendix $\mathrm{C}$ was used to determine whether or not the reported variable was measured with an approved instrument. Additionally, coding procedures revealed that 18 studies claiming to measure employee engagement measured work engagement with the UWES instrument, prompting exclusion. And last, two studies were in Korean and, due to the PDF format, cutting and pasting the articles into Google Translate was unavailable. The final result saw 69 articles being coded for review. Table 4.2 outlines the reasons and numbers for coding as well as the final study inclusion.

Table 4.2

Coding Results

\begin{tabular}{llc}
\hline Coding Reason & Total Coded & Excluded \\
\hline Unavailable & 136 & 7 \\
Unavailable - Not in English & 129 & 9 \\
Correlations Not Available & 120 & 17 \\
Two Variables Not Measured & 103 & 14 \\
UWES Used & 89 & 18 \\
Foreign Language Not Translatable & 71 & 2 \\
Studies Coded & 69 & - \\
\hline
\end{tabular}

\section{Descriptive Statistics}


Variable pair distribution. Results for the 69 studies coded for inclusion indicated that 57 of those articles measured the variable pair "work-family conflict" and "intent to turnover", and 12 measured the variable pair "employee engagement" and "intent to turnover". Within the following measured variable pairings, no studies passed screening and coding: "work-family conflict" and "supportive organizational culture", "work-family conflict" and "employee engagement", "employee engagement" and "intent to turnover", and finally "supportive organizational culture" and "intent to turnover". Table 4.3 contains the number of studies by variable pair.

Table 4.3

Variable Pair Distribution

\begin{tabular}{ll}
\hline Variable Pair & Number of
\end{tabular}

Studies

Work-Family Conflict - Supportive Organizational Culture

0

Work-Family Conflict - Employee Engagement

0

Work-Family Conflict - Intent to Turnover 57

Supportive Organizational Culture - Employee Engagement

Supportive Organizational Culture - Intent to Turnover

Employee Engagement - Intent to Turnover

Publication type and methodology. Results suggested that much of the research included in this examination were peer-reviewed journal articles. The most present methodology in the reviewed articles was cross-sectional (looking at populations over time), which was followed by correlational studies (looking at relationships at a single 
point of time) (Field et al., 2012). Tables 4.4 and 4.5 list the publication type as well as the methodology by variable pairing.

Table 4.4

Publication Type by Variable Pairing

\begin{tabular}{llll}
\hline Publication Type & WFC/TO & EE/TO & Total \\
\hline Journal & 45 & 10 & 55 \\
Government/Agency Report & 0 & 0 & 0 \\
Dissertation/Thesis & 10 & 1 & 11 \\
Conference presentation & 2 & 1 & 3 \\
Other & 0 & 0 & 0 \\
Unknown & 0 & 0 & 0 \\
\end{tabular}

Table 4.5

Study Methodology by Variable Pairing

\begin{tabular}{llll}
\hline Methodology & WFC/TO & EE/TO & Total \\
\hline Experiment & 0 & 0 & 0 \\
Quasi-Experiment & 1 & 0 & 1 \\
Correlational & 17 & 7 & 24 \\
Cross-Sectional & 34 & 4 & 38 \\
Longitudinal & 1 & 0 & 1 \\
Meta-Analytic/Systematic Review & 1 & 0 & 1 \\
Other & 1 & 1 & 2 \\
Unknown & 2 & 0 & 2 \\
\hline
\end{tabular}

Instrument reliability. Instrument reliability was recorded and is presented in table 4.6. Overall, employee engagement measures Cronbach's alphas, the measure of a survey instruments reliability, ranged from .72 to .96 . Work-family conflict instruments alphas ranged from .67 to .97 . Finally, intent to turnover Cronbach’s alphas ranged from .66 to .96 . Cronbach alphas for two employee engagement studies, four work-family 
conflict studies, and 16 intent to turnover studies were not reported. In the case of intent to turnover, the high number is due to only one question being asked for the intent to turnover sub-scale and no Cronbach's alpha being calculated. The range of the instruments Cronbach's alphas as well as the number of studies-not including this statistic_-are located in Table 4.6.

Table 4.6

Instrument Reliability Statistics

\begin{tabular}{lllll}
\hline Variable & Alpha Range & Median & Reported & Not Reported \\
\hline Employee Engagement & $.72-.96$ & .87 & 10 & 2 \\
Work-Family Conflict & $.67-.97$ & .87 & 53 & 4 \\
Intent to Turnover & $.66-.96$ & .835 & 53 & 16 \\
\hline
\end{tabular}

Use of employee engagement instruments. Results for studies coded measuring employee engagement indicate that the most used instrument was the Rich et al. (2010) scale. The use of the Rich et al. (2010) instrument — which was used in four studies — was double the nearest two mostly used instruments: The May et al. (2004) (used twice) and the Saks (2006) instrument (used three times). Despite these instruments' long availability (over 10 years for May et al. [2004] and Saks [2006]), the low usage compared to the 18 UWES studies that made it through screening-but were discarded in coding - suggests that the UWES is still used as a primary measure for employee engagement. The continued use by researchers of the UWES instrument suggests an unfamiliarity with findings discussed in chapter 2 on the use of the UWES to measure employee engagement (see Christian et al., 2013). Table 4.7 displays the reported use of the employee engagement instruments. 
Table 4.7

Employee Engagement Instrument Use

\begin{tabular}{ll}
\hline Employee Engagement Measure & Reported (N = 12) \\
\hline May et al. (2004) & 2 \\
Saks (2006) & 3 \\
Britt (1999) & 4 \\
Rich et al. (2010) & 0 \\
Rothbard (2001) & 0 \\
Strumph et al. (2013) & 1 \\
Proprietary, Harter et al. (2002)/ (Gallup Q12) & 1 \\
Proprietary, Other & 1 \\
Other & 0 \\
Unknown & \\
\hline
\end{tabular}

Effect size and Fisher's Z transformation. Correlations were coded and transformed into Fisher's Z, as described in chapter 3. Table 4.8 lists the results of this transformation.

Table 4.8

Correlations and Fisher's Z Transformation

\begin{tabular}{lccccc}
\hline Author(s) & Year & $N$ & Pairing & Fisher's \\
& & & & & Z \\
\hline Aboobaker et al. & 2017 & 150 & WFC/TO & .585 & .67 \\
Ali \& Baloch & 2009 & 283 & WFC/TO & .584 & .67 \\
Alshutwi & 2016 & 113 & WFC/TO & .43 & .46 \\
Anwar et al. & 2017 & 281 & WFC/TO & .445 & .48 \\
Bagger & 2006 & 196 & WFC/TO & .255 & .26
\end{tabular}




\begin{tabular}{|c|c|c|c|c|c|}
\hline Bande et al. & 2015 & 209 & WFC/TO & .26 & .27 \\
\hline Battistelli et al. & 2013 & 440 & WFC/TO & .18 & .18 \\
\hline Blomme et al. & 2010 & 247 & WFC/TO & .45 & .48 \\
\hline Chelariu \& Stump & 2011 & 185 & WFC/TO & .36 & .38 \\
\hline Chen et al. & 2015 & 186 & WFC/TO & .551 & .62 \\
\hline Daderman \& Basinska & 2016 & 188 & WFC/TO & .35 & .37 \\
\hline Dion & 2006 & 112 & WFC/TO & .207 & .21 \\
\hline Field & 2010 & 399 & WFC/TO & .18 & .18 \\
\hline Flaxman & 1999 & 92 & WFC/TO & .11 & .11 \\
\hline Grandey \& Cropanzano & 1999 & 132 & WFC/TO & .21 & .21 \\
\hline Grobelna \& Tokarz-Kocik & 2016 & 60 & WFC/TO & .524 & .58 \\
\hline Haar & 2004 & 100 & WFC/TO & .27 & .28 \\
\hline Haar et al. & 2012 & 197 & WFC/TO & .41 & .44 \\
\hline Hammer et al. & 2011 & 197 & WFC/TO & .33 & .34 \\
\hline Hee & 2017 & 101 & WFC/TO & .326 & .34 \\
\hline Huang \& Cheng & 2012 & 170 & WFC/TO & .34 & .35 \\
\hline Huh & 2017 & 158 & WFC/TO & .215 & .22 \\
\hline Kao \& Chang & 2016 & 240 & WFC/TO & .244 & .25 \\
\hline Karatepe, Osman M. & 2009 & 189 & WFC/TO & .427 & .46 \\
\hline Karatepe \& Azar & 2013 & 141 & WFC/TO & .434 & 46 \\
\hline Karatepe \& Kilic. & 2015 & 144 & WFC/TO & .087 & .09 \\
\hline Kossek et al. & 2006 & 245 & WFC/TO & .18 & .18 \\
\hline Kuvaas et al. & 2017 & 4518 & WFC/TO & .37 & .39 \\
\hline
\end{tabular}




\begin{tabular}{|c|c|c|c|c|c|}
\hline Liao & 2011 & 236 & WFC/TO & .12 & .12 \\
\hline Ma. Regina & 2013 & 991 & WFC/TO & .34 & .35 \\
\hline Mack & 2015 & 59 & WFC/TO & .9 & 1.47 \\
\hline Masuda et al. & 2012 & 3914 & WFC/TO & .23 & .23 \\
\hline Mauno et al. & 2015 & 814 & WFC/TO & .099 & .10 \\
\hline Molino et al. & 2016 & 617 & WFC/TO & .06 & .06 \\
\hline Nei et al. & 2015 & 2781 & WFC/TO & .21 & .21 \\
\hline Payne et al. & 2012 & 316 & WFC/TO & .28 & .29 \\
\hline Prati \& Zani & 2016 & 5195 & WFC/TO & -.24 & -.24 \\
\hline Ribeiro et al. & 2016 & 851 & WFC/TO & .355 & .37 \\
\hline Roulin et al. & 2014 & 1547 & WFC/TO & .35 & .37 \\
\hline Sabokro et al. & 2013 & 494 & WFC/TO & .41 & .44 \\
\hline Sachau et al. & 2012 & 1185 & WFC/TO & .34 & .35 \\
\hline Sorensen et al. & 2016 & 234 & WFC/TO & .25 & .26 \\
\hline Spector et al. & 2007 & 5270 & WFC/TO & .20 & .20 \\
\hline Sturman \& Walsh & 2014 & 1032 & WFC/TO & .31 & .32 \\
\hline Tauetsile & 2016 & 438 & WFC/TO & .295 & .30 \\
\hline Van Dyck & 2012 & 156 & WFC/TO & .45 & .48 \\
\hline Wang \& Zhang & 2009 & 139 & WFC/TO & .37 & .39 \\
\hline Wang et al. & 2017 & 325 & WFC/TO & .37 & .39 \\
\hline Yardley & 1994 & 343 & WFC/TO & .24 & .24 \\
\hline Yavas et al. & 2008 & 723 & WFC/TO & .32 & .33 \\
\hline Yonetani et al. & 2007 & 179 & WFC/TO & .15 & .15 \\
\hline
\end{tabular}




\begin{tabular}{llllll} 
Yunita \& Kismono & 2014 & 210 & WFC/TO & .363 & .38 \\
Zorlu & 2012 & 206 & WFC/TO & .673 & .82 \\
Kim \& Jang & 2014 & 225 & WFC/TO & .40 & .40 \\
Park & 2013 & 267 & WFC/TO & -.229 & -.23 \\
Lee et al. & 2014 & 143 & WFC/TO & .21 & .21 \\
Jungman \& Dous & 2015 & 378 & WFC/TO & .29 & .30 \\
Alfes et al. & 2013 & 328 & EE/TO & -.40 & -.42 \\
Appelbaum et al. & 2013 & 17 & EE/TO & -.67 & -.81 \\
bin Salahudin et al. & 2016 & 170 & EE/TO & -.955 & -1.89 \\
de Villiers \& Stander & 2011 & 278 & EE/TO & -.25 & -.26 \\
Foster & 2013 & 120 & EE/TO & .46 & .50 \\
Gyensare et al. & 2017 & 336 & EE/TO & -.21 & -.21 \\
Halliday et al. & 2018 & 23439 & EE/TO & -.62 & -.73 \\
Liss-Levinson et al. & 2015 & 10246 & EE/TO & -.026 & -.03 \\
Malinen \& Harju & 2017 & 221 & EE/TO & .29 & .30 \\
Shuck et al. & 2013 & 241 & EE/TO & .61 & .71 \\
Shuck et al. & 2011 & 283 & EE/TO & -.56 & -.63 \\
Shuck & 2010 & 283 & EE/TO & -.56 & -.63 \\
\hline & & & & & \\
\hline
\end{tabular}

Note. $N=$ study sample size; $r=$ correlation coefficient.

\section{Random-Effects Model Results}

Homogeneity results. Homogeneity tests show that the resultant variable pairings are statistically significant. This statistically significant result suggests that rejecting the null hypothesis: the studies under review are not estimating the same true 
effect and are heterogeneous, is proper. The results indicate a statistical result for the $Q$ statistic, which indicated that a significant amount of heterogeneity in effect size was present. The significance of $Q$ for both pairings suggests that the true effects vary, but it does not address the magnitude (Borenstein et al., 2009). This result also suggests that the use of the random-effects model was appropriate (Medina, Sanchez-Meca, MarinMartinez, \& Botella, 2006). According to Maeda \& Harwell (2016), the use of the $Q$ statistic and Fisher's Z to evaluate effect size is not critically impacted by the low amount of studies found with the variable pairing employee engagement/intent to turnover. The mean effect size for work-family conflict and intent to turnover is .327 . The mean effect size for employee engagement and intent to turnover is -.337 . The lower/upper limits and standard error for work-family conflict and intent to turnover is smaller and lower than that of employee engagement and intent to turnover, which, along with the $Z$ score significance, suggests that the pairing of work-family conflict and intent to turnover is more significant and accurate then the findings for employee engagement and intent to turnover. Table 4.9 reports the results of the Homogeneity tests. Table 4.10 displays the results of heterogeneity testing.

Table 4.9

\section{Homogeneity Results}

\begin{tabular}{|c|c|c|c|c|c|c|c|c|c|}
\hline $\begin{array}{l}\text { Correlated } \\
\text { Variables }\end{array}$ & $k$ & $M$ & $S E_{M}$ & $L L_{M}$ & $U L_{M}$ & $Z$ & Q & $\tau$ & $\tau^{2}$ \\
\hline WFC/TO & 57 & .327 & .030 & .269 & .385 & $11.06^{*}$ & $1892.784 *$ & .213 & .045 \\
\hline EE/TO & 12 & -.337 & .200 & -.729 & .055 & -1.68 & 4468.649* & .687 & .472 \\
\hline \multicolumn{10}{|c|}{$\begin{array}{l}\text { Note. } \mathrm{WFC}=\text { work-family conflict; } \mathrm{EE}=\text { employee engagement } \mathrm{TO}=\text { intent to turnover; } k=\text { number of } \\
\text { studies; } M=\text { mean effect size; } S E_{M}=\text { standard error of mean effect size; } L L_{M}=\text { lower limit of } 95 \% \\
\text { confidence interval; } U L_{M}=\text { upper limit of } 95 \% \text { confidence interval; } \mathrm{Z}=\mathrm{Z} \text { score; } \mathrm{Q}=\mathrm{Q} \text { Statistic; } \tau=\text { square }\end{array}$} \\
\hline
\end{tabular}




\section{Heterogeneity Results}

\begin{tabular}{llllllll}
\hline Pairing & $k$ & $M$ & $\mathrm{Q}$ & $\tau$ & $\tau^{2}$ & $\mathrm{I}^{2}$ & $\mathrm{H}^{2}$ \\
\hline WFC/TO & 57 & $.327^{*}$ & $1892.784^{*}$ & .213 & .045 & 96.69 & 30.20 \\
EE/TO & 12 & -.337 & $4468.64 *$ & .687 & .472 & 99.87 & 760.74 \\
\hline
\end{tabular}

Note. WFC = work-family conflict; TO =intent to turnover; EE = employee engagement; $k=$ number of studies; $M=$ mean effect size; $\mathrm{Q}=\mathrm{Q}$ statistic; $\tau=$ square root of estimated $\tau^{2} ; \tau^{2}=$ estimated amount of total heterogeneity; $\mathrm{I}^{2}=$ ratio of total heterogeneity/total variation in effect sizes; $\mathrm{H}^{2}=$ ratio of total variability/sampling variability.

$*_{p}<.001$.

Confidence intervals. Confidence intervals were calculated using the confint() command in the R statistics software. Confidence intervals give us insight on moderator effect estimations. According to Borenstein et al. (2009), researchers assign "a value judgment" based on these results. In the case of the findings in Tables 4.11a and 4.11busing Borenstein et al. (2009) as a guide - the interpretation of the results for tau, tau being the measure for variability between studies - point to work-family conflict/intent to turnover result as "useful" in understanding the true effect variation, and for "harmful" understanding the true effect variation of employee engagement/intent to turnover (p.117). A possible contributor to these figures are both the multiple scales used to measure the variables as well as the low number of studies $(\mathrm{k})$, especially in the case of employee engagement/intent to turnover. In other words, the estimates for work-family conflict appear to have a narrow confidence interval making the estimation useful for understanding variance. However, the rather large confidence intervals for employee 
engagement/intent to turnover estimations can be interpreted as having low confidence in the solidity of the estimations for variance and true effect size. Table $4.11 \mathrm{a}$ and $4.11 \mathrm{~b}$ contain the confidence intervals per variable pairing and moderator effect.

Table 4.11a

Work-Family Conflict/Intent to Turnover Confidence Intervals

\section{$95 \% \mathrm{CI}$}

Effect

Estimate

$L L \quad U L$

$\tau$

.2127

.1808

.2792

$\tau^{2}$

.0452

.0327

.0780

$\mathrm{I}^{2}$

96.6886

95.4757

98.0510

$\mathrm{H}^{2}$

30.1991

22.1031

51.3071

Note. $\mathrm{CI}=$ confidence interval; $U L=$ upper limit; $L L=$ lower limit; $\tau=$ square root of estimated $\tau^{2} ; \tau^{2}=$ estimated amount of total heterogeneity; $\mathrm{I}^{2}=$ ratio of total heterogeneity/total variation in effect sizes; $\mathrm{H}^{2}=$ ratio of total variability/sampling variability.

Table 4.11b

Employee Engagement/Intent to Turnover Confidence Intervals

\begin{tabular}{|c|c|c|c|}
\hline \multirow[b]{2}{*}{ Effect } & \multirow[b]{2}{*}{ Estimate } & \multicolumn{2}{|c|}{$95 \% \mathrm{CI}$} \\
\hline & & $L L$ & $U L$ \\
\hline$\tau$ & .6871 & .4824 & 1.1716 \\
\hline$\tau^{2}$ & .4721 & .2327 & 1.3726 \\
\hline $\mathrm{I}^{2}$ & 99.8685 & 99.7337 & 99.9547 \\
\hline $\mathrm{H}^{2}$ & 760.7361 & 375.4532 & 2209.8005 \\
\hline
\end{tabular}


Mean effect size conversion. After calculation of a mean effect size by variable pairing, effect sizes were converted back into bi-serial correlations. The total number of participants as well as the number of studies examined is also included. The resulting effects size and correlation for work-family culture to intent to turnover were .327 and .316 , respectively. Employee engagement to intent to turnover was -.337 and -.325, respectively. According to Cohen (1992), these effects (as measured by r) fall into the medium (.3) and large (.5) for both the work-family conflict and intent to turnover path as well as the employee engagement and intent to turnover path. However, these are just guidelines suggesting that results meeting or exceeding these guidelines could or could not be ultimately meaningful (Ferguson, 2007). Such summary results are of great value as the sample sizes of individual studies have great influence on the statistical result wherein the conversion as well as the mathematical efforts to isolate and account for that variation gives us better insight to the true effect (Thompson, 2002). Table 4.12 contains the conversion of mean effect sizes into correlations by variable pairing.

Table 4.12

Conversion of Mean Effect Sizes to Correlations

\begin{tabular}{lllll}
\hline Effect & $M$ & $r$ & $N$ & $k$ \\
\hline WFC/TO & .327 & .316 & 39104 & 57 \\
EE/TO & -.337 & -.325 & 35962 & 12 \\
\hline
\end{tabular}

Note. WFC $=$ work-family conflict; $\mathrm{TO}=$ intent to turnover; $M=$ mean effect size; $r=$ Pearson correlation $\mathrm{EE}=$ Employee Engagement; $N=$ number of total participants; $k=$ Number of Studies.

\section{Publication Bias}


Funnel plots. Funnel plots were created using the statistical software, specifically the funnel() command in the "metaphor" package. Funnel plots assist the researcher in determining, by way of plot asymmetry, if a publication bias exists (Viechtbauer, 2010). The funnel plots for the variable pairings are below, in Figure 4.1. This figure represents the pairing work-family conflict/intent to turnover while Figure 4.2 represents employee engagement/intent to turnover. The results for Figure 4.1 suggest that, possibly, there might be some publication bias — specifically smaller, non-significant unpublished studies - that are missing from the bottom of the funnel plot (Borenstein et al., 2009). In the case of employee engagement/intent to turnover, the results suggest that there are many studies missing due to the dispersal toward the top of most of the studies - which was discovered by this meta-analysis - and absence of studies elsewhere. The results overall indicate that there are missing studies - however, the small amount of studies present in analysis (12) makes a judgement on whether there really missing studies speculative. Additionally, the results for work-family conflict/intent to turnover suggest that there is no evidence of bias using the random-effects funnel model. 


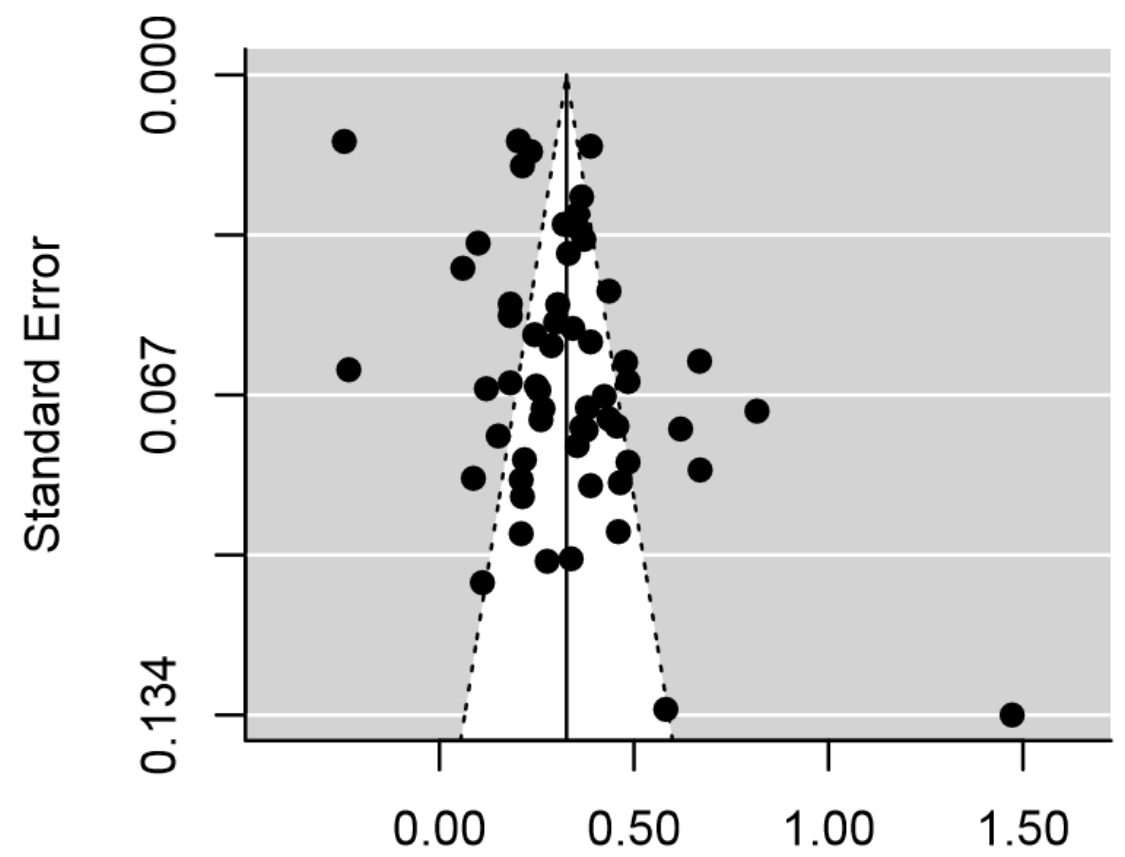

Fisher's z Transformed Correlation Coefficient

Figure 4.1. Funnel plot for pairing work-family conflict/intent to turnover. 


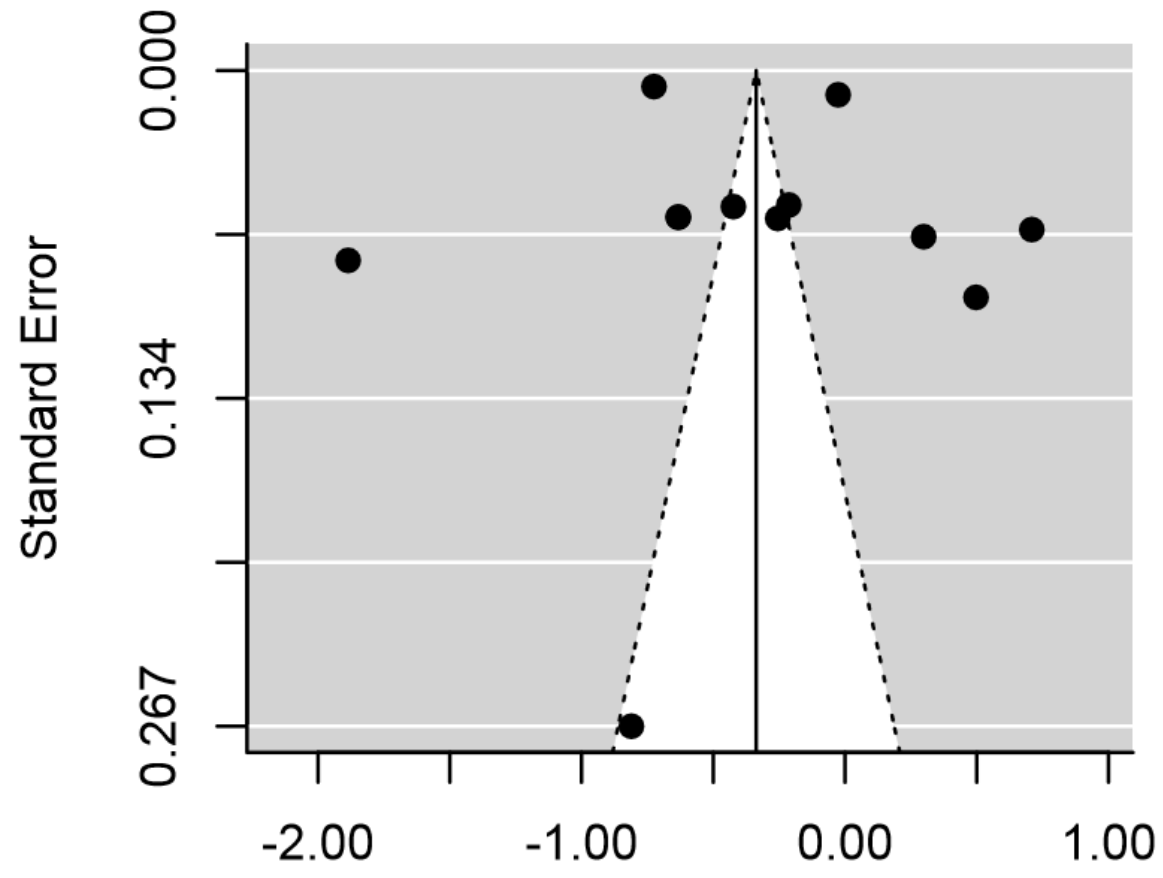

\section{Fisher's z Transformed Correlation Coefficient}

Figure 4.2. Funnel plot for pairing employee engagement/intent to turnover.

Trim-and-fill results. Trim-and-fill funnel plots were created to review the impact of missing studies on the overall effect size estimation. The trimfill() command in the statistical package $\mathrm{R}$ was used to generate the model and plots. Results are presented in Table 4.13. A problem using the trim-and-fill method is that it is impacted by the presence of heterogeneity; any results suggesting publication bias must be viewed with the caveat that the low number of studies, and the presence of large heterogeneity, could indicate a bias where one does not exist (Borenstein et al., 2009). The trim-and-fill results indicate there are 25 missing studies in work-family conflict/intent to turnover pairing and two missing studies for the employee engagement/intent to turnover pairing. The disparity in the number of missing studies between variable pairings could be due to the similar number of participants observed for each variable paring as reported in Table 
4.10. Table 4.14 compares effect sizes and correlations between the model presented in Table 4.11 and the model results in Table 4.12. The drop in the effect size in both variable pairings is worth noting. As stated earlier the trim-and-fill model is based on the assumptions of the model used (Borenstein et al., 2009). The heterogeneity results indicate the presence of a large amount of heterogeneity. Noting the differences in the effect size in table 4.14, and the missing studies in table 4.13 , it is likely that the underlying heterogeneity is driving the trim-and-fill model to indicate the presence of missing studies. Additionally, the low amount of studies, especially the employee engagement/intent to turnover pairing, suggest that the trim-and-fill results are being influence by the large heterogeneity amount. Said another way, the increase in sample size from the "missing" studies, allowed for the model to more accurately predict the mean effect size, however, the model would assume that heterogeneity was not present, and therefore the results should be viewed with that caveat in mind. In fact, looking at figures 4.1 and 4.3 we can see that the evidence of bias is due to the fact that the $x$-axis of the plot has widened to include the "missing" studies.

Table 4.13

Trim-and-Fill Model Results

\begin{tabular}{|c|c|c|c|c|c|c|c|c|}
\hline Pairing & $k(O r g)$ & $k(M i s)$ & $k(T o t) \quad M$ & $S E_{M}$ & $L L_{M}$ & $U L_{M}$ & Z & Q \\
\hline WFC/TO & 57 & 25 & $.124 *$ & .004 & .115 & .132 & $28.17 *$ & $3508.273 *$ \\
\hline EE/TO & 12 & 2 & $-.51 *$ & .005 & -.521 & -.5 & $-97.2 *$ & $4468.64 *$ \\
\hline
\end{tabular}

Note. $\mathrm{WFC}=$ work-family conflict; $\mathrm{TO}=$ intent to turnover; $\mathrm{EE}=$ employee engagement; $k(\mathrm{Org})=$ number of studies in this review; $k(M i s)=$ number of studies missing per trim and fill; $k(T o t)=$ total number of studies on trim and fill model $M=$ mean effect size; $S E_{M}=$ standard error of mean effect size; $L L_{M}=$ lower limit of $95 \%$ confidence interval of mean effect size; $U L_{M}=$ upper limit of $95 \%$ confidence interval of mean effect size; $\mathrm{Z}=\mathrm{Z}$ score; $\mathrm{Q}=\mathrm{Q}$ Statistic.

$* p<.001$ 
Table 4.14

Mean Effect - Correlation Model Comparison

\begin{tabular}{lcccccc}
\hline Effect & $M_{R E}$ & $M_{T F}$ & $r_{R E}$ & $r_{T F}$ & $k_{R E}$ & $k_{T F}$ \\
\hline WFC/TO & .327 & .124 & .316 & .123 & 57 & 82 \\
EE/TO & -.337 & -.51 & -.325 & -.47 & 12 & 14 \\
\hline
\end{tabular}

Note. $\mathrm{WFC}=$ work-family conflict; $\mathrm{TO}=$ intent to turnover; $\mathrm{EE}=$ employee engagement; $M_{R E}=$ mean effect size random effects model; $r_{R E}=$ Pearson correlation random effects model; $k_{R E}=$ number of studies random effects model; $M_{T R}=$ mean effect size trim and fill model; $r_{T R}=$ Pearson correlation trim and fill model; $k_{T R}=$ number of studies trim and fill model. 


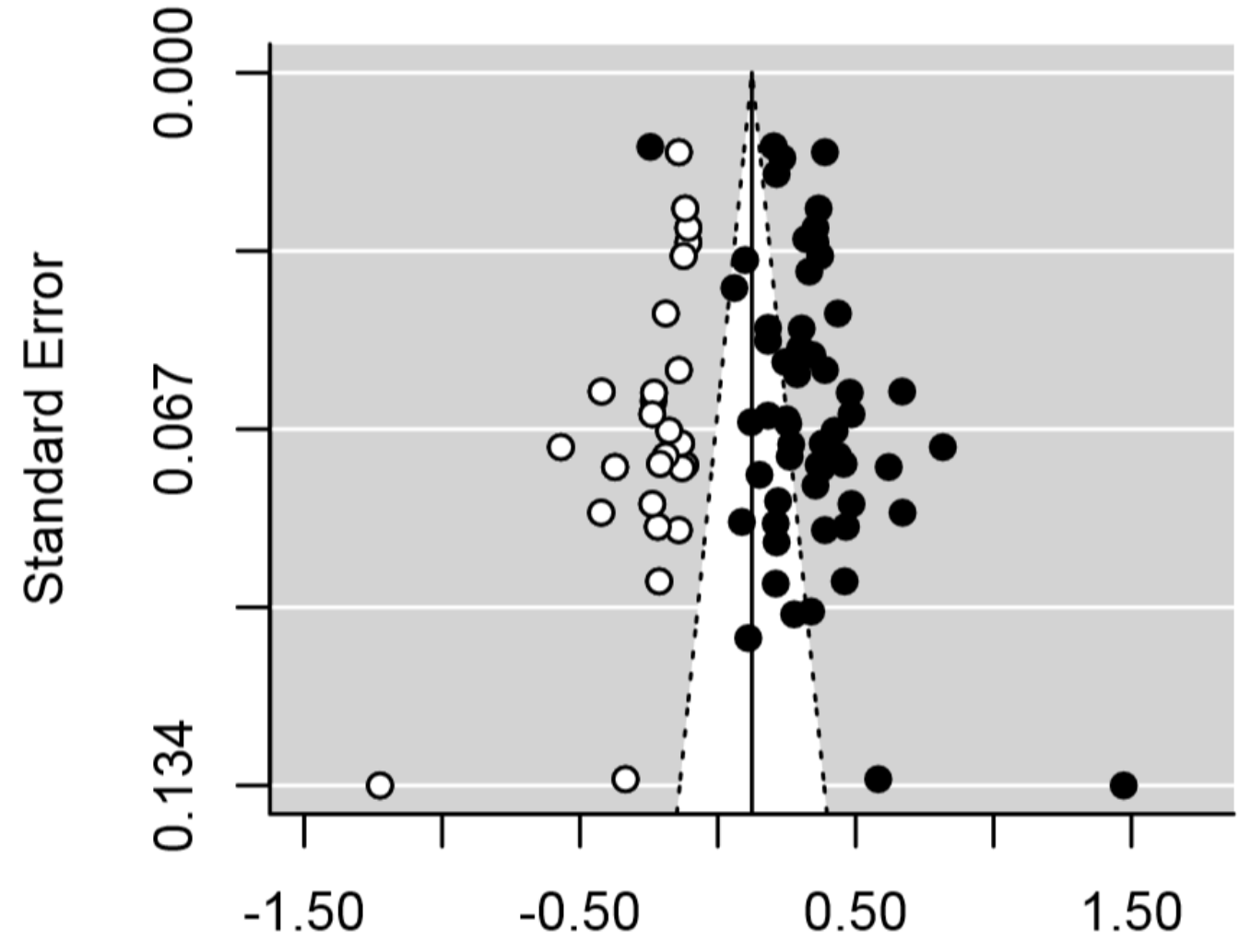

Fisher's z Transformed Correlation Coefficient

Figure 4.3. Trim-and-Fill funnel plot for pairing work-family conflict/intent to turnover. 


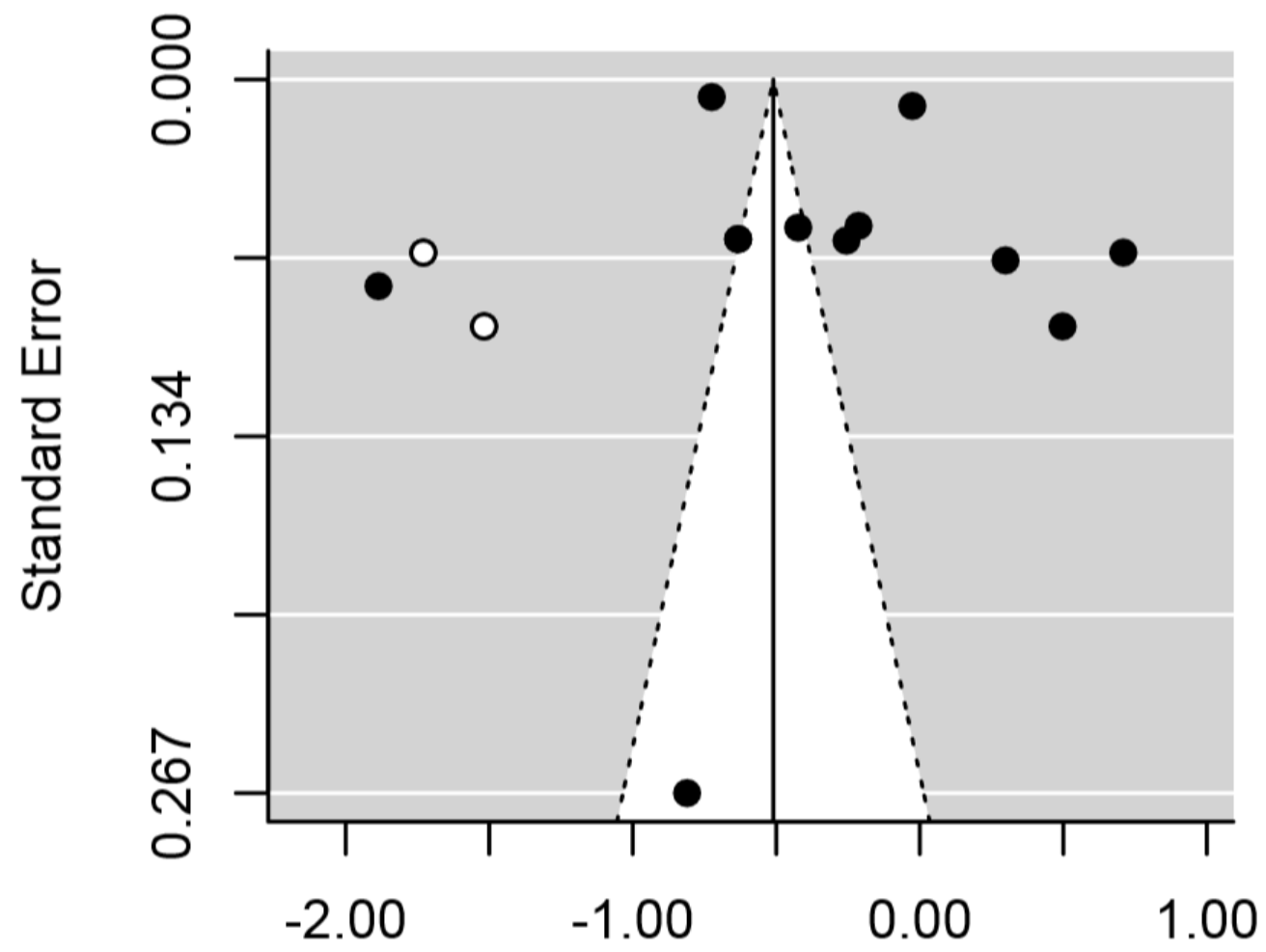

Fisher's z Transformed Correlation Coefficient

Figure 4.4. Trim-and-Fill funnel plot for pairing employee engagement/intent to turnover.

\section{Summary}

This chapter covered search, screening and coding results, descriptive statistics, the results of the random-effects model for the resultant variable pairings, and results for publication bias detection. Chapter five will examine and explain these results, explore study limitations, and draw implications on future research. 


\section{CHAPTER 5}

\section{DISCUSSION}

This chapter includes a discussion of the study results from chapter four, and it is broken down into five sections. Section one covers this study's summary. Section two reports a synopsis of the results. Section three details the results pertinent to each research question. Section four reviews the implications for theory, research and practitioners. Finally, section five examines the study's limitations.

\section{Study Summary}

Low levels of employee engagement cost organizations up to $\$ 400$ billion dollars annually (Byrne, 2015). Research indicates that higher levels of employee engagement saves organizations from costs such as safety incidents, low performance, recruitment and retention costs, and restructuring costs due to organizational gaps caused by turnover (Fairlie, 2011; Harter et al., 2010; Kumar \& Pansari, 2014; Lockwood, 2007). A significant variable impacting organizational costs is an individual's intention to turnover (Hancock et al., 2011; Shuck et al., 2011). Connected, an individual's level of workfamily conflict in concert with a supportive organizational culture - to equip an individual to mitigate work-family conflict - have been shown to increase an individual's employee engagement whilst decreasing turnover intentions (Allen \& Shanock, 2013, Byron, 2005; Bendarkar \& Pandita; Halbesleben et al., 2009).

To address low levels of employee engagement, researchers have created a variety

of frameworks and instruments to understand and measure employee engagement (Byrne, 
2015). Yet these competing frameworks and measurements have not resulted in a common approach to understanding employee engagement (Purcell, 2014, Saks \& Gruman, 2014). However, research suggested that individual antecedents, such as workfamily conflict, as well as organizational antecedents, such as supportive organizational culture, could be connected and could have an impact on both employee engagement as well as outcomes such as intent to turnover (Wollard \& Shuck, 2011). Research into employee engagement measures suggested the Utrecht Work Engagement Scale (UWES) is the predominant employee engagement measure (Cole et al., 2011), confounding employee engagement research. Understanding employee engagement frameworks is thus diluted by the proliferation of UWES. Furthermore, the interactions of individual and organizational employee engagement antecedents with employee engagement as well as employee engagement outcomes will facilitate researchers and practitioners in understanding the nature and impact that employee engagement has on individuals as well as organizations.

The study investigated the relation between individual and organization employee engagement antecedents, employee engagements, work-family conflict, supportive organizational culture, and intent to turnover. Specifically, using the Wollard and Shuck (2011) employee engagement conceptual model, I explored the relation of individual and organizational antecedents of employee engagement, the effect of those antecedents on employee engagement, and the relation to intent to turnover. Additionally, I synthesized whether or not employee engagement mediated the relationship between employee engagement antecedents and organizational outcomes. Seven research questions were posited to explore these relationships: 
Q1: To what extent does work-family conflict and a supportive organizational culture affect each other?

Q2a: To what extent does work-family conflict have an effect on an individual's level of employee engagement?

$\mathrm{Q}_{2 \mathrm{~b}}$ : To what extent does work-family conflict have an effect on an individual's turnover intentions?

$\mathrm{Q}_{3 \mathrm{a}}$ : To what extent does a supportive organizational culture have an effect on an individual's level of employee engagement?

$Q_{3 b}$ : To what extent does a supportive organizational culture have an effect on an individual's turnover intentions?

Q4: To what extent does employee engagement have an effect on an individual's turnover intentions?

Q5: To what extent does employee engagement mediate the effects of workfamily conflict and a supportive organizational culture on individual turnover intentions?

A systematic review was conducted to explore the variable pairings under consideration. A screening guide was used to identify relevant studies. A coding guide categorized study features that were further explored using meta-analytic tools. Effect size transformation and analysis of variances were employed to examine variable relations and answer research questions.

The results suggest that the number of studies employing a measure for employee engagement other than the UWES is low. Furthermore, the construct confounding, that is the use of one variable construct measured by a similar yet conceptually different 
variable construct (e.g. work engagement and employee engagement), is also found with the variables supportive organizational culture and work-family conflict. Additionally, certain variable pairings yielded zero studies due to variable conflation. Intriguingly, despite the examination of four variables and five pairings, the intent to turnover variable was examined in all studies that passed screening and were coded.

\section{Study Synopsis}

This researched examined 69 studies. Of the 69,57 were comparing work-family conflict to intent to turnover, and 12 were covering employee engagement to intent to turnover. These studies contained over 75,000 participants, over 39,000 participants for work-family conflict and intent to turnover, and close to 36,000 for employee engagement to intent to turnover. Studies not included were those covering the other variable pairings of work-family conflict to supportive organizational culture, supportive organizational culture to employee engagement, and finally supportive organizational culture to employee engagement. The lack of studies containing those variable pairings is likely due to instrumentation of both supportive organizational culture as well as employee engagement. In both cases, instruments that actually measure other similar variables were used. In the case of employee engagement, the instrument used was the UWES, which was excluded from consideration. Supportive organizational culture was likewise measured predominantly using the perceived organizational support scale developed by Eisenburger, Huntington, Hutchinson, and Sowa (1986), which I excluded (see Appendix C).

A majority of studies (80\%) were derived from peer-reviewed journals, with the remaining (16\%) from dissertations or theses. Over half of the studies included used a 
cross sectional design methodology while approximately $35 \%$ were correlational in nature. Few studies were quasi-experimental, longitudinal, or systematic reviews in their own right. The instruments used for the remaining variables of interest (work-family conflict, employee engagement, and intent to turnover) were found to be in a desirable range. In terms of employee engagement measures, the most used was the Rich et al. (2010) scale, which more than doubled the two next most used scales of May et al. (2004) and Saks (2006).

\section{Findings}

This section discusses the findings yielded for each research question. The results imply that, despite the prevalence and proliferation of quantitative research concerning this studies variable parings, only two research questions were fully answerable, while one is partially answerable.

Research questions Q1, Q2a, Q3a, and Q3b. Research questions Q1, Q2a, Q3a, Q3b were found to be unanswerable due to a lack of studies that measured and correlated the variable pairings of work-family conflict to supportive organizational culture, workfamily conflict to employee engagement, supportive organizational culture to employee engagement, and, lastly, supportive organization culture to intent to turnover. Screening and coding results suggest that, regarding employee engagement, this likely occurred due to the use of the UWES to measure employee engagement with work-family conflict and supportive organizational culture. Additionally, the results indicate that, similar to employee engagement, variable instrumentation is likely a concern for supportive organizational culture scholars. An examination of the issues arising from each question follows. 
Research question Q1. The variable pairing work-family conflict and supportive organizational culture produced no studies for consideration. An examination of the screening results indicates that no studies with this variable pairing appeared. A plausible explanation is that, despite these two variables having empirical data available in connection with employee engagement, there has been no research examining the correlational link between these two specific employee engagement antecedents.

Research question Q2a. The variable pairing work-family conflict and employee engagement produced three studies for consideration: Amah (2016), Baer et al. (2016), and Halbesleben (2010). The Amah (2016) study is instructive as to the confounding of work engagement and employee engagement that led to these three promising studies' exclusion from the systematic review. In the abstract for Amah (2016), the author states, "high employee engagement is beneficial to organizations" wherein "highly engaged employees experience high levels of work-family conflict." The abstract then details the correlational analyses used to examine this linkage. Additionally, the first two keywords from the abstract are "employee engagement, work-family conflict". This verbiage led to inclusion to be coded and analyzed. Despite this promising lead, the Amah (2016) study failed to be coded due to the use of the UWES as the employee engagement survey instrument. The Amah (2016) literature review covers employee engagement pillars such as Kahn (1990), May et al. (2004), as well as Macey and Schneider (2008). Additionally, the term "employee engagement" is used throughout.

However, a deeper review of literature and framework reveals which type of engagement is actually under examination — that is, links to work engagement are found in the study's framework. The study uses both the Hobfoll (1989) conservation of 
resource model as well as the Bakker and Demerouti (2007) job demand-resources model. An examination of these models reveals roots in work engagement and not employee engagement.

The Hobfoll (1989) model was further explored and expanded by Halbesleben et al. (2009), which examined work engagement and work-family conflict under another name. In the Halbesleben et al (2009) study, the authors explore the linkage between work engagement and work-family conflict, finding that "engagement could also be associated with potentially negative consequences" that seem to signify "that engagement not only has relevance within organizations but also has implications that transcend the workplace and enter into the intersection of work and home.” (p. 1461). Interestingly, the quotes above omit the type of engagement despite the study being about work engagement and the UWES used as the survey instrument. The abstract keywords also omit the type of engagement by simply using the vague keyword "engagement".

Similarly, the Bakker and Demerouti (2007) study states that using the job demand-resources model will assist organizations in developing strategies that "may decrease the risk for burnout, and increase the likelihood of work engagement and good performance" (p.324). Therefore, the whole basis of the Amah (2016) article exploring employee engagement is built upon a work engagement base, thus leading to construct confounding. Lastly, the survey instrument used to measure employee engagement was the UWES instrument, thus excluding that research from further consideration.

A key finding is the suggestion that quantitative data concerning antecedents and employee engagement — as suggested by Wollard and Shuck (2011)—might not be grounded in employee engagement, but, as the Amah (2016) indicates, grounded in a 
work engagement framework. Similarly, the Baer et al. (2016) study employed the UWES survey instrument to measure employee engagement, yet stated in the keywords the simple non-descriptive "engagement". However, where the Amah (2016) study presented a literature review that contained various frameworks to support employee engagement, the Baer et al. (2016) did not contain a similar in-depth literature review, but the same generic use of "engagement" was found in both abstracts and keywords. Lastly, the Halbesleben study systemically reviewed employee engagement with both intent to turnover and work-family conflict. Nonetheless, Halbesleben included the UWES instrument that made the research results inadmissible.

Research question Q3a. The variable pairing of supportive organizational culture and employee engagement produced one study for consideration: Lo and Nieh (2015). This promising article was excluded due to it missing information on what measures were used for employee engagement and supportive organizational culture. The authors did present a correlation for this variable pairing of 0.427 with 176 respondents. Efforts were made to contact the authors to obtain the required information regarding instrument reliability and source, as this information was not reported. However, it is unlikely that, had this information been received, that inclusion would have swayed the results for this particular variable pairing as this was the only study under consideration. Additionally, the section reviewing literature and defining the variables begins "the research on Perceived Organizational Support," which suggested that the instrument used to measure supportive organizational culture would exclude Lo and Nieh (2015) from this review (p. 340). That researchers have explored this pairing is reassuring that the links posited by 
Wollard and Shuck are being explored, albeit in Taiwan within the hospitality industry (Lo and Nieh, 2015).

Research Question $Q 3 b$. The variable pairing of supportive organizational culture and intent to turnover produced two studies for consideration: Dupre and Day (2007) and Wang et al. (2016). Both studies, however, were excluded for supportive organizational culture measures and not for employee engagement measures, but the reasons for exclusion are similar and warrant discussion. In Dupre and Day (2007), the authors examine supportive management practices impact on turnover intentions within a military organization. An abstract examination reveals that, similar to employee engagement abstracts discussed above that masked work engagement under the cloak of "engagement", the same masking might occur with supportive organizational culture frameworks and measures. For example, the title implies that the study will examine supportive management, yet the abstract breaks down supportive management into a host of "factors" (i.e., different types of support: supervisor, organization, and mention of work-life balance). Similar to Amah (2016), the authors create a supportive management foundation with a literature review. The third paragraph on supportive management reveals that the authors are turning toward perceived organizational support as a base to explore and explain a supportive organizational culture. In fact, this study uses the Eisenberger et al. (1986) perceived organizational support survey instrument, thus leading to the Dupre and Day (2007) being excluded from this examination. However, similar to the discussion above regarding work employee engagement confounding, an examination of Dupre and Day (2007) suggested that supportive organizational culture could face a similar issue. 
Wang et al. (2016) was initially considered and later rejected due the variable pairing of employee engagement (measured by the UWES) and work-family conflict. However, the Wang et al. (2016) study also looked at what was called "perceived wellness climate". Further examination revealed that this variable was measured by the family-supportive organizational perceptions by Allen (2001), a measure excluded from this analysis. Interestingly, this measure was used to measure, correlate, and explore "perceived wellness climate" and not a variable more focused on organizational culture, such as perceived organizational support or a supportive organizational culture. The translation of the climate variable could also reflect the limitations of translation software because the Wang et al. (2016) article was published in The Journal of the Korean Contents Association and in the Korean language.

Research question Q2b. The coding results for the resultant variable pairs of work-family conflict to turnover intentions as well as employee engagement to turnover intentions suggest that the antecedent variables (work-family conflict and employee engagement) have a significant effect on the outcome variable of turnover intentions. Findings from Q2b regarding the extent of impact of work-family conflict to an individual's turnover intention (reported as $\mathrm{M}=.327, r=.316$ ) is positive, but it also has a small to medium overall effect—as suggested by Cohen (1992)—being right in the middle of the range. What this suggests is that work-family conflict could influence an individual's desire to depart their organization — however, it is not a large or driving reason someone would choose to voluntarily turnover, and, likely, there are other factors that ultimately influence that decision. 
Research question Q4. Interestingly, the impact of employee engagement to an individual's turnover (reported as $\mathrm{M}=-.337, r=-.325$ ) is similar to the in size to workfamily conflict and turnover intentions being in the middle of the small and medium overall effect range provided by Cohen (1992), however the direction of the relationship is negative. This finding suggests that, as similar to the work-family conflict to intent to turnover relationship, an individual's level of employee engagement could influence an individual's intent to turnover. Put another way, if an individual has a low level of employee engagement, the low level of employee engagement will influence their turnover intention. In practice, this could mean that a low level of employee engagement may not be the single reason someone decides to leave an organization and most likely would not be the main reason. Similar to work-family conflict and intent to turnover pairing the combination of these variables (high work-work family conflict, low support from the organization, low levels of employee engagement) could together strongly influence intent to turnover.

However, caution must be taken with interpreting the overall results. This pairing did not reach the threshold for power described in chapter 3 , i.e. at least 40 studies. The number of studies included for this pairing was only $k=12$. Although the overall sample size for this variable pairing is $\mathrm{N}=35,962$ is in close to overall sample size in the number of participants derived from work-family conflict and intent to turnover, $\mathrm{N}=39,104$, the number of studies is almost four times as great: WFC/TO $k=57$. A review of underlying data indicates that two studies: Halliday et al. (2017) and Liss-Levinson et al. (2015) are responsible for 33,685 ( $k=23,439 \& k=10,246$ respectively) or nearly $94 \%$ of the total sample population. Here the tau statistic helps with interpretation and is the real story. 
The reported tau for this pairing is .687. This figure is over four times as great as the same value reported for work-family conflict and intent to turnover (tau $=.045)$. This statistic indicates that, in concert with confidence intervals, is that approximate range of true effects is between .48 and 1.17, a distribution that using Borenstein et al. (2009) as guide could be classified as harmful. Said another way I cannot substantively say with confidence that the overall correlation $r=-.325$ (as transformed from the overall mean effect of $M=-.337$ ), is an accurate figure to make generalized statements about the population. Given the number of different measures used for employee engagement, along with the large tau, large tau confidence intervals, and the large $I^{2}$, a likely source of variance is amongst the differing measures used for employee engagement and the low amount of studies under examination.

Lastly, the low number of studies, as mentioned above, indicates that this variable pairing has a low power. A review of trim and fill results would suggest that there are only two studies missing, bringing the total number of studies only to fourteen. A plausible reason for the low number of missing studies leads back to the influence of Halliday et al. (2017) and Liss-Levinson et al. (2015). However, the results for this pairing give us two points for further exploration and discussion. Firstly, the resultant correlation/mean effect size $(r=-.325$ and $\mathrm{M}=-.337)$, provide a good starting point for discussions relating to this variable pairing with both employee engagement and as a comparison to work engagement. Secondly, and the more interesting finding, is the large amount of heterogeneity found with this pairing. Future research into employee engagement should look more deeply into the measures of employee engagement to understand and explain such large variance. 
Research question Q5. The interpretation described in the previous paragraph provides partial insight to answer the portion of Q5 that seeks to understand the mediation impact of employee engagement, however there is no quantitative data present to support the conclusions that follow. The conclusions drawn from the interpretations of the previous questions are only speculative in nature and are included to provide scholars with some thoughts on the possible outcomes in future studies of employee engagement without the UWES and ideas on possible linkages that include the UWES. Given that I do not have any studies that correlated work-family conflict to employee engagement, I can only speculate based on both of those variables' relationship to intent to turnover. What those results suggest is that, if a small to medium effect size existed between workfamily conflict and employee engagement, that employee engagement - though impacted by work-family conflict — could possibly, in theory, reduce the effect upon overall turnover intentions through higher employee engagement. In other words, although there is an impact, other organizational and individual antecedents - as identified by Wollard and Shuck (2011) — might actually increase an individual's level of engagement and thus mitigate the impact of work-family conflict on intent to turnover. Without studies examining the work-family conflict to employee engagement pairing that do not use the UWES, we can only venture thoughts on that plausible impact. However, a large effect size in the range of .7 or greater, if present and if gathered from a significant number of studies, at least 50 to 75 , such a finding might suggest that employee engagement does mitigate the impact of work-family conflict on intent to turnover. Though such a finding would also have to look at the amount of variance underlying the effect size. If the result of future meta-analysis of employee engagement as mediator indicates a similar amount 
of variance, as measured by tau and $I^{2}$, found in this study, further analysis using metaregression or subgroup analysis should be performed to better understand the source of the variation (Borenstein et al., 2009).

\section{Theory Implications}

The findings suggest that the antecedenal links suggested by Wollard and Shuck (2011) do somewhat exist. Additionally, the construct confounding between work engagement and employee engagement also exists in work-family conflict (sometimes theorized and measured as work-life balance) and supportive organizational culture (sometimes theorized and measured as perceived organization support). Previous employee engagement systematic reviews/meta-analysis included most, if not all, the available measures offered at the time of publishing — or in the case of Cole et al. (2011) and Christian et al. (2011), chose to specifically focus on the UWES. No previous research systematically examined employee engagement specifically excluding the UWES instrument. Additionally, no research examined the individual/organizational antecedent-employee engagement outcome linkage proposed by Wollard and Shuck (2011). The results imply that linkages are both present as well as of a significant size to influence each other. HRD researchers and practitioners can benefit from these findings in two ways. First, when addressing organizational performance and engagement, HRD researchers as well as practitioners can narrow the scope of engagement interventions by focusing on specific antecedent and outcome pairings as part of an overall engagement improvement strategy. For example, organizational leaders can focus on reducing turnover intentions by actively working to lower the amount of work-family conflict an employee experiences. The results would demonstrate to the employer as well as the 
employee that the tangible connections between engagement, engagement antecedents, and outcomes. Secondly, the availability of other measures besides the UWES-with the additional research showing just how deep the confounding between employee engagement and work engagement runs — should encourage not only the use of other employee engagement instruments, but also foster the development of an instrument that can replace the UWES as the standard employee engagement instrument.

The findings reveal the importance of terms as well as how those terms are used and interpreted. The screening guide used abstracts and keywords to determine whether or not a study met the inclusion criteria. Previous employee engagement research illuminated the confounding and interchangeability of the terms employee engagement and work engagement. This research confirmed the employee/work engagement confounding in addition to the use of job engagement (e.g., see Rich et al., 2010; Kelley, 2012) as well as a hybrid employee-work engagement to describe engagement that is measured by the UWES. A significant finding was that this type of interchangeability also occurs in employee engagement antecedent variables. For example, a study's abstract, title, and keyword might imply that a study is the examination of work-family conflict, but only to measure and discuss work-life balance. Additionally, supportive organizational culture study turns out to be theoretically grounded and measured as perceived organization support (e.g., see Dupre \& Day, 2007). Researchers can address this by looking at the individual and organization variables provided by Wollard and Shuck (2011), and then looking for commonality in naming conventions in order to identify potential pairings that might have intertwined theoretical groundings. 
Finally, the results indicate the need for common and agreed upon frameworks and measures. This examination purposely excluded the UWES, and this exclusion reduced the number of studies under consideration, which revealed that the number of studies using another engagement instrument is many and varied. Without a current agreed upon employee engagement instrument, results indicate that a likely candidate is the Rich et al. (2010) job engagement instrument. This measure is theoretically grounded in engagement as conceptualized by Kahn $(1990,1992)$ - however, as the name implies, the measure is "job" and not "employee" engagement. That said, given the preponderance of theory on employee engagement is based on Kahn, this instrument - in the absence of an agreed upon instrument within the HRD field — is a good candidate for acceptance and use, which is the reason the Rich et al. (2010) instrument was included. The Byron (2005) meta-analysis of work-family conflict provides insight into the path that employee engagement measurements should not follow, as there are two to three commonly used instruments, and many of said instruments are used only once or twice, never to be used again. What is needed is not only more studies that measure variable pairing, but more studies using an agreed upon employee engagement instrument that is used as much for employee engagement as the UWES is used for both work and employee engagement.

\section{Research Implications}

Further research needs to be conducted on the variable pairings between individual and organization antecedent variables. Research should not only focus on the "natural seeming" links, but also between variables that may not at first glance have any interaction such as value congruence (individual) and level of task challenge (organizational). An examination might reveal a linkage not thought of previously, or it 
could confirm that no linkage exists. Either way, this line of research will further define and expand employee engagement antecedents as well as further refine employee engagement as a whole.

Additionally, where there is no verification of empirical evidence for an antecedenal pairing - therefore, future research could be conducted focusing on developing employee engagement antecedents, empirically, with a path toward a future systematic review. For example, researchers could identify emotional fit (individual) with feedback (organizational), exploring, defining, and measuring them individually and using correlational analysis tied to employee engagement as well as an engagement outcome. Once research has been conducted across a spectrum of settings (e.g., sectors, industries, regions), this research could be meta-analyzed to determine overall effects. The number of potential pairings allows for the creation of a vast research agenda. These studies will give organizations as well as individuals an understanding of which variable pairings have the greatest impact on employee engagement and engagement outcomes, allowing once again for the creation of targeted engagement interventions to improve organizational and individual efficiencies.

Furthermore, the development and employment of an agreed upon employee engagement measure will have benefits across the academic and practitioner communities. Academic communities will benefit from a single source for engagement measures. The benefit will be results based on a single instrument, thus improving reliability (specifically the reliability derived from a single instrument), and validity as the results will come from a single instrument source. Additionally the influence of the UWES could be eliminated. Shuck, Adelson, \& Reio (2017) have recently created such 
an instrument, the Employee Engagement Scale (EES) based on a proposed unifying framework that could gain community alignment and use (Shuck, Kobena, Zigarmi, \& Nimon, 2017). Practitioner communities will benefit from the additional research that an agreed upon measure, such as the EES, would produce because it would provide practitioners with a better understanding of employee engagement. This understanding will assist in the creation of impactful employee engagement strategies to successfully impact the organizational bottom line. A final additional benefit will be comparing the future single measure employee engagement results with existing literature on work engagement. This comparison will assist researchers in defining and understanding the differences between work engagement and employee engagement, and, thus, help to unravel future construct confounding.

\section{Practitioner Implications}

HRD practitioners tasked with increasing employee engagement levels now have a starting point when it comes to understanding the various factors that influence employee engagement and employee engagement outcomes. This analysis offers a starting point in using the antecedent $\rightarrow$ employee engagement $\rightarrow$ outcome model posited by Wollard and Shuck (2011). Additionally, the results indicate significant effect sizes for the variable pairings under consideration that can be used as a guide when crafting employee engagement strategies. Further, the results validate that, despite a reported plethora of employee engagement research, when taking into account the proliferation of the UWES instrument, the remaining employee engagement landscape is not as full as previously reported (Saks \& Gruman, 2014). Armed with the knowledge provided here, practitioners can review variables within existing empirical data with a discerning eye to 
data obtained from using the UWES instrument. Therefore, any employee engagement strategies developed will be founded upon frameworks rooted in employee engagement and not work engagement, thus facilitating the creation of sound interventions.

Taken further, HRD practitioners can serve as trainers and educators to middle, upper, and executive management as well as leadership by clearly defining employee engagement. Additionally, HRD practitioners can educate on the influence of employee engagement antecedents pertaining to both employee engagement and employee engagement outcomes. The understanding of the Wollard and Shuck (2011) model will facilitate a multi-level and multi-pronged approach to identify, address, and increase employee engagement as well as positive employee engagement outcomes (e.g., organizational citizenship behaviors) whilst mitigating and decreasing negative impacting antecedents and outcomes (e.g., work-family conflict, turnover intentions). This understanding will enable leaders to create and support engagement efforts within the various departments and teams under their purview (Li \& Liao, 2014).

Finally, this inquiry will assist practitioners in understanding the conception as well as influences, and assist in the creation of engagement interventions and strategies (Shuck \& Rose, 2013). Practitioners can also expand their role as employee engagement educators by creating employee training to facilitate employee engagement strategies and comprehension at the employee level (Shuck \& Rose, 2013). This facilitation could create an open avenue for employees to provide additional feedback such as the impact of strategies on an individual's passion and well being (Zigarmi \& Nimon, 2011). Evidence indicates that previous research into the natural seeming links between organizational and individual antecedents exists, but it is influenced by the use of the UWES instrument. 
Practitioners can assess natural seeming links as well as existing research to craft training, strategies, and specific interventions that not only illuminate and develop leadership employee engagement, but also create an avenue for employee feedback for providing the practitioner with critical real-time data on intervention and strategy effectiveness.

\section{Study Limitations}

Study limitations are addressed below. Firstly, only examined a specific set of variable pairings. The antecedenal pairing (work-family conflict/supportive organizational culture) and outcome were selected based upon construct longevity, antecedenal relation, antecedent to outcome relation, and relation to employee engagement (Andrew \& Sofian, 2014; Bedarkar \& Pandita, 2014, Byron, 2005, Han, 2012; Sok et al., 2014, Timms et al., 2015). While previous research identified linkage between variables, future research should take into consideration that individual and organizational antecedents could be rooted in the same framework and measurement as the pairing of perceived organization support and supportive organization culture (e.g., see Dupre \& Day, 2007).

The second limitation is the inclusion of multiple measures for the variable under examination. The use of multiple instruments to systematically review engagement suffers from the conundrum faced when examining results including the UWES: Do these measures really measure employee engagement? For the purposes of this study, the answer is yes and, from here, suggested future research should drive the creation of a singular accepted employee engagement framework and measure. The findings suggest that the use of multiple measures for work-family conflict is in line with previous 
findings in Byron (2005) of the most widely used instruments (e.g., Frome et al., 1992a; Netemeyer et al., 1996). This meta-analysis underscores the need not only for an accepted employee engagement measure, but the development of single source measures for other employee engagement related variables (Byrne, 2015).

Lastly, the screening guide allowed for the exclusion of studies not in the English language. This exclusion was with understanding, as stated by Borenstein et al, (2009), that "English-language databases and journals are likely to be searched" (p.279-80) thus reducing the number of possible foreign-language studies being returned. A metaanalysis SME was consulted on the possibility of language bias, and after consultation the exclusion was kept in place. Despite the use of English language databases there were foreign language studies that appeared in the search results, though small in number, lessening a potential impact (Borenstein et al., 2009). For example, a record was returned with only title, author, and language information indicating that the record under review was written in Mandarin Chinese; this record was discarded. Most often the case occurred that a record would include variables of interest in title or abstract, yet not contain any information about language, other than a deduction based on the journal title, that the record under review was in a foreign language. These records were included in the coding process. Many foreign language studies included in this review made it through the screening process this way.

Once identified as a study reported in a foreign language it was decided that to reduce potential language bias, every effort and use of technology (i.e., Google Translate) should be made to capture and incorporate those results. A meta-analysis SME was consulted and the decision was made to include any results that could be obtained using 
methods described above. The Campbell Policies and Guidelines, Series No.1 support this action, advising researchers to minimize, where possible, the introduction of bias. Additionally, specific to the language exclusion, researchers should ensure that any exclusion does not disqualify a significant portion of the research results. (The Campbell Collaboration, 2019) The results signify a body of research and researchers into employee engagement as well as employee engagement outcomes and antecedents, particularly within the Korean peninsula. Undoubtedly, research into employee engagement is a global effort and certainly not limited to the North American or European spheres. Future researchers should be aware of this body of research and anticipate that other regions (such as the Middle East and South America), could begin to build a body of research that is not reported in the English language.

I conclude with a parting insight on both language and the development of constructs within social science. Author and amateur philologist Bill Bryson (1990) provides two insights that illuminate the language problem discussed in the preceding paragraphs and the debate on the work engagement - employee engagement confound. The first insight is there is a variety of words in the English language that mean the same general thing yet there is a subtle difference between the words in question. The example is the difference between a house and a home. Bryson notes that this distinction is both present and absent in other languages. For example romance languages such as French does not have the house/home distinction; In some Eskimo languages there are a multitude of words for snow all of which mean snow, however have subtler meanings to describe the exact kind of snow. This first insight ties into the second insight Bryson (1990) makes: English is becoming the dominate language in commerce, science, and 
other aspects of everyday life: the modern lingua franca. A related point is that academic English is almost a language of its own. This suggests that the number of foreign language studies might decline over the years. However, studies will still be published in other languages. The question arises: will the distinction (academically as well as linguistically) we have for the various types of engagement discussed in this analysis (job, work, employee) carry over into another language? Is there such a distinction? This question leads us back, in a way, to the focus of this study: what is the impact of employee engagement and not work engagement. As we seek to define and examine constructs care should be taken in creating clear, parsimonious and perhaps easily translatable definitions and measures to ensure what is being sought after is truly measured. 


\section{REFERENCES}

* Denotes study used in meta-analysis.

Abelson, M. A., \& Baysinger, B. D. (1984) Optimal and dysfunctional turnover: Toward an organizational level model, Academy of Management Review, 9, 331-341

Aboobaker, N., Edward, M., \& Pramatha, K. P. (2017). Work-family Conflict, Familywork Conflict and Intention to Leave the Organization: Evidences Across Five Industry Sectors in India. Global Business Review, 18(2), 524-536. doi:http://dx.doi.org/10.1177/0972150916668696

Abugre, J. B. (2017). Relations at workplace, cynicism and intention to leave A proposed conceptual framework for organisations. International Journal of Organizational Analysis, 25(2), 198-216. doi:10.1108/IJOA-09-2016-1068

Adams, G. A., King L. A., and King D. W. (1996). Relationships of Job and Family Involvement, Family Social Support, and Work- Family Conflict with Job and Life Satisfaction. Journal of Applied Psychology, 81(4), 411-420.

Alacron.G., Lyons, J.B., \& Tartaglia, F., (2010). Understanding Predictors of Engagement Within the Military, Military Psychology, 22, 301-310. doi: $10.1080 / 089956052010492695$

Alagaraja, M. \& Shuck, B., (2015). Exploring Organizational Alignment-Employee Engagement Linkages and Impact on Individual Performance: A Conceptual Model, Human Resource Development Review, 14(1), 17-37. doi:

$10.1177 / 1534484314549455$ 
Albrecht S. (2010). Employee Engagement: 10 key questions for research and practice. In S. Albrecht (Ed.), Handbook of Employee Engagement: Perspectives, Issues, Research and Practice (pp. 3-19). Northampton, MA: Edward Elgar Publishing Limited.

Alexander, J. A., Bloom, J. R., \& Nuchols, B. A., (1994) Nursing turnover and hospital efficiency: An organizational-level analysis, Industrial Relations, 33, 505-520

*Alfes, K., Shantz, A.D., Truss, C., \& Soane, E.C. (2013). The link between perceived human resource management practices, engagement and employee behavior: a moderated mediation model, The International Journal of Human Resource Management, 24(2), 330-351. doi: 10.1080/09585192.2012.679950

*Ali, N., \& Baloch, Q. B. (2009). Predictors of Organizational Commitment and Turnover Intention of Medical Representatives (An Empirical Evidence of Pakistani Companies). Journal of Managerial Sciences, 3(2), 262-273.

Allard, K., Haas, L., Hwang, C., (2011). Family-Supportive Organizational Culture and Fathers' Experiences of Work-family Conflict in Sweden. Gender, Work and Organization, 18(2), 141-157. doi: doi:10.1111/j.1468-0432.2010.00540.x

Allen, D.G., \& Shanock, L.R., (2013) Perceived organizational support and embeddedness as key mechanisms connecting socialization tactics to commitment and turnover among new employees, Journal of Organizational Behavior, 34, 350-369, doi: 10.1002/job.1805

*Alshutwi, S. (2016). The influences of family supportive supervisor behaviors on the relationships among work-family conflict, stress, and turnover intention in Saudi Arabian registered nurses. (10247193 Ph.D.), The University of Wisconsin - 
Milwaukee, Ann Arbor. Retrieved from

https://search.proquest.com/docview/1867751145?accountid=14665

Amah, O. E. (2016). Employee engagement and the work-family conflict relationship:

The role of personal and organisational resources. South African Journal of Labour Relations, 40(2), 118-138.

Andrew, O.C., \& Sofian, S., (2012). Individual Factors and Work Outcomes of Employee Engagement, Procedia - Social and Behavioral Sciences 20, 498-508. doi:

1016/j.sbspro.2012.03.222

Anitha J., (2014). Determinants of employee engagement and their impact on employee performance, International Journal of Productivity and Performance Management, 63(3), 308-323. doi: 10.1108/IJPPM-01-2013-0008

Anwar, F., Sidin, J. P., \& Javed, A. (2017). Antecedents of work exhaustion, its mediating role and subsequent effects on turnover intentions. Business Management Dynamics, 6(8), 85-94.

*Appelbaum, S. H., Louis, D., Makarenko, D., Saluja, J., Meleshko, O., \& Sevag, K. (2013). Participation in decision making: a case study of job satisfaction and commitment (part three). Industrial and Commercial Training, 45(7), 412-419. doi:http://dx.doi.org/10.1108/ICT-09-2012-0049

Aytug, Z.G., Rothstein, H.R., Zhou, W., \& Kern, M.C. (2012). Revealed or Concealed? Transparency of Procedures, Decisions, and Judgment Calls in Meta-Analyses, Organizational Research Methods 15(1), 103-133. doi:

$10.1177 / 1094428111403495$ 
Baer, S. M., Jenkins, J. S., \& Barber, L. K. (2016). Home is Private ... Do Not Enter! Introversion and Sensitivity to Work-Home Conflict. Stress and Health, 32(4), 441-445. doi:10.1002/smi.2628

*Bagger, J. M. (2006). A test of time's objective and subjective influence on work-family conflict in Sweden and the United States. (67), ProQuest Information \& Learning, US. Retrieved from http://search.ebscohost.com/login.aspx?direct=true\&db=psyh\&AN=2006-99021013\&site=ehost-live

Bakker, A.B., (2011). An Evidence-Based Model of Work Engagement, Current Directions in Psychological Science, 20(4), 265-269. doi: $10.1177 / 0963721411414534$

Bakker, A.B., \& Demerouti, E., (2007). The Job Demands-Resources model: state of the art, Journal of Managerial Psychology, 22(3), 309-328. doi:

$10.1108 / 02683940710733115$

Bakker, A.B., \& Demerouti, E., (2008). Towards a model of work engagement, Career Development International, 13(3), 209-223. doi: 10.1108/13620430810870476

Ballard, J. K. (2012). Call center turnover: A study of the relationships between leadership style, burnout, engagement and intention to quit. (3549435 Ph.D.), Capella University, Ann Arbor. Retrieved from http://echo.louisville.edu/login?url=https://search.proquest.com/docview/1283387 142? accountid=14665

*Bande, B., Fernández-Ferrín, P., Varela, J. A., \& Jaramillo, F. (2015). Emotions and salesperson propensity to leave: The effects of emotional intelligence and 
resilience. Industrial Marketing Management, 44, 142-153.

doi:10.1016/j.indmarman.2014.10.011

Bates, S. (2004, February). Getting engaged. HR Magazine, 49(2), 44-51.

Bedarkar, M., \& Pandita, D., (2014). A study on the drivers of employee engagement impacting employee performance, Procedia - Social and Behavioral Sciences 133, 106-115. doi: 10.1016/j.sbspro.2014.04.174

*bin Salahudin, S. N., bin Alwi, M. N. R., Baharuddin, S. S. B., Santhasaran, Y., \& Balasubramaniam, V. (2016). The Relationship between Occupational Stress, Employee Engagement and Turnover Intention. In R. Thambusamy, M. Minas, \& Z. Bekirogullari (Eds.), Be-Ci 2016 : 3rd International Conference on Business and Economics (Vol. 17, pp. 457-464). London, United Kingdom: Future Academy.

*Blomme, R. J., Van Rheede, A., \& Tromp, D. M. (2010). Work-family conflict as a cause for turnover intentions in the hospitality industry. Tourism \& Hospitality Research, 10(4), 269-285. doi:10.1057/thr.2010.15

Boles, J.S., Howard, W.G., Donofrio, H.H. (2001). An Investigation Into The InterRelationships Of Work-Family Conflict, Family-Work Conflict And Work Satisfaction. Journal of Managerial Issues, 13(3). 376-390.

Bolman, L.G. \& Deal T.E. (2008). Reframing Organizations: Artistry, Choice and Leadership. San Francisco, CA: Jossey-Bass.

Bond, S. (2004). Organisational culture and work-life conflict in the UK, International Journal of Sociology and Social Policy, 24(12), 1- 24. doi: https://doi.org/10.1108/01443330410790795 
Borenstein, M., Hedges, L.V., Higgins, J.P.T., \& Rothstein, H.R. (2009). Introduction to Meta-Analysis. West Sussex, UK: Wiley

Boroff, K.E., \& Lewin, D., (1997). Loyalty, voice, and intent to exit a union firm. A conceptual and empirical analysis. Industrial and Labor Relations Review 51(1), 50-63

Boshoff, C., Allen, J. (2000). The influence of selected antecedents on frontline staff's perceptions of service recovery performance. International Journal of Service Industry Management, 11(1), 63-90.

Breugh, J.A., (2003). Effect Size Estimation: Factors to Consider and Mistakes to Avoid, Journal of Management, 29(1), 79-97

Britt, T.W., Adler, A.B., \& Bartone, P.T. (2001). Deriving Benefits From Stressful Events: The Role of Engagement in Meaningful Work and Hardiness. Journal of Occupational Health Psychology, 6(1), 53-63. doi: 10.1037//1076-8998.6.J.53

Brashear, T., Manolis, C., \& Brooks, C. M. (2005). The effects of control, trust, and justice on salesperson turnover. Journal of Business Research, 58, 241-249.

Brown, S.P., \& Leigh, T.W. (1996). A New Look at Psychological Climate and Its Relationship to Job Involvement, Effort, and Performance. Journal of Applied Psychology, 81(4), 358-368

Brown, A.D., \& Starkey, K. (1994). The Effect Of Organizational Culture On Communication and Information, Journal of Management Studies, 31(6), 807-828

Bryson, B. (1990). The mother tongue: English and how it got that way. New York, New York: Harper Collins. 
Buckingham, M., \& Coffman, C. (1999). First, break all the rules: What the world's greatest managers do differently. New York: Simon \& Schuster.

Burke, Burgess, \&Oberrlaid, (2003). Do Male Psychologists Benefit from Organizational Values Supporting Work-Personal Life Balance, Equal Opportunities International, 23(1/2), 97-107

Byrne, Z.S. (2015). Understanding Employee Engagement: Theory, Research and Practice. New York, NY: Routledge.

Byron, K. (2005). A meta-analytic review of work-family conflict and its antecedents. Journal of Vocational Behavior, 67. 169-198. doi: 10.1016/j.jvb.2004.08.009

The Campbell Collaboration. Campbell systematic reviews: policies and guidelines Campbell Policies and Guidelines Series No. 1 DOI: 10.4073/cpg.2016.1

Cammann, C., Fichman, M., Jenkins, D., \& Klesh, J. (1979). The Michigan organizational assessment questionnaire. Unpublished manuscript, University of Michigan, Ann Arbor, MI.

Cammann, C., Fichman, M., Jenkins, G.D. Jr and Klesh, J.R. (1983), “Assessing the attitudes and perceptions of organizational members", in Seashore, S.F., Lawler, E.E., Mirvis, P.H. and Cammann, C. (Eds), Assessing Organizational Change: A Guide to Methods, Measures, and Practices, John Wiley \& Sons, New York, NY, pp. $71-138$.

Carasco-Saul, M., Kim, W. \& Kim, T., (2015). Leadership and Employee Engagement: Proposing Research Agendas Through a Review of Literature, Human Resource Development Review, 14(1), 38-63. doi: 10.1177/1534484314560406 
Carlson, D., Kaemar, K., Williams, J., (2000). Construction and Initial Validation of a Multidimensional Measure of Work-Family Conflict, Journal of Vocational Behavior 56, 249-276. doi:10.1006/jvbe.1999.1713,

Carmeli, A., \& Weisberg, J., (2006). Exploring Turnover Intentions among Three Professional Groups of Employees, Human Resource Development International, 9(2), 191-206. doi: 10.1080/13678860600616305

Chandler, G., Keller, C., \& Lyon, D., (2000). Unraveling the Determinants and Consequences of an Innovation-Supportive Organizational Culture. Entrepreneurship Theory and Practice, 3, 59-76

*Chen, I. H., Brown, R., Bowers, B. J., \& Chang, W.-Y. (2015). Work-to-family conflict as a mediator of the relationship between job satisfaction and turnover intention. Journal of Advanced Nursing, 71(10), 2350-2363. doi:10.1111/jan.12706

Chen Z., Powell, G.N., \& Cui, W., (2014). Dynamics of the relationships among work and family resource gain and loss, enrichment, and conflict over time, Journal of Vocational Behavior, 84. 293-302. doi: 10.1016/j.jvb.2014.02.006

Christian, M.S., Garza, A.S., \& Slaughter, J.E., (2011). Work Engagement: A Quantitative Review and Test Of Its Relations With Task and Contextual Performance, Personnel Psychology, 64, 89-136

Cohen, B.H. (2008). Explaining Psychological Statistics (3 ${ }^{\text {rd }}$ Ed.). Hoboken, NJ: John Wiley \& Sons.

Cohen, J., (1992). A Power Primer., Psychological Bulletin, 112(1), 155-159

Colarelli, S. M. (1984). Methods of communication and mediating processes in realistic job previews. Journal of Applied Psychology, 69, 633-642. 
Cole, M.S., Walter, F., Bedeian, A.G., \& O’Boyle, E.H. (2011). Job burnout and employee engagement: A meta-analytic examination of construct proliferation. Journal of Management, XX, 1-29. doi: 10.1177/0149206311415252

Cortina, J.M. (1993). What is Coefficient Alpha? An Examination of Theroy and Applications, Journal of Applied Psychology, 78(1), 98-104, doi:10.1037/00219010.78 .1 .98

Crawford, E.R., LePine, J.A., \& Rich, B.L., (2010). Linking Job Demands and Resources to Employee Engagement and Burnout: A Theoretical Extension and MetaAnalytic Test, Journal of Applied Psychology, 95(5), 834-848, doi: $10.1037 / \mathrm{a} 0019364$

Croker, K.J., Smith, F.L., \& Tabak, F., (2002). Creating Work-Life Balance: A Model of Pluralism across Life Domains, Human Resource Development Review, 1(4), 387419, doi: $10.1177 / 1534484302238434$

Cropanzano, R., Howes, J. C., Grandey, A. A., \& Toth, P. (1997). The relationship of organizational politics and support to work behaviors, attitudes, and stress. Journal of Organizational Behavior, 18, 159-180.

Cropanzano, R., James, K., \& Konovsky, M. A. (1983). Dispositional affectivity as a predictor of work attitudes and job performance. Journal of Organizational Behavior, 14, 595-600.

Czarnowsky, M. (2008). Learning's role in employee engagement: An ASTD research study. Alexandria, VA: American Society for Training \& Development. 
*Daderman, A. M., \& Basinska, B. A. (2016). Job Demands, Engagement, and Turnover Intentions in Polish Nurses: The Role of Work-Family Interface. Frontiers in Psychology, 7. doi:10.3389/fpsyg.2016.01621

Dalton, D. R., \& Todor, W. D., (1979). Turnover turned over: An expanded and positive perspective, Academy of Management Review, 4, 225-235

Dess, G.G., \& Shaw, J.D., (2001) Voluntary Turnover, Social Capital, and Organizational Performance, The Academy of Management Review, 26(3). 446-456

*de Villiers, J. R., \& Stander, M. W. (2011). Psychological Empowerment, Work Engagement and Turnover Intention: The Role of Leader Relations and Role Clarity in a Financial Institution. Journal of Psychology in Africa, 21(3), 405-412.

*Dion, M. J. (2006). The impact of workplace incivility and occupational stress on the job satisfaction and turnover intention of acute care nurses. (3221535 Ph.D.), University of Connecticut, Ann Arbor. Retrieved from https://search.proquest.com/docview/305323874?accountid=14665

Dollard, M.F., \& Bakker, A.B., (2010). Psychosocial safety climate as a precursor to conducive work environments, psychological health problems, and employee engagement, Journal of Occupational and Organizational Psychology, 83, 579599. doi: 10.1348/096317909X470690

Downey, S.N., VanDerWerff, L., Thomas, K.M., \& Plaut, V.C., (2014), The role of diversity practices and inclusion promoting trust and employee engagement. Journal of Applied Social Psychology. doi: 10.1111.jasp.12273 
Dupre, K. E., \& Day, A. L. (2007). The effects of supportive management and job quality on the turnover intentions and health of military personnel. Human Resource Management, 46(2), 185-201. doi:10.1002/hrm.20156

Eisenberger, R., Huntington, R., Hutchison, S., \& Sowa, D., (1986), Perceived Organizational Support, Journal of Applied Psychology, 71(3), 500-507.

Erkutlu, H., (2011). The moderating role of organizational culture in the relationship between organizational justice and organizational citizenship behaviors, Leadership \& Organization Development Journal, 32(6), 532-554. doi:

$10.1108 / 01437731111161058$

Ferguson, C.J., (2009). An Effect Size Primer: A Guide for Clinicians and Researchers Professional Psychology: Research and Practice, 40(5), 532-538. doi: $10.1037 / \mathrm{a} 0015808$

*Field, M. P. (2010). An investigation of the moderating effect of emotional intelligence on attitudes towards work and family. (71), ProQuest Information \& Learning, US. Retrieved from http://search.ebscohost.com/login.aspx?direct=true\&db=psyh\&AN=2010-99180397\&site=ehost-live

*Flaxman, G. I. (1999). Work-family conflict as a mediator between family responsive policies and job outcomes. (1397481 M.A.), California State University, Long Beach, Ann Arbor. Retrieved from https://search.proquest.com/docview/219931440?accountid=14665 
Fournier, C., Tanner, J.F., Chonko, L.B., \& Manolis, C. (2010). Themoderating role of ethical climate on salesperson propensity to leave. Journal of Personal Selling and Sales Management, 1(Winter), 7-22.

Foster, K. E. (2013). An investigation of the dimensionality of fit in the workplace. (3671091 Ph.D.), The University of Akron, Ann Arbor. Retrieved from https://search.proquest.com/docview/1645427570?accountid=14665

Frome, M.R., Russell, M., \& Cooper, M.L. (1992). Antecedents and outcomes of workfamily conflict: Testing a model of the work-family interface. Journal of Applied Psychology, 77, 65-78.

Geurts, S. A. E. (2000). SWING: Survey Work-Home Interaction-Nijmegen (Internal research report). Nijmegen, The Netherlands: University of Nijmegen.

Ghosh, P., Rai, A., \& Sinha, A., (2014), Organizational justice and employee engagement: Exploring the linkage in the public sector banks in India, Personnel Review, 43(4), 628-652. doi: 10.1108/PR-082013-0148

Godkin, L., (2015) Mid-Management, Employee Engagement, and the Generation of Reliable Sustainable Corporate Social Responsibility, Journal of Business Ethics, 130,15-28. doi:10.1007/s10551-014-2149-0

*Grandey, A. A., \& Cropanzano, R. (1999). The conservation of resources model applied to work-family conflict and strain. Journal of Vocational Behavior, 54(2), 350370. doi:10.1006/jvbe.1998.1666

Greenhaus, J.H. \& Beutell, N. J. (1985). Sources of conflict between work and family roles. Academy of Management Review, 10, 76-88 
*Grobelna, A., \& Tokarz-Kocik, A. (2016). "Work-Life Balance”: and its Importance for the work process in the hospitality industry: A persprective of Generation Y employees. In Z. Primorac, C Bussoli, \& N Recker (Eds.), 16th International Scientific Conference on Economic and Social Development - "The Legal Challenges of Modern World” (pp. 489-497). Varazdin, Croatia: Varazdin Development and Entrepreneurship Agency.

Gruman, J.A. \& Saks, A.M., (2011). Performance management and employee engagement. Human Resource Management Review, 21. 123-136. doi: 10.1016/j.hrmr.2010.09.004

Gubbins, C. \& Rousseau, D.M., (2015) Embracing Translational HRD Research for Evidence-Based Management: Let's Talk About How to Bridge the ResearchPractice Gap, Human Resource Development Review, 26(2), 109-125. doi: 10.1002/hrdq. 21214

Guglielmi, D., Paplomatas, A., Simbula, S., Depolo, M. (2011). Prevenzione dello stress lavoro correlato: validazione di uno strumento per la valutazione dei rischi psicosociali nella scuola. Psicologia della Salute, 3, 53-74. doi:10.3280/PDS2011-003003

Guilding, C., Lamminmaki, D., \& McManus, L., (2014). Staff turnover costs: In search of accountability, International Journal of Hospitality Management, 36, 231-243. doi: 10.1016/j.ijhm.2013.10.001

Gutek, B. A., Searle, S., \& Klepa, L. (1991). Rational versus gender role explanations for work-family conflict. Journal of Applied Psychology, 76(4), 560-568. doi: http://dx.doi.org/10.1037/0021-9010.76.4.560 
*Gyensare, M. A., Kumedzro, L. E., Sanda, A., \& Boso, N. (2017). Linking transformational leadership to turnover intention in the public sector. African Journal of Economic and Management Studies, 8(3), 314-337.

Fairlie, P. (2011). Meaningful Work, Employee Engagement, and Other Key Employee Outcomes: Implications for Human Resource Development. Advances in Developing Human Resources, (13)4, 508-525. doi: 10.1177/1523422311431679

Farh, J.L, Tsui, A.S., Xin, K.R., \& Cheng, B.S. (1998).The influence of relationaldemography and guanxi: The Chinese case. Organisational Sciences, 9(2), 1-18.

Fearon, C., McLaughlin, H., \& Morris, L., (2013). Conceptualising work engagement: An individual, collective and organisational efficacy perspective, European Journal of Training and Development, 37(3), 244-256, doi: $10.1108 / 03090591311312723$

Field, A., Miles, J., \& Field, Z. (2012). Discovering Statistics Using R. London, Great Britain: Sage

Ferguson, C.J., \& Brannick, M.T., (2012). Publication Bias in Psychological Science: Prevalence, Methods for Identifying and Controlling, and Implications for the Use of Meta-Analyses, Psychological Methods, 17(1), 120-128. doi: $10.1037 / \mathrm{a} 0024445$

Frome, M.R., Russell, M., \& Cooper, M.L. (1992a). Antecedents and Outcomes of WorkFamily Conflict: Testing a Model of the Work-Family Interface. Journal of Applied Psychology, 77(1). 65-78. 
Frome, M.R., Russell, M., \& Cooper, M.L. (1992b). Prevalence of Work-Family Conflict: Are Work and Family Boundaries Asymmetrically Permeable?, Journal of Organizational Behavior, 13(7), 723-729

Gallup (2006): From First, Break All the Rules, What the World's Greatest Managers Do Differently by Marcus Buckingham \& Curt Coffman, Simon \& Schuster, 1999.

Greenfield, M.L.V.H., Kuhn, J.E., \& Wojtys, E.M. (1998). A Statistics Primer: Validity and Reliability. The American Journal of Sports Medicine, 26(3), 483-485.

Greenhaus, J.H., Callanan, G.A., \& Godshalk, V.M. (2000). Career Management, (3 ${ }^{\text {rd }}$ ed.), Orlando, FL: The Dryden Press.

Grover, S.L., \& Crooker, K.J. (1995). Who appreciates family-responsive human resource policies: The relationship of work-family policies on the organisational attachment of parents and non-parents, Personnel Psychology, 48, 271-288.

Grzywacz, J. \& Marks, N. (2000). Family, work, work-family spillover, and problem drinking during midlife. Journal of Marriage and Family, 62(1), 336-348

*Haar, J. M. (2004). Work-family conflict and turnover intention: Exploring the moderation effects of perceived work-family support. New Zealand Journal of Psychology, 33(1), 35-39.

*Haar, J. M., Roche, M., \& Taylor, D. (2012). Work-family conflict and turnover intentions of indigenous employees: the importance of the whanau /family for Maori. International Journal of Human Resource Management, 23(12), 25462560. doi:10.1080/09585192.2011.610344 
Halbesleben, J.R.B., (2006). Sources of Social Support and Burnout: A Meta-Analytic Test of the Conservation of Resources Model, Journal of Applied Psychology, 91(5), 1134-1145, doi: 10.1037/0021-9010.91.5.1134

Halbesleben, J. R. B. (2010). A meta-analysis of work engagement: Relationships with burnout, demands, resources, and consequences. In A. B. Bakker \& A. B. Bakker (Eds.), Work engagement: A handbook of essential theory and research. (pp. 102117). New York, NY, US: Psychology Press.

Halbesleben, J.R.B., \& Wheeler, A.R., (2008). The relative roles of engagement and embeddedness in predicting job performance and intention to leave, Work \& Stress, 22(3), 242-256. doi: 10.1080/02678370802383962

Halbesleben, J.R.B., (2011). The consequences of engagement: the good, the bad, the ugly, European Journal of Work and Organizational Psychology, 20(1), 68-73. doi: 10.1080/1359432X.2010.514327

Halbesleben, J.R.B., Harvey, J., \& Bolino, M.C., (2009). Too Engaged? A Conservation of Resources View of the Relationship Between Work Engagement and Work Interference With Family, Journal of Applied Psychology, 94(6), 1452-1465. doi: $10.1037 / \mathrm{a} 0017595$

*Halliday, C. S., Paustian-Underdahl, S. C., Ordóñez, Z., Rogelberg, S. G., \& Zhang, H. (2018). Autonomy as a key resource for women in low gender egalitarian countries: A cross-cultural examination. Human Resource Management, 57(2). doi:10.1002/hrm.21874

*Hammer, L. B., Kossek, E. E., Anger, W. K., Bodner, T., \& Zimmerman, K. L. (2011). Clarifying Work-Family Intervention Processes: The Roles of Work-Family 
Conflict and Family-Supportive Supervisor Behaviors. Journal of Applied Psychology, 96(1), 134-150. doi:10.1037/a0020927

Hammerstrøm K, Wade A, Jørgensen AMK. Searching for studies: A guide to information retrieval for Campbell Systematic Reviews Campbell Systematic Reviews 2010: Supplement 1 DOI: 10.4073/csrs.2010.1

Harter J., Agrawal, S., Plowman, S. \& Asplund, J., (2010). Employee Engagement and Earnings per Share: A Longitudinal Study of Organizational Performance During the Recession. Washington D.C.: Gallup.

Harter, J.K., Schmidt, F.L, Agrawal, S., Plowman, S.K., (2012). The Relationship Between Engagement At Work and Organizational Outcomes. Washington D.C.: Gallup

Harter, J.K., Schmidt, F.L. \& Hayes, T.L. (2002). Business-Unit-Level Relationship Between Employee Satisfaction, Employee Engagement, and Business Outcomes: A Meta-Analysis, Journal of Applied Psychology, 87(2), 268-279. doi: $10.1037 / / 0021-9010.87 .2 .268$

Han, H., 2012. The Relationship among Corporate Culture, Strategic Orientation, and Financial Performance, Cornell Hospitality Quarterly, 53(3), 207-219, doi: $10.1177 / 1938965512443505$

Hancock, J.I., Allen, D.G., Bosco, F.A., McDaniel, K.R., \& Pierce, C.A., (2011). MetaAnalytic Review of Employee Turnover as a Predictor of Firm Performance, Journal of Management, 39(3), doi: 10.1177/0149206311424943

Hedges, L.V., \& Vevea, J.L., (1998). Fixed- and Random-effects models in metaanalysis, Psychological Methods, 3(4), 486-504. doi: 10.1037/1082-989X.3.4.486 
*Hee, K. K. (2017). The relationship of Gender Discrimination Consciousness, WorkFamily Conflict and Facilitation and Turnover Intention of Married Female Hospital Nurses. Journal of Digital Convergence, 15(7), 425-434. doi:10.14400/JDC.2017.15.7.425

Higgins, J., Thompson, S., Deeks, J, Altman, D., (2003). Measuring inconsistency in meta-analyses BMJ, 327(7414), 557-560. doi: https://doi.org/10.1136/bmj.327.7414.557

Hobfoll, S. E. (1989). Conservation of resources: A new attempt at conceptualizing stress. American Psychologist, 44(3), 513-524.

Holston-Okae, B. (2017). Employee Turnover Intentions in the Hospitality Industry. (10287336 D.B.A.), Walden University, Ann Arbor. Retrieved from http://echo.louisville.edu/login?url=https://search.proquest.com/docview/1914314 482? accountid $=14665$

Hom, P.W., Mitchell, T.R., Lee, T.W., \& Griffeth, R.W., (2012). Reviewing Employee Turnover: Focusing on Proximal Withdrawal States and an Expanded Criterion. Psychological Bulletin, 138(5), 831-858, doi: 10.1037/a0027983

*Huang, M.-H., \& Cheng, Z.-H. (2012). The effects of inter-role conflicts on turnover intention among frontline service providers: does gender matter? Service Industries Journal, 32(3), 367-381. doi:10.1080/02642069.2010.545391

*Huh, Y. (2017). Examining Influence of Domain Transition and Spouse Reaction on Relationship between Employee's Job Demands and Turnover Intention. (10617382 M.A.), State University of New York at Albany, Ann Arbor. Retrieved from 
http://echo.louisville.edu/login?url=https://search.proquest.com/docview/1949665

161 ?accountid=14665

Huedo-Medina, T. B., Sánchez-Meca, J., Marín-Martínez, F., \& Botella, J. (2006).

Assessing heterogeneity in meta-analysis: Q statistic or $\mathrm{I}^{2}$ index? Psychological

Methods, 11(2), 193-206. http://dx.doi.org/10.1037/1082-989X.11.2.193

*Jungman, H. \& Dous, K. (2015). The Effects of Pilot Support Policies, Psychological Well-being, and Work-Family Conflict of Air Force Pilots on Their Turnover Intention. The Quarterly Journal of Defense Policy Studies, 31(2), 159-194.

Kahn, W. (1990). Psychological conditions of personal engagement and disengagement at work. Academy of Management Journal, 33, 692-724.

Kahn, W. A. (1992). To be fully there: Psychological presence at work. Human Relations, 45, 321-349.

*Kao, J.-T., \& Chang, W.-J. A. (2016). A role perspective on turnover intentions: Examining behavioral predictors. In G. Saridakis, C. L. Cooper, G. Saridakis, \& C. L. Cooper (Eds.), Research handbook on employee turnover. (pp. 201-212). Northampton, MA, US: Edward Elgar Publishing.

*Karatepe, O. M. (2009). An Investigation of the joint effects of organisational tenure and supervisor support on work-family conflict and turnover intentions. Journal of Hospitality and Tourism Management, 16(1). doi:10.1375/jhtm.16.1.73

*Karatepe, O. M., \& Azar, A. K. (2013). The Effects of Work-Family Conflict and Facilitation on Turnover Intentions: The Moderating Role of Core SelfEvaluations. International Journal of Hospitality \& Tourism Administration, 14(3), 255-281. doi:10.1080/15256480.2013.809987 
*Karatepe, O. M., \& Kilic, H. (2015). Does Manager Support Reduce the Effect of Work-Family Conflict on Emotional Exhaustion and Turnover Intentions? Journal of Human Resources in Hospitality \& Tourism, 14(3), 267-289. doi:10.1080/15332845.2015.1002069

Karatepe, O., \& Uludağ, O. (2008). Affectivity, conflicts in the work-family interface, and hotel employee outcomes. International Journal of Hospitality Management, $27,30-41$.

Karras, D.J. (1997a). Statistical Methodology: II. Reliability and Validity Assessment in Study Design, Part A, Academic Emergency Medicine, 4(1). 64-71

Karras, D.J. (1997b). Statistical Methodology: II. Reliability and Validity Assessment in Study Design, Part B, Academic Emergency Medicine, 4(2). 144-149

Kelloway, E. K., Gottlieb, B. H., \& Barham, L. (1999). The source, nature, and direction of work and family conflict: A longitudinal investigation. Journal of Occupational Health Psychology, 4(4), 337-346.

Ketter, P. (2008). What's the big deal about employee engagement? Training \& Development, 62, 44-49.

Kim, W., Kolb, J.A., \& Kim, T., (2013). The Relationship Between Work Engagement and Performance: A Review of Empirical Literature and a Proposed Research Agenda, Human Resource Development Review, 1-29. doi: $10.1177 / 153448312461635$

*Kim, Y., \& Jang, I. (2014). Moderating and Mediating Effects of Social Support in the Relationship between Work-family Conflict, Job Satisfaction and Turnover 
Intention among Married Women Nurses. Journal of Korean Academy of Nursing Administration, 20(5), 525-534. doi:10.11111/jkana.2014.20.5.525

Kopelman, R. E., Greenhaus, J. H., \& Connolly, T. F. (1983). A model of work, family and interrole conflict: A construct validation study. Organizational Behavior and Human Performance, 32, 198-215

*Kossek, E. E., Lautsch, B. A., \& Eaton, S. C. (2006). Telecommuting, Control, and Boundary Management: Correlates of Policy Use and Practice, Job Control, and Work-Family Effectiveness. Journal of Vocational Behavior, 68(2), 347-367.

Kossek, E.E., \& Ozeki, C. (1999). Bridging the work-family policy and productivity group: A literature review, Community, Work \& Family, 2(1), 7-32

Kumar, V. \& Pansari, A. (2014). The Construct, Measurement, and Impact of Employee Engagement: A Marketing Perspective, Customer Needs and Solutions, 1, 52-67. doi: 10.1007/s40547-013-0006-4

Kuvaas, B. (2008). An exploration of how the employee-organization relationship affects the linkage between perception of developmental human resource practices and employee outcomes. Journal of Management Studies, 45(1), 1-25.

*Kuvaas, B., Buch, R., Weibel, A., Dysvik, A., \& Nerstad, C. G. L. (2017). Do intrinsic and extrinsic motivation relate differently to employee outcomes? Journal of Economic Psychology, 61, 244-258. doi:10.1016/j.joep.2017.05.004

Leana, C.R., \& Van Buren, H.J., (1999). Organizational Social Capital and Employment Practices. The Academy of Management Review, 24(3), 538-555 
*Lee, S., Lee, C., \& Kim, S. (2014). Working Family Conflict and Turnover Intention Moderating Effects of Flexible Working. Journal of Human Resource Management Research, 21(5), 245-262. doi:10.14396/jhrmr.2014.21.5.245

Lemons, L. (2013). Do I stay or do I go? A mixed-methods study of factors of attrition as reported by leavers of secondary agriculture programs. (Doctoral dissertation). Retrieved from https://repositories.tdl.org/ttu-ir/handle/2346/50626

Li, A. N., \& Liao, H. (2014). How Do Leader-Member Exchange Quality and Differentiation Affect Performance in Teams? An Integrated Multilevel Dual Process Model. Journal of Applied Psychology. Advance online publication, 120. doi:10.1037/a0037233

*Liao, P. Y. (2011). Linking work-family conflict to job attitudes: the mediating role of social exchange relationships. International Journal of Human Resource Management, 22(14), 2965-2980. doi:10.1080/09585192.2011.606117

*Liss-Levinson, R., Bharthapudi, K., Leider, J. P., \& Sellers, K. (2015). Loving and Leaving Public Health: Predictors of Intentions to Quit Among State Health Agency Workers. Journal of Public Health Management and Practice, 21, S91S101. doi:10.1097/PHH.0000000000000317

Lockwood, N.R., (2007). Leveraging Employee Engagement for Competitive Advantage: HR's Strategic Role, 2007 SHRM® Research Quarterly, 1-12

Lo, C. H., \& Nieh, F. P. (2015). A Study on the Correlations among Organizational Support, Professional Commitment, and Employee Engagement in Catering Industry. Acta Oeconomica, 65, 339-350. doi:10.1556/032.65.2015.S2.25 
Lok, P., \& Crawford, J., (2004). The effect of organisational culture and leadership style on job satisfaction and organisational commitment: A cross-national comparison, Journal of Management Development, 23(4), 321-328. doi:

$10.1108 / 02621710410529785$

Louison, C. P. (2007). Convergent and discriminant validity of employee engagement. (3298898 Ph.D.), Alliant International University, San Diego, Ann Arbor. Retrieved from http://echo.louisville.edu/login?url=https://search.proquest.com/docview/3047015 00 ?accountid $=14665$

Lourel, M., Gana, K., \& Wawrzyniak, S. (2005). Home-work interaction: A French adaptation and validation of "Survey Work-Home Interaction-Nijmegen" (SWING). Psychologie du Travail et des Organizations, 11, 227-239. doi 10.1016/ j.pto.2005.10.003

Ludwig, T.D., \& Frazier, C.B., (2012). Employee Engagement and Organizational Behavior, Journal of Organizational Behavior Management, 31(1), 75-82. doi: $10.1080 / 01608061.2011 .619439$

Lum, L.J., Clark, K.K., Reid, F., Sirola, W. (1998). Explaining nursing turnover intent: job satisfaction, pay satisfaction, or organizational commitment, Journal of Organizational Behavior, 19, 305-320.

Luthans, F., and Peterson, S.J., (2002). Employee engagement and manager self-efficacy: Implications for managerial effectiveness and development, Journal of Management Development, 21(5), 376-387. doi: 10.1108/02621710210426862 
*Ma. Regina, M. H. (2013). The call center as a revolving door: a Philippine perspective. Personnel Review, 42(3), 349-365. doi:http://dx.doi.org/10.1108/00483481311320444

Macey, W.H., \& Schneider, B. (2008). The meaning of employee engagement. Industrial and Organizational Psychology, 1, 3-30. doi: 10.1111/j.1754-9434.2007.0002x

Macey, W. H., Schneider, B., Barbera, K. M., \& Young, S. A. (2009). Employee engagement: Tools for analysis, practice, and competitive advantage. Malden, WA: Wiley- Blackwell.

MacDermid, S.M., Hertzog, J.L., Kensinger, K.B., \& Zipp, J.F., (2001). The Role of Organizational Size and Industry I Job Quality and Work-Family Relationships, Journal of Family and Economic Issues, 22(2), 191-216

*Mack, J. K. (2015). Faculty work-family conflict and faculty intention to resign. (3700798 Psy.D.), The University of the Rockies, Ann Arbor. Retrieved from http://echo.louisville.edu/login?url=https://search.proquest.com/docview/1680592 579? accountid $=14665$

MacLeod, D. \& Clarke N. (2009) Engaging for Success: Enhancing performance through employee engagement. London: BIS

Madden, L., Mathais, B.D., \& Madden, T.M., (2015). In Good Company: The impact of perceived organizational support and positive relationships at work on turnover intentions, Management Research Review, 38(3), 242-263. doi: 10.1108/MRR-092013-0228

Maeda, Y., \& Harwell, M.R., (2016). Guidelines for Using $Q$ Test in Meta-Analysis, Mid-Western Educational Researcher, 28(1), 55-72 
*Malinen, S., \& Harju, L. (2017). Volunteer Engagement: Exploring the Distinction Between Job and Organizational Engagement. Voluntas, 28(1), 69-89. doi:10.1007/s11266-016-9823-z

Maslach C. \& Leiter M.P. 1997. The Truth About Burnout. San Francisco: Jossey-Bass Maslach, C., Schaufeli, W.B., \& Leiter, M.P., (2001). Job Burnout, Annual Review of Psychology, 52, 397-422

*Masuda, A. D., Poelmans, S. A. Y., Allen, T. D., Spector, P. E., Lapierre, L. M., Cooper, C. L., . . Moreno-Velazquez, I. (2012). Flexible Work Arrangements Availability and their Relationship with Work-to-Family Conflict, Job Satisfaction, and Turnover Intentions: A Comparison of Three Country Clusters. Applied Psychology: An International Review, 61(1), 1-29. doi:10.1111/j.14640597.2011.00453.x

*Masuda, A. D., Poelmans, S. A. Y., Allen, T. D., Spector, P. E., Lapierre, L. M., Cooper, C. L., . . Woo, J. M. (2012b). 'Flexible work arrangements availability and their relationship with work-to-family conflict, job satisfaction, and turnover intentions: A comparison of three country clusters': Corrigendum. Applied Psychology: An International Review, 61(2), 347-347.

Matthews, R.A., Mills, M.J., Trout, R.C., \& English, L., (2014). Family-Supportive Supervisor Behaviors, Work Engagement, and Subjective Well-Being: A Contextually Dependent Mediated Process, Journal of Occupational Health Psychology, 19z92) 168-181. doi: 10.1037/a0036012

*Mauno, S., De Cuyper, N., Kinnunen, U., Ruokolainen, M., Rantanen, J., \& Makikangas, A. (2015). The prospective effects of work-family conflict and 
enrichment on job exhaustion and turnover intentions: comparing long-term temporary vs. permanent workers across three waves. Work and Stress, 29(1), 7594. doi:10.1080/02678373.2014.1003997

Mauno, S., Kinnunen, U., \& Ruokolainen, M., (2007). Job demands and resources as antecedents of work engagement: A longitudinal study, Journal of Vocational Behavior, 70, 149-171. doi: 10.1016/j.jvb.2006.09.006

May, D.R., Gilson, R. L., \& Harter, L.M., (2004), The psychological conditions of meaningfulness, safety and availability and the engagement of the human spirit at work, Journal of Occupational and Organizational Psychology, 77, 11-37

Mesmer-Magnus, J.R., \& Viswesvaren, C., (2006). How Family-Friendly Work Environments Affect Work/Family Conflict: A Meta-Analytic Examination, Journal of Labor Research, 27(4), 555-574

The metafor Package: A Meta-Analysis Package for R. (n.d.) Retrieved from http://www.metafor-project.org/doku.php/metafor

Meyer, J.P., Allen, N.J., Smith, C.A. (1993). Commitment to organizations and occupations: extension and test of a three-component conceptualization. Journal of Applied Psychology, 78(4), 538-551. doi:10.1037/0021-9010.78.4.538

Meyer, J.P., Gagne, M., and Parfyonova, N.M. (2010). Toward an evidence-based model of engagement: what can we learn from motivation and commitment research. In S. Albrecht (Ed.), Handbook of Employee Engagement: Perspectives, Issues, Research and Practice (pp. 3-19). Northampton, MA: Edward Elgar Publishing Limited.

Michel, J.S., Mitchelson, J.K., Kotrbra, L.M., LeBreton, J.M. and Baltes, B.B. (2009). A 
comparative test of work-family conflict models and critical examination of workfamily linkages, Journal of Vocational Behavior, 74, 199-218, doi:

10.1016/j.jvb.2008.12.005

Mobley, W.H. (1977). Intermediate linkages in the relationship between job satisfaction and employee turnover. Journal of Applied Psychology, 62(2), 237-240.

Moja, L., Moschetti, I., Liberati, A., Gensini, G.F., \& Gusinu, R. (2007). Understanding systematic reviews: the meta-analysis graph (also called 'forest plot'). Intern Emerg Med, 2, 140-142. doi: 10.1007/s11739-007-0036-8

*Molino, M., Bakker, A. B., \& Ghislieri, C. (2016). The role of workaholism in the job demands-resources model. Anxiety, Stress \& Coping, 29(4), 400-414. doi:10.1080/10615806.2015.1070833

Moore, J.E. (2000). One Road to Turnover: An Examination of Work Exhaustion in Technology Professionals. MIS Quarterly, 24(1), 141-168.

National Center for Educational Statistics [NCES]. (2014). Schools and Staffing Survey (SASS). Retrieved from: https://nces.ed.gov/surveys/sass/

*Nei, D., Snyder, L. A., \& Litwiller, B. J. (2015). Promoting retention of nurses: A metaanalytic examination of causes of nurse turnover. Health Care Management Review, 40(3), 237-253. DOI: 10.1097/HMR.0000000000000025

Netemeyer, R., Boles, J. \& McMurrian, R., (1996). Development and Validation of Work-Family Conflict and Family-Work Conflict Scales, Journal of Applied Psychology, 8(4), 400-410 
Newman, Hitchcock, \& Newman, (2015). The Use of Research Syntheses and Nomological Networks to Develop HRD Theory, Advances in Developing Human Resources, 17(1), 117-134. DOI: 10.1177/1523422314559810

Nienbar, H., \& Martins, N. (2014), An Employee Engagement Instrument and Framework Building on Existing Research, Mediterranean Journal of Social Sciences, 5(20), 485-496. doi 10.5901/mjss.2014.v5n20p485

Nohe, C., \& Sonntag, K., (2014). Work-family conflict, social support, and turnover intentions: A longitudinal study, Journal of Vocational Behavior, 1 -12, doi: 10.1016/j.jvb.2014.03.007

Oswick, C., (2015). Guest Editorial: Engaging With Employee Engagement in HRD Theory and Practice, Human Resource Development Review, 14(1), 8-16. doi: $10.1177 / 1534484314558743$

*Park, H-M. (2013). Analysis of the Job Satisfaction, Work-Family Conflict and Turnover Intention of Dental Health Care Worker. The Korean Journal of Health Service Management, 7(2), 191-203.

Park H.S. (2002). Relationship between perceived nursing care role orientation, job characteristics, and turnover among nurses [master's thesis]. Seoul: Yonsei University;

Park, T.Y. and Shaw, J.D., (2013). Turnover Rates and Organizational Performance: A Meta-Analysis, Journal of Applied Psychology, 98(2), 268-309. doi: $10.1037 / \mathrm{a} 0030723$

*Payne, S. C., Cook, A. L., \& Diaz, I. (2012). Understanding childcare satisfaction and its effect on workplace outcomes: The convenience factor and the mediating role 
of work-family conflict. Journal of Occupational \& Organizational Psychology, 85(2), 225-244. doi:10.1111/j.2044-8325.2011.02026.x

Pearce, J. L. (1983). Job attitudes and motivation differences between volunteers and employees from comparable organizations. Journal of Applied Psychology, 68(4), $646-652$.

Pool, S. (2000). The learning organization: motivating employees by integrating TQM philosophy in a supportive organizational culture, Leadership \& Organization Development Journal, 21(8), 373-378. doi: 10.1108/01437770010379276

*Prati, G., \& Zani, B. (2016). A moderated multilevel study of work-to-family conflict, empowerment, and turnover intentions. Quality \& Quantity: International Journal of Methodology, 50(5), 2279-2292. doi:10.1007/s11135-015-0262-5

Preston, C., Ashby, B., Smyth, R., (2004). Adjusting for publication bias: modeling the selection process, Journal of Evaluation in Clinical Practice, 10(2), 313-322

Protas, D.J. (2013). Relationships among employee perception of their manager's behavioral integrity, moral distress, and employee attitudes and well-being. Journal of Business Ethics, 113. 51-60. doi: 10.1007/s10551-012-1280-z

Pryczak, F., \& Bruce, R.R. (2011). Writing Empirical Research Reports (7 $7^{\text {th }}$ Ed.). Glendale, CA: Pryczak Publishing.

Purcell, J., (2014). Disengaging from engagement, Human Resource Management Journal, 24(3), 241-254. doi: 10.1111.1748-8583.12046

Quinn, R. and Rohrbaugh, J. (1983) A Spatial Model of Effectiveness Criteria: Toward a Competing Values Approach to Organizational Analysis. Management Science, 29, 363-377. doi: http://dx.doi.org/10.1287/mnsc.29.3.363 
Rana, S., Ardichvili, A., \& Tkachenko, O. (2014). A theoretical model of the antecedents and outcomes of employee engagement. Journal of Workplace Learning, 26(3/4), 249-266. doi:http://dx.doi.org/10.1108/JWL-09-2013-0063

Reio, Jr., T.G., Nimon, K., \& Shuck, B., (2015). Preface: Quantitative Data- Analytic Techniques to Advance HRD Theory and Practice. Advances in Developing Human Resources, 17(1), 3-11. doi: 10.1177/1523422314559653

Reio, Jr., T.G., \& Sanders-Reio, J. (2011). Thinking About Workplace Engagement: Does Supervisor and Coworker Incivility Really Matter? Advances in Developing Human Resources 13(4), 462-478. doi: 10.1177/1523422311430784

Reychav, I. and Sharkie, R. (2010). Trust: an antecedent to employee extra-role behavior, Journal of Intellectual Capital, 11(2), 227-247.

*Ribeiro, S., Bosch, A., \& Becker, J. (2016). Retention of women accountants: The interaction of job demands and job resources. SA Journal of Human Resource Management, 14(1), 1-11. doi:http://dx.doi.org/10.4102/sajhrm.v14i1.759

Rich, B.L, Lepine, J.A., \& Crawford, E.R. (2010). Job Engagement: Antecedents and Effects on Job Performance. Academy of Management Journal, 53(3). 617-635

Rivera, A. \& Flinck, J., (2011). Employee-Led, Employee Engagement in the Federal Government: SAMHSA PeopleFirst, Academy in Developing Human Resources, 13(4) 479-493. doi: 10.1177/1523422311431680

Roodt, G. (2004). Concept redundancy and contamination in employee commitment research: Current problems and future directions. SA Journal of Industrial Psychology, 30(1), 82-90 
Rose, K., Shuck, B., Twyford, D., \& Bergman, M., (2015). Skunked: An Integrative Review Exploring the Consequences of the Dysfunctional Leader and Implications for Those Employees Who Work for Them, Human Resource Development Review, 14(1), 64-90. doi: 10.1177/1534484314552437

*Roulin, N., Mayor, E., \& Bangerter, A. (2014). How to Satisfy and Retain Personnel Despite Job-Market Shortage Multilevel Predictors of Nurses' Job Satisfaction and Intent to Leave. Swiss Journal of Psychology, 73(1), 13-24. doi: $10.1024 / 1421-0185 / \mathrm{a} 000123$

Rurkkhum, S., \& Bartlett, K.R., (2012). The relationship between employee engagement and organizational citizenship behavior in Thailand, Human Resource Development International, 15(2), 157-174. doi: 10.1080.13678868.2012.664693

Saks, A.M., (2006). Antecedents and consequences of employee engagement, Journal of Managerial Psychology, 21(7), 600-619. doi: 10.1108/02683940610690169

Saks, A.M., \& Gruman, J.A., (2014). What Do We Really Know About Employee Engagement?, Human Resource Development Quarterly, 25(2), 155-183. doi: 10.1002/hrdq. 21187

Sambasivan, M. \& Yen, C.N., (2010). Strategic alliances in a manufacturing supply chain, International Journal of Physical Distribution \& Logistics Management, 40(6), 456-474. doi: 10.1108/09600031011062191

Schaufeli, W.B., (2014). What is Engagement?. In C.Truss, R Delbridge, K. Alfes, A. Shantz \& E. Soane. (Eds.). Employee engagement in theory and practice (pp.1535). London: Routledge. 
Schaufeli, W.B. \& Bakker, A.B. (2004). Job demands, job resources, and their relationship with burnout and engagement: A multi-sample study. Journal of Organizational Behavior, 25, 293-315.

Schaufeli, W. B., Bakker, A. B., \& Salanova, M., (2006). The measurement of work engagement with a short questionnaire: A cross-national study, Educational and Psychological Measurement, 66, 701-716.

Schaufeli, W. B., Salanova, M., González-Roma, V., \& Bakker, A. B. (2002). The measurement of engagement and burnout: A two sample confirmatory factor analytic approach. Journal of Happiness Studies, 3, 71-92.

Schein, E.H. (2010). Organizational Culture and Leadership $\left(4^{\text {th }}\right.$ Ed.). San Francisco, CA: Jossey-Bass

Shadish, W.R., Cook, T.D., \& Campbell, D.T. (2002). Experimental and QuasiExperimental Designs for Generalized Causal Inference. Belmont, CA: Wadsworth

Shafer, M.A., Harrison, D.A., Gilley, K.M., and Luk, D.M., (2002). Struggling for balance amid turbulence on international assignments: work-family conflict, support and commitment, Journal of Management, 27, 99-121

Shankar, T. \& Bhatnagar, J., (2010). Work Life Balance, Employee Engagement, Emotional Consonance/Dissonance \& Turnover Intention The Indian Journal of Industrial Relations, 46(1), 74-87

Shavelson, R.J. (1996). Statistical Reasoning for the Behavioral Sciences $\left(3^{\text {rd }}\right.$ Ed.). Boston, MA: Allyn and Bacon. 
Shaw, J.D., Gupta, N., Delery, J.E., (2005). Alternative Conceptualizations of the Relationship Between Voluntary Turnover and Organizational Performance, Academy of Management Journal, 48(1), 50-68

Shuck, B. (2011). Integrative Literature Review: Four Emerging Perspectives of Employee Engagement: An Integrative Literature Review, Human Resource Development Review, 10(3). 304-328. doi: 10.1177/1534484311410840

*Shuck, A. L., Shuck, B., \& Reio, T. G. (2013). Emotional Labor and Performance in the Field of Child Life: Initial Model Exploration and Implications for Practice. Childrens Health Care, 42(2), 168-190. doi:10.1080/02739615.2013.766116

Shuck, B., Adelson, J., \& Reio, T., (2017). The Employee Engagement Scale: Initial Evidence for Construct Validity and Implications for Theory and Practice, Human Resource Management, 56(6), 953-977. doi: https://doi.org/10.1002/hrm.21811

Shuck B., Ghosh, R., Zigarmi, D., and Nimon, K., (2013). The Jingle Jangle of Employee Engagement: Further Exploration of the Emerging Construct and Implications for Workplace Learning and Performance, Human Resource Development Review, 12(11), 11-35. doi: 10.1177/1534484312463921

Shuck, B., Kobena, O., Zigarmi, D., \& Nimon, K., (2017). Definitional and Conceptual Muddling: Identifying the Positionality of Employee Engagement and Defining the Construct, Human Resource Development Review, 16(3), 263-293. doi: https://doi.org/10.1177/1534484317720622

*Shuck, B, Reio Jr., T.G., \& Rocco, T.S., (2011). Employee engagement: an examination of antecedent and outcome variables, Human Resource Development International, 14(4), 427-445. doi: 10.1080/136788868.2011.601587 
Shuck, B., \& Rose, K., (2013). Reframing Employee Engagement Within the Context of Meaning and Purpose: Implications for HRD, Advances in Developing Human Resources, 15(4), 341-355. doi: https://doi.org/10.1177/1523422313503235

Shuck, B,. Twyford, D., Reio, Jr., T.G., \& Shuck, A., (2014). Human Resource Development Practices and Employee Engagement: Examining the Connection With Employee Turnover Intentions, Human Resource Development Quarterly, 25(2), 239-270. doi: 10.1002/hrdq.21190

Shuck, B. \& Wollard, K. (2010). Employee Engagement and HRD: A seminal Review of the Foundations. Human Resource Development Review, 9(1). 89-110. doi: $10.1177 / 1534484309353560$

*Shuck, M. B. (2010). Employee engagement: An examination of antecedent and outcome variables. (3431310 Ed.D.), Florida International University, Ann Arbor. Retrieved from http://echo.louisville.edu/login?url=https://search.proquest.com/docview/7929596 78? accountid $=14665$

Silverthorne, C., (2004). The impact of organizational culture and person-organization commitment and job satisfaction in Taiwan, Leadership \& Organizational Development Journal, 25(7/8), 592-599. doi: 10.1108/01437730410561477

Singh, J., Verbeke, W., \& Rhoads, G.K. (1996). Do organizational practices matter in role stress processes? A study of direct and moderating effects for marketingoriented boundary spanners. Journal of Marketing, 60, 69-86. 
Sjöberg, A., \& Sverke, M. (2000). The interactive effect of job involvement and organizational commitment on job turnover revisited: A note on the mediating role of turnover intention. Scandinavian Journal of Psychology, 3, 247-252.

Sok, J., Bloome, R., \& Tromp, D. (2014). Positive and Negative Spillover from Work to Home: The Role of Organizational Culture and Supportive Arrangements, British Journal of Management, 25, 456-472. doi: 10.1111/1467-8551.12058

Soane, E., Truss, C., Alfes, K., Shantz, A., Rees, C., \& Gatenby, M. (2012): Development and application of a new measure of employee engagement: the ISA Engagement Scale, Human Resource Development International, 15:5, 529-547 http://dx.doi.org/10.1080/13678868.2012.726542

*Sorensen, T. J., McKim, A. J., \& Velez, J. J. (2016). Why Agriculture Teachers Leave: A National Examination of Turnover Intentions and Work-Family Conflict. Journal of Agricultural Education, 57(4), 186-201.

Spector, P.E., Dwyer, D.J., \& Jex, S.M. (1988). The relationship of job stressors to affective, health, and performance outcomes: A comparison of multiple data sources. Journal of Applied Psychology, 73, 11-19.

*Spector, P. E., Allen, T. D., Poelmans, S. A. Y., Lapierre, L. M., Cooper, C. L., O'Driscoll, M., \& Widerszal-Bazyl, M. (2007). Cross-national differences in relationships of work demands, job satisfaction, and turnover intentions with work-family conflict. Personnel Psychology, 60(4), 805-835. doi:10.1111/j.17446570.2007.00092.x 
Spell, H.B., Eby, L.T., \& Vandenburg, R.J., (2014). Developmental climate: A crosslevel analysis of voluntary turnover and job performance, Journal of Vocational Behavior, 84, 283-292. doi: 10.1016/j.jvb.2014.02.001

Staw, B. M., (1980). The consequences of turnover. Journal of Occupational Behavior, 1, 253-273.

Stephans, G, K. \& Sommer, S, M. (1996). The Measurement of Work to Family Conflict. Educational and Psychological Measurement. 56, 475-486.

Sterne, J.A.C., \& Egger, M. (2001). Funnel plots for detecting bias in meta-analysis: Guidelines on choice of axis. Journal of Clinical Epidemiology, 54, 1046-1055

*Sturman, M. C., \& Walsh, K. (2014). Strengthening the employment relationship: The effects of work-hours fit on key employee attitudes. Journal of Organizational Behavior, 35(6), 762-784. doi:10.1002/job.1925

Swinder, B.W., \& Zimmerman, R.D., (2014). Prior and future withdrawal and performance: A meta-analysis of their relations in panel studies. Journal of Vocational Behavior, 84, 225-236. doi: 10.1016/j.jvb.2014.01.004

*Tauetsile, J. O. (2016). Employee engagement: extension of the job demands resource (jd-r) model with the ubuntu construct. (10589329 Ph.D.), Bournemouth University (United Kingdom), Ann Arbor. Retrieved from http://echo.louisville.edu/login?url=https://search.proquest.com/docview/1885887 720 ?accountid $=14665$

Tekleab, A.G., Takeughi, R., and Taylor, M.S. (2005). Extending the Chain of Relationships Among Organizational Justice, Social Exchange, and Employee 
Reactions: The Role of Contract Violations. Academy of Management Journal, 48(1), 146-157.

Ten Brink, B. (2004) Psychological contract: A useful concept?. PhD thesis, Kurt Lewin Instituut Vrije Universiteit, Amsterdam.

Timms, C., Brough, P., O’Driscoll, M., Kalliath, T., Siu, O.L., Sit, C., \& Lo, D., (2015).

Flexible work arrangements, work engagement, turnover intentions and psychological health, Asia Pacific Journal of Human Resources, 1-24. doi: $10.1111 / 1744-7941.12030$

Thompson, B., (2002). What Future Quantitative Social Science Research Could Look Like: Confidence Intervals for Effect Sizes, Educational Researcher, 31(3), 25-32

Thompson, C.A., Beauvis, L.L., and Lyness, K.S., (1999). When Work-Family Benefits Are Not Enough: The Influence of Work-Family Culture on Benefit Utilization, Organizational Attachment, and Work-Family Conflict, Journal of Vocational Behavior, 54, 392-415

Tuckey, M.R., Bakker, A.B., \& Dollard, M.F., (2012), Empowering Leaders Optimize Working Conditions for Engagement: A Multilevel Study, Journal of Occupational Health Psychology, 17(1), 15-27. doi: 10.1037/a0025942

Valentin, C., (2014). The extra mile deconstructed: a critical and discourse perspective on employee engagement and HRD, Human Resource Development International, 17(4), 475-490. doi: 10.1080/13678868.2014.932091

Valentine, J.C., Pigott, T.D. \& Rothstein, H.R., (2010). How Many Studies Do You Need?: A Primer on Statistical Power for Meta-Analysis, Journal of Educational and Behavioral Statistics, 35(2), 215-247. doi: 10.3102/1076998609346961 
*Van Dyck, S. E. (2012). Horizontal Workplace Aggression and Coworker Social Support Related to Work-Family Conflict and Turnover Intentions. (1532526 M.S.), Portland State University, Ann Arbor. Retrieved from http://echo.louisville.edu/login?url=https://search.proquest.com/docview/1286775 769 ?accountid $=14665$

van Schalkwyk, S., du Toit, D. H., Bothma, A. S., \& Rothmann, S. (2010). Job Insecurity, Leadership Empowerment Behaviour, Employee Engagement and Intention to Leave in a Petrochemical Laboratory. South African Journal of Human Resource Management, 8(1), 1-7. doi:10.4102/sajhrm.v8i1.234

van Veldhoven, M., \& Meijman, T. F. (1994). Het meten van psychosociale arbeidsbelasting Complexity of Job Stress Models 27 met een vragenlijst: de vragenlijst beleving en beoordeling van de arbeid (VBBA) [The measurement of psychosocial job demands with a questionnaire: The questionnaire on the experience and evaluation of work (QEEW)]. Amsterdam, Nederlands: Instituut voor Arbeidsomstandigheden.

Viechtbauer, W., (2010). Conducting Meta-Analyses in R with the metaphor Package, Journal of Statistical Software, 36(3), 1-48. Retrieved at https://lirias.kuleuven.be/1059637?limo=0

Voight, E. (2011). Intention to leave and employee turnover: expanding understanding of key antecedents in the modern workforce. Unpublished doctoral dissertation, Monash University.

Voydanoff, P., (1998). Work Role Characteristics, Family Structure Demands, and Work Family/Conflict, Journal of Marriage and Family, 50(3), 749-761 
Wachter, J.K., \& Yorio, P.L., (2014). A system of safety management practices and worker engagement for reducing and preventing accidents: An empirical and theoretical investigation, Accident Analysis and Prevention, 68, 117-130. doi: 10.1016/j.aap.2013.07.029

Wang, D., Cha, Y., Nam, Y., (2016). The Relationship between Work-Family Conflict and Individual Engagement: Moderating Effect of Perceived Wellness Climate. The Journal of the Korea Contents Association, 16(1), 568-577. doi:10.5392/JKCA.2016.16.01.568

Wang, D., \& Zhang, W. (2009). Moderating Effects of Organizational Commitment on the Relationships between Work-family Conflict and Turnover Intentions of Chinese University. Faculty Proceedings of 2009 Conference on Systems Science, Management Science \& System Dynamics. (Vol 6, pp. 189-194). Shanghai, China.

*Wang, I. A., Lee, B.-W., \& Wu, S.-T. (2017). The relationships among work-family conflict, turnover intention and organizational citizenship behavior in the hospitality industry of Taiwan. International Journal of Manpower, 38(8), 11301142. doi:10.1108/IJM-04-2015-0056

Watts, K. (2017). The Impact of Transformational Leadership's Four Characteristics on Employee Engagement and Retention in Nonprofit Organizations. (10274370 D.B.A.), Northcentral University, Ann Arbor. Retrieved from http://echo.louisville.edu/login?url=https://search.proquest.com/docview/1909316 964 ? accountid $=14665$ 
Westring, A.F. \& Ryan, A.M. (2011). Anticipated work-family conflict: a construct investigation. Journal of Vocational Behaivor, 79(2), 596-610.

Whitney, D, J. \& Lindell, M, K. (1996). Antecedents and Consequences of Organizational Commitment (LEPC's). Paper presented at the 11th Annual Conference of Society for Industrial and Organizational Psychology, San Diego, CA

Wollard, K.K. \& Shuck, B. (2011). Antecedents to Employee Engagement: A Structured Review of the Literature. Advances in Developing Human Resources, 13(4). 429446. doi: $10.1177 / 1523422311431153$

Wu, L-Z, Kwan, H.K., Liu, J., Resick, C.J. (2012). Work-to-family spillover effects of abusive supervision, Journal of Managerial Psychology, 27(7), 714-731 doi: $10.1108 / 02683941211259539$

*Yardley, J. K. (1994). The relationships of work-family conflict with work outcomes: A test of a model. (9509180 Ph.D.), State University of New York at Buffalo, Ann Arbor. Retrieved from http://echo.louisville.edu/login?url=https://search.proquest.com/docview/3041301 01 ?accountid=14665

*Yavas, U., Babakus, E., \& Karatepe, O. M. (2008). Attitudinal and behavioral consequences of work-family conflict and family-work conflict - Does gender matter? International Journal of Service Industry Management, 19(1), 7-31. doi:10.1108/09564230810855699

*Yonetani, Y., Watanabe, S., \& Kanazawa, Y. (2007). On the relationships among organisational family supportiveness, work-family conflict, and turnover 
intention: evidence on Japanese men. International Journal of Human Resources Development \& Management, 7(3/4), 319-334.

doi:10.1504/IJHRDM.2007.017137

*Yunita, P. I., \& Kismono, G. (2014). Influence of Work-Family Conflict and FamilyWork Conflict on employees' turnover intentions with gender, social support, and individual value as moderating effects. Journal of Indonesian Economy \& Business, 29(1), 17-30.

Zhang, M., Griffeth, R.W., Fried D.D., (2012). Work-family conflict and individual consequences", Journal of Managerial Psychology, 27(7), 696-713. doi: $10.1108 / 02683941211259520$

Zigarmi, D., Nimon, K., (2011). A Cognitive Approach to Work Intention: The Stuff That Employee Work Passion Is Made of?, Advnaces in Developing Human Resources, 13(4), 447-461. doi: 10.1177/1523422311431152

*Zorlu, K. (2012). A comparative study of using the methods of multiple linear regression and artificial neural networks in organizational correlations for the fields of management and organization, International Journal of Management Economics and Business, 8(17), 1-26. doi:10.11122/ijmeb.2012.8.17.343 


\section{Appendix A}

\section{Screening Guide}

\begin{tabular}{|c|c|}
\hline \multicolumn{2}{|l|}{ Report Characteristics } \\
\hline \multicolumn{2}{|l|}{ Identification Number } \\
\hline \multicolumn{2}{|l|}{ Page Range } \\
\hline \multicolumn{2}{|l|}{ First Author Last Name } \\
\hline \multicolumn{2}{|l|}{ All Authors Name } \\
\hline \multicolumn{2}{|l|}{ Publication Year } \\
\hline Publication Type & $\begin{array}{l}0=\text { Journal } \\
1=\text { Government/Agency Report } \\
2=\text { Dissertation/Thesis } \\
3=\text { Conference presentation } \\
4=\text { Other } \\
5=\text { Unknown }\end{array}$ \\
\hline \multicolumn{2}{|l|}{ Inclusion Criteria } \\
\hline $\begin{array}{l}\text { I1: Is the study available in English } \\
\text { IF NO STOP }\end{array}$ & $\begin{array}{l}0=\text { No } \\
1=\text { Yes } \\
99=\text { Unsure/Cant tell }\end{array}$ \\
\hline $\begin{array}{l}\text { I2: Does the study measure at least on path } \\
\text { (two variables) } \\
\text { IF NO STOP }\end{array}$ & $\begin{array}{l}0=\text { No } \\
1=\text { Yes } \\
99=\text { Unsure/Cant tell }\end{array}$ \\
\hline $\begin{array}{l}\text { I3: Does the study use a measure for } \\
\text { employee engagement other than the } \\
\text { UWES? } \\
\text { IF NO goto I3a }\end{array}$ & $\begin{array}{l}0=\text { No } \\
1=\text { Yes } \\
98=\text { Study does not measure EE } \\
99=\text { Unsure/Cant tell }\end{array}$ \\
\hline $\begin{array}{l}\text { I3a: Does the UWES study contain at least } \\
\text { two other variables covered in this study? } \\
\text { IF NO STOP }\end{array}$ & $\begin{array}{l}0=\text { No } \\
1=\text { Yes } \\
98=\text { Study does not measure EE } \\
99=\text { Unsure/Cant tell }\end{array}$ \\
\hline $\begin{array}{l}\text { I4: Is the study quantitative? } \\
\text { IF NO STOP }\end{array}$ & $\begin{array}{l}0=\text { No } \\
1=\text { Yes } \\
99=\text { Unsure/Cant tell }\end{array}$ \\
\hline $\begin{array}{l}\text { I5: Does the study report correlations? } \\
\text { IF NO STOP }\end{array}$ & $\begin{array}{l}0=\text { No } \\
1=\text { Yes } \\
99=\text { Unsure/Cant tell }\end{array}$ \\
\hline $\begin{array}{l}\text { I6: Is this a study we want? } \\
\text { IF NO STOP }\end{array}$ & $\begin{array}{l}0=\text { No } \\
1=\text { Yes } \\
99=\text { Unsure/Cant tell }\end{array}$ \\
\hline
\end{tabular}




\section{Appendix B}

\section{Coding Guide}

\begin{tabular}{|c|c|}
\hline \multicolumn{2}{|l|}{ Report Characteristics } \\
\hline \multicolumn{2}{|l|}{ Identification Number } \\
\hline \multicolumn{2}{|l|}{ Page Range } \\
\hline \multicolumn{2}{|l|}{ First Author Last Name } \\
\hline \multicolumn{2}{|l|}{ All Authors Name } \\
\hline \multicolumn{2}{|l|}{ Publication Year } \\
\hline Publication Type & $\begin{array}{l}0=\text { Journal } \\
1=\text { Government } / \text { Agency Report } \\
2=\text { Dissertation } / \text { Thesis } \\
3=\text { Conference presentation } \\
4=\text { Other } \\
99=\text { Unknown }\end{array}$ \\
\hline \multicolumn{2}{|l|}{ Design Characteristics } \\
\hline D1: Research design type & $\begin{array}{l}0=\text { Experiment } \\
1=\text { Quasi-experiment } \\
2=\text { Correlational } \\
3=\text { Cross-sectional } \\
4=\text { Longitudinal } \\
5=\text { Meta-Analytic/Systematic Review } \\
6=\text { Other } \\
99=\text { Unknown }\end{array}$ \\
\hline D2: Correlation matrix reported? & $\begin{array}{l}0=\text { No } \\
1=\text { Yes } \\
99=\text { Unsure/Cant tell }\end{array}$ \\
\hline $\begin{array}{l}\text { D3: Variables Reported } \\
\text { Code all pairings }\end{array}$ & $\begin{array}{l}1=\mathrm{WFC} / \mathrm{SOC} \\
2=\mathrm{WFC} / \mathrm{EE} \\
3=\mathrm{WFC} / \mathrm{TO} \\
4=\mathrm{SOC} / \mathrm{EE} \\
5=\mathrm{SOC} / \mathrm{TO} \\
6=\mathrm{EE} / \mathrm{TO} \\
0=\text { Does not measure two variables of } \\
\text { interest (STOP) }\end{array}$ \\
\hline D4: Employee Engagement measure used & $\begin{array}{l}1=\text { May et al. (2004) } \\
2=\text { Saks }(2006) \\
3=\text { Britt }(1999) \\
4=\text { Rich et al. }(2010) \\
5=\text { Rothbard (2001) } \\
6=\text { Soane et al. }(2012) \\
7=\text { Strumph et al. }(2013) \\
8=\text { Propietary, Harter et al. (2002);(Gallup } \\
\text { Q12) }\end{array}$ \\
\hline
\end{tabular}




\begin{tabular}{|c|c|}
\hline & $\begin{array}{l}9=\text { Proprietary }, \text { Other } \\
10=\text { Other } \\
98=\text { UWES }(\text { STOP }) \\
99=\text { Unknown } \\
0=\text { Employee Engagement not measured }\end{array}$ \\
\hline \multicolumn{2}{|l|}{ Effect Size Information } \\
\hline \multicolumn{2}{|l|}{ E1: Correlation Effect Size } \\
\hline $\begin{array}{l}\text { E2: Which pair of variables does this } \\
\text { correlation represent }\end{array}$ & $\begin{array}{l}1=\mathrm{WFC} / \mathrm{SOC} \\
2=\mathrm{WFC} / \mathrm{EE} \\
3=\mathrm{WFC} / \mathrm{TO} \\
4=\mathrm{SOC} / \mathrm{EE} \\
5=\mathrm{SOC} / \mathrm{TO} \\
6=\mathrm{EE} / \mathrm{TO}\end{array}$ \\
\hline E3: Direction of Effect size & $\begin{array}{l}0=\text { zero } \\
1=\text { positive } \\
2=\text { negative } \\
3=\text { reported positive/no ES } \\
4=\text { reported positive/no ES } \\
5=\text { no report/no ES }\end{array}$ \\
\hline E4: Effect size report type & $\begin{array}{l}1=\text { correlation } \\
2=\text { Beta } \\
3=\text { covariance } \\
4=\text { odd-ratio }\end{array}$ \\
\hline E5: Is Effect Size statistically significant & $\begin{array}{l}0=\text { no } \\
1=\text { Yes } \\
99=\text { cant tell/not reported }\end{array}$ \\
\hline \multicolumn{2}{|l|}{ E6: Degrees of Freedom reported in study } \\
\hline E7: Effect size source & $\begin{array}{l}0=\text { as reported } \\
1=\text { calculated for meta-analysis }\end{array}$ \\
\hline \multicolumn{2}{|l|}{ Measures for Effect Size } \\
\hline $\begin{array}{l}\text { M1: Was reliability reported for test } \\
\text { instruments }\end{array}$ & $\begin{array}{l}0=\text { No } \\
1=\text { Yes } \\
99=\text { Cant tell }\end{array}$ \\
\hline $\begin{array}{l}\text { M2: What was the variable and value of the } \\
\text { reliability if reported: Cronbach's } \boldsymbol{\alpha}\end{array}$ & \\
\hline
\end{tabular}




\section{Appendix C}

\section{Instrument Inclusion and Exclusion Criteria}

Table C-1 contains the distinction specific inclusion and exclusion parameters on which measures are included in this meta-analysis. Specific attention was paid to what a measure purports to measure, and what is actually measured. For employee engagement, the Shuck and Wollard (2011) definition provides a base for operationalization of employee engagement as: an individuals choice to invest discretionary and personal resources to include ones cognitive, emotional and behavioral energies of ones true and preferred self in the completion of organizational tasks within the organizational setting (Kahn, 1990; Shuck \& Wollard, 2010). The focus of this operationalization is the individual and the individuals' choice in investing resources. By this operationalization measure included ate May, Gilson, \& Harter (2004); Saks (2006) job engagement scale, and the job engagement scale of Rich, Lepine, \& Crawford (2010). The focus of these measures is the individual and the individual choosing to engage resources of a cognitive, behavioral, and emotional nature. Measures excluded are the Utrecht Work Engagement Scale of Maslach, Schaufeli, \& Leiter (2001). This scale operationalizes employee engagement as vigor, absorption and dedication and has been suggested to be empirically redundant with the Maslach Burnout Inventory (Christian et al., 2012). Saks (2006) organization engagement scale is excluded due to the focus of this scale on the organization and not the individual perspective. Soane et al. (2012) ISA social engagement scale is excluded due to the focus on the employee's interactions with other employees as the base for engagement. Lastly the Harter, Schmidt \& Hayes (2002) satisfaction-engagement measure is excluded due to the focus on an employee's 
satisfaction with his employment and not the investment of resources in pursuit of organizational goals.

Work-Family Conflict is operationally defined as a conflict between work roles interfering with family roles (work interfering with family (WIF)) or a conflict between family roles interfering with work roles and responsibilities (family interfering with work (FIW)) (Frome, Russell \& Cooper, 1992a). The measures included above reflect the confliction of work and family roles with one another. For example: Gutek, Searle, \& Klepa (1991) Sample item: WIF: On the job I have so much work to do that it takes away from my personal interests; FIW: My personal demands are so great that it takes away from my work demonstrates this conflict as operationalized by Frome et al. (1992). Excluded from the work family conflict measures was the work family balance measure of Thompson, Beauvais \& Lyness, 1999 as this measure focuses on the balance an individual strives to maintain and not the conflict inherent in that balance.

A supportive organizational culture is defined as a culture that "represents and protects its core values by trying to use the flexibility of operational procedures to meet the employees' needs, maintaining human relations and showing concern for people" (Sok, Bloome, \& Tromp, 2014, p. 460). Operationally a supportive organizational culture is an organization culture that proactively engages the employee population through policies and procedures designed to assist the employee process events that could interfere with the performance of the employees roles and responsibilities. Measures included are those measures which focus on the organizations actions through policies and procedures to support the employee in mitigating events that would hinder the employees ability to focus on performing tasks towards organizational goals. For 
example: As measured by Bond (2004) Work-life culture: sample item: It is not difficult to get time off during work or take care of personal or family matters. Measures excluded are all measures that concentrate on an employee's perception of support, such as any scale using Eisenburger, Huntington, Hutchinson, \& Sowa (1986) perceived organization support scale as a base for measuring supportive organization culture. The Eisenburger et al. (1986) scale focuses on individuals perceptions and not the organization actual efforts.

Turnover intentions are "a conscious and deliberate desire to leave the organization within the near future" (Carmeli \& Weisberg, 2006, p. 193). These intentions are operationally defined as a stated desire or belief that an individual will leave their current place of employment for another employer or opportunity at some future point. Measures included outline this desired state such as Protass (2013) sample item: "Taking everything into consideration, how likely is it that you will make a genuine effort to find a new job within the next year?" This question centers around and individuals likely intention but not the actual action of turnover. Excluded measures are actual turnover rates as these measure the action after the intention. 
Table C-1

Instrument Inclusion and Exclusion Criteria

\begin{tabular}{|c|c|c|}
\hline Variable & Definition & Operational Definition \\
\hline $\begin{array}{l}\text { Employee } \\
\text { engagement }\end{array}$ & $\begin{array}{l}\text { "an individual } \\
\text { employee's } \\
\text { cognitive, } \\
\text { emotional, and } \\
\text { behavioral } \\
\text { state directed } \\
\text { toward desired } \\
\text { organizational } \\
\text { outcomes." } \\
\text { Shuck \& } \\
\text { Wollard, 2010, } \\
\text { p.103 }\end{array}$ & $\begin{array}{l}\text { An individual's choice } \\
\text { to invest discretionary } \\
\text { and personal resources } \\
\text { to include ones } \\
\text { cognitive, emotional } \\
\text { and behavioral } \\
\text { energies of one's true } \\
\text { and preferred self in } \\
\text { the completion of } \\
\text { organizational tasks } \\
\text { within the } \\
\text { organizational setting } \\
\text { (Kahn, 1990; Shuck \& } \\
\text { Wollard, 2010) }\end{array}$ \\
\hline
\end{tabular}

What it is

As measured by May, Gilson, \& Harter (2004) Sample items:

Cognitive engagement - Time passes quickly when I perform my job; Emotional engagement: I get excited when I perform well on my job; Physical engagement: I stay until the job is done.

As measured by Saks (2006) job engagement scale: Sample item: I am highly engaged in this job;

Physical, Emotional, and Cognitive engagement as measured by Rich, Lepine, \& Crawford (2010) sample items: I devote a lot of energy to my job; I am excited about my job; At work, I concentrate on my job

\section{What it is not}

As measured by Saks (2006) organization engagement scale: Sample item: Being a member of this organization make me come "alive";

As measured by the Utrecht Work Engagement Scale Maslach, Schaufeli, \& Leiter (2001): sample item: Vigor: When I get up in the morning, I feel like going to work; Dedication: I am enthusiastic about my job; Absorption: When I am working I forget everything else around me.

As measured by Shaufeli, Salanova, Gonzalez-Roma \& Bakker (2002):

Sample items: Vigor: At my work, I am bursting with energy, Dedication: My job inspires me; Absorption: I am proud of the work that I do

As measured by the Soane, Truss, Alfes, Shantz, Rees, \& Gatenby (2012) 
ISA social engagement scale: sample item: I share the same work goals as my colleagues; Intellectual engagement scale: I pay a lot of attention to my work; Affective engagement scale: I am enthusiastic in my work

As measured by Harter, Schmidt \& Hayes (2002) satisfaction-engagement framework using the Gallup Workplace Audit: Sample item: At work, my opinions seem to count, At work, I have the opportunity to do what I do best every day

Work Family Conflict "a

form of

interrole

conflict in

which the role

pressures

from the work

and family

domains are

mutually

incompatible

in some

respect. That

is, participation
A conflict between work roles interfering with family roles (work interfering with family (WIF)) or a conflict between family roles interfering with work roles and responsibilities (family interfering with work (FIW)); Frome, Russell \& Cooper (1992a)
As measured by Frome, Russell \& Cooper (1992a): Sample item: work-family conflict - How often does your job or career interfere with your responsibilities at home, such as yard work, cooking, cleaning, repairs, shopping, paying bills or child care; family-work conflict - How often does your homelife interfere with your responsibilities at work such as getting to work on time, accomplishing daily tasks, or working overtime?
As measured by Thompson, Beauvais \& Lyness, 1999 (work family culture) sample item: In this organization employees can easily balance their work and family lives. 
in

the work

(family) role is

made more

difficult by

virtue of

participation in

the family

(work) role"

(Greenhaus \&

Beutell, 1985,

p. 77).
A culture that

"represents and protects its
As measured by Netemeyer, Boles, \& McMurrian (1996) sample item: Work-family conflict: The demands of my work interfere with my home and family life; family-work conflict: the demands of my family or spouse/partner interfere with work-related activities

As measured by Gutek, Searle, \& Klepa (1991) Sample item: WIF:

On the job I have so much work to do that it takes away from my personal interests; FIW: My personal demands are so great that it takes away from my work

As measured by Carlson, Kacmar \& Williams (2000) sample item: WIF: My work keeps me from my family activities more then I would like; FIW: The time I spend on family activities often interfere with my work responsibilities

As measured by Bond (2004) Worklife culture: sample item: It is not Perceived organization support as An organization culture that proactively Organization engages the employee difficult to get time off during work measured by Saks (2006) sample item: My organization really cares about my 
core values by trying to use the flexibility of operational procedures to meet the employees' needs, maintaining human relations and showing concern for people" (Sok, Bloome, \& or take care of personal or family

population through policies and procedures designed to assist the employee process events that could interfere with the performance of the employees roles and responsibilities

\section{matters}

Family supportive organizational culture as measured by Allard,

Hass, \& Hwang (2011) sample item: "The top managers care about how men's jobs affect family life" well-being, My organization cares about my opinions

Perceived organizational support as measured by Eisenburger, Huntington, Hutchinson, \& Sowa (1986)

Organizational culture as assessed by Quinn and Rihrbaugh (1983) organizational culture assessment instrument (OCAI)

Innovation supportive culture as measured by Chandler, Keller, \& Lyon (2000) 


\begin{tabular}{|c|c|c|c|c|}
\hline $\begin{array}{l}\text { Turnover } \\
\text { Intentions }\end{array}$ & $\begin{array}{l}\text { "a conscious } \\
\text { and deliberate } \\
\text { desire to leave } \\
\text { the } \\
\text { organization } \\
\text { within the near } \\
\text { future" } \\
\text { (Carmeli \& } \\
\text { Weisberg, } \\
\text { 2006, p. 193). }\end{array}$ & $\begin{array}{l}\text { a stated desire or belief } \\
\text { that an individual will } \\
\text { leave their current } \\
\text { place of employment } \\
\text { for another employer } \\
\text { or opportunity at some } \\
\text { future point. }\end{array}$ & $\begin{array}{l}\text { As measured by Van Veldhoven \& } \\
\text { Meijman (1994): Sample Item: I } \\
\text { intend to change jobs during the } \\
\text { next year; As measured by Saks } \\
\text { (2006) sample item: I frequently } \\
\text { think about quitting my job; As } \\
\text { measured by Boroff \& Lewin } \\
\text { (1997) (from Soane et al 2012); } \\
\text { Sample item: I am seriously } \\
\text { considering quitting my current } \\
\text { employer for an alternate employer } \\
\text { Turnover likelihood as measured by } \\
\text { Protass (2013) sample item } \\
\text { "Taking everything into } \\
\text { consideration, how likely is it that } \\
\text { you will make a genuine effort to } \\
\text { find a new job within the } \\
\text { next year?', }\end{array}$ & Actual turnover rates \\
\hline
\end{tabular}




\section{Appendix D}

\section{Random Effects Table}

The table below is a continuation of table 4.9. Table D-1 contains more descriptive statistics of what the studies looked like (i.e. reliability, measurements used, sample, study weighting). The purpose of this table is to give the reader a better understanding of the underlying data that produced the effect sizes and variance reported in chapter 4 and discussed in chapter 5 . As can be seen: the similar study weighting as a function of sample size, and the various measures used to observe work-family conflict, employee engagement, and intention to turnover, contributed to the high levels of heterogeneity reported. Additionally, the low number of studies, particularly employee engagement/intention to turnover, contributed to high heterogeneity. The trim and fill method is formulated on the assumptions of the fixed effect model (Borenstein et al., 2009). As such when there is a high level of heterogeneity, which small samples tend to estimate imprecisely (Veichtbauer, 1998), and lead to similar weighting amongst the studies under review. 
Table D-1

Work Family Conflict/Intention to Turnover Study Information

\begin{tabular}{|c|c|c|c|c|c|c|c|c|}
\hline \multirow[t]{2}{*}{ Author(s)/Year } & \multirow[t]{2}{*}{$N$} & \multirow[t]{2}{*}{$r$} & \multirow{2}{*}{$\begin{array}{c}\text { Fisher's } \\
\text { Z }\end{array}$} & \multirow{2}{*}{$\begin{array}{l}\text { Study } \\
\text { Weight }\end{array}$} & \multirow{2}{*}{$\begin{array}{l}\text { WFC } \\
\text { Inst. }\end{array}$} & \multirow[t]{2}{*}{$\alpha$} & \multirow{2}{*}{$\begin{array}{l}\text { TO } \\
\text { Inst. }\end{array}$} & \multirow[t]{2}{*}{$\alpha$} \\
\hline & & & & & & & & \\
\hline Aboobaker et al. (2017) & 150 & .585 & .67 & .378 & Carlson et al. (2000) & .904 & Mobley (1997) & .872 \\
\hline Ali \& Baloch (2009) & 283 & .584 & .67 & .719 & Carlson et al. (2000) & .81 & Cammann et al. (1979) & .92 \\
\hline Alshutwi (2016) & 113 & .43 & .46 & .282 & Netemeyer (1996)* & .89 & Cammann et al. (1979) & .78 \\
\hline Anwar et al. (2017) & 281 & .445 & .48 & .714 & Adams et al. (1996) & .863 & Moore (2000) & .829 \\
\hline Bagger (2006) & 196 & .255 & .26 & .496 & Gutek et al. (1991) & .705 & Cropanzano et al. (1997) & .815 \\
\hline Bande et al. (2015) & 209 & .26 & .27 & .529 & Netemeyer (1996) & .91 & Fournier et al. (2010) & .94 \\
\hline Battistelli et al. (2013) & 440 & .18 & .18 & 1.122 & Netemeyer (1996) & .91 & Self-developed & NR \\
\hline Blomme et al. (2010) & 247 & .45 & .48 & .627 & Self-Developed & .92 & Ten Brink (2004) & .93 \\
\hline Chelariu \& Stump (2011) & 185 & .36 & .38 & .467 & Netemeyer (1996) & 9 & Cammann et al. (1983) & .87 \\
\hline Chen et al. (2015) & 186 & .551 & .62 & .470 & Carlson et al. (2000) & .91 & Mobley et al. (1978) & .72 \\
\hline $\begin{array}{l}\text { Daderman } \\
\text { \& Basinska (2016) }\end{array}$ & 188 & .35 & .37 & .475 & Netemeyer (1996) & .89 & Self-developed & NR \\
\hline Dion (2006) & 112 & .207 & .21 & .280 & Netemeyer (1996) & .88 & Cammann et al. (1983) & .83 \\
\hline
\end{tabular}




\begin{tabular}{|c|c|c|c|c|c|c|c|c|}
\hline Field (2010) & 399 & .18 & .18 & 1.017 & Netemeyer (1996) & .925 & Kelloway et al. (1999) & .94 \\
\hline Flaxman (1999) & 92 & .11 & .11 & .229 & $\begin{array}{l}\text { Stephans } \\
\text { \& Sommer (1996) }\end{array}$ & .86 & $\begin{array}{l}\text { Whitney } \\
\text { \& Lindell (1996) }\end{array}$ & .66 \\
\hline $\begin{array}{l}\text { Grandey } \\
\text { \& Cropanzano (1999) }\end{array}$ & 132 & .21 & .21 & .331 & $\begin{array}{l}\text { Kopelman et al. } \\
\text { (1983) }\end{array}$ & .9 & Cropanzano et al. (1993) & .74 \\
\hline $\begin{array}{l}\text { Grobelna } \\
\text { \& Tokarz-Kocik (2016) }\end{array}$ & 60 & .524 & .58 & .146 & Netemeyer (1996) & .87 & Boshoff and Allen (2000) & .86 \\
\hline Haar (2004) & 100 & .27 & .28 & .249 & $\begin{array}{l}\text { Greenhaus et al. } \\
(2000)\end{array}$ & .89 & Grover \& Crooker (1995) & NR \\
\hline Haar et al. (2012) & 197 & .41 & .44 & .498 & Carlson et al. (2000) & .78 & Kelloway et al. (1999) & .85 \\
\hline Hammer et al. (2011) & 197 & .33 & .34 & .917 & Netemeyer (1996) & .87 & Boroff \& Lewin (1997) & .8 \\
\hline Hee (2017) & 101 & .326 & .34 & .252 & Netemeyer (1996) & .88 & $\begin{array}{l}\text { Grzywacz, J. } \\
\text { \& Marks, N. (2000) }\end{array}$ & .82 \\
\hline Huang \& Cheng (2012) & 170 & .34 & .35 & .429 & Netemeyer (1996) & .93 & Netemeyer (1996) & .9 \\
\hline Huh (2017) & 158 & .215 & .22 & .398 & Gutek et al. (1991) & .87 & Kelloway et al. (1999) & .92 \\
\hline Kao \& Chang (2016) & 240 & .244 & .25 & .609 & $\begin{array}{l}\text { Westring } \\
\text { \& Ryan (2011) }\end{array}$ & .863 & Voight (2011) & .78 \\
\hline Karatepe (2009) & 189 & .427 & .46 & .478 & Netemeyer (1996) & .82 & Singh et al. (1996) & .87 \\
\hline Karatepe \& Azar (2013) & 141 & .434 & .46 & .354 & Grzywacz & .78 & Singh et al. (1996) & .8 \\
\hline
\end{tabular}


\& Marks, N. (2000).

\begin{tabular}{|c|c|c|c|c|c|c|c|}
\hline Karatepe \& Kilic (2015) & 144 & .087 & .09 & .362 & Carlson et al. (2000) & .87 & Singh et al. (1996) \\
\hline Kossek et al. (2006) & 245 & .18 & .18 & .622 & Gutek et al. (1991) & .73 & Boroff \& Lewin (1997) \\
\hline Kuvaas et al. (2017) & 4518 & .37 & .39 & 11.597 & Gutek et al. (1991) & .85 & Kuvaas (2008) \\
\hline Liao (2011) & 236 & .12 & .12 & .598 & Gutek et al. (1991) & .8 & Tekleab et al. (2005) \\
\hline Ma. Regina (2013) & 991 & .34 & .35 & 2.538 & $\begin{array}{l}\text { Kopelman et al. } \\
\text { (1983) }\end{array}$ & .88 & Self-developed \\
\hline Mack (2015) & 59 & .9 & 1.47 & .144 & Self-Developed & NR & Self-developed \\
\hline Masuda et al. (2012) & 3914 & .23 & .23 & 1.045 & Carlson et al. (2000) & .85 & Spector et al. (1988) \\
\hline Mauno et al. (2015) & 814 & .099 & .10 & 2.083 & Carlson et al. (2002) & .82 & Self-developed \\
\hline Molino et al. (2016) & 617 & .06 & .06 & 1.577 & Netemeyer (1996) & .91 & Schaufeli \& Bakker, 2004 \\
\hline Nei et al. (2015) & 2781 & .21 & .21 & 7.135 & Not Reported & NR & Not Reported \\
\hline Payne et al. (2012) & 316 & .28 & .29 & .804 & Carlson et al. (2000) & .88 & Cammann et al. (1983) \\
\hline Prati \& Zani (2016) & 5195 & -.24 & -.24 & 13.336 & $\begin{array}{l}\text { Guglielmi } \\
\text { et al. (2011) }\end{array}$ & .73 & Meyer et al. (1993) \\
\hline Ribeiro et al. (2016) & 851 & .355 & .37 & 2.178 & Netemeyer (1996) & .97 & Roodt (2004) \\
\hline
\end{tabular}




\begin{tabular}{|c|c|c|c|c|c|c|c|c|}
\hline Roulin et al. (2014) & 1547 & .35 & .37 & 3.966 & Guerts (2000) & .86 & Self-developed & NR \\
\hline Sabokro et al. (2013) & 494 & .41 & .44 & 1.261 & Netemeyer (1996) & .842 & Self-developed & .821 \\
\hline Sachau et al. (2012) & 1185 & .34 & .35 & 3.036 & Netemeyer (1996) & .77 & Self-developed & .85 \\
\hline Sorensen et al. (2016) & 234 & .25 & 260 & .593 & Carlson et al. (2000) & 93 & $\begin{array}{l}\text { School and Staffing } \\
\text { Survey (2014) } \\
\text { Lemons (2013) }\end{array}$ & .88 \\
\hline Spector et al. (2007) & 5270 & .20 & .20 & 13.528 & Carlson et al. (2000) & NR & Spector et al. (1988) & NR \\
\hline Sturman \& Walsh (2014) & 1032 & .31 & .32 & 2.643 & Netemeyer (1996) & .9 & Kelloway et al. (1999) & .95 \\
\hline Tauetsile (2016) & 438 & .295 & .30 & 1.117 & $\begin{array}{l}\text { Kopelman et al. } \\
\text { (1983) }\end{array}$ & .93 & Farh et al. (1998) & .77 \\
\hline Van Dyck (2012) & 156 & .45 & .48 & .393 & Netemeyer (1996) & .93 & Kelloway et al. (1999) & 96 \\
\hline Wang \& Zhang (2009) & 139 & .37 & .39 & .349 & Boles et al. (2001) & NR & Self-developed & NR \\
\hline Wang et al. (2017) & 325 & .37 & .39 & .827 & Carlson et al. (2000) & .874 & Meyer et al. (1993) & .897 \\
\hline Yardley (1994) & 343 & .24 & .24 & .873 & Self developed\# & NR & Cammann et al. (1979) & NR \\
\hline Yavas et al. (2008) & 723 & .32 & .33 & 1.849 & $\begin{array}{l}\text { Netemeyer (1996) } \\
\text { and Boles et al. (2001) }\end{array}$ & ${ }^{N R}$ & Boshoff and Allen (2000) & NR \\
\hline Yonetani et al. (2007) & 179 & .15 & .15 & .452 & Netemeyer (1996) & .91 & Self-developed & .84 \\
\hline
\end{tabular}




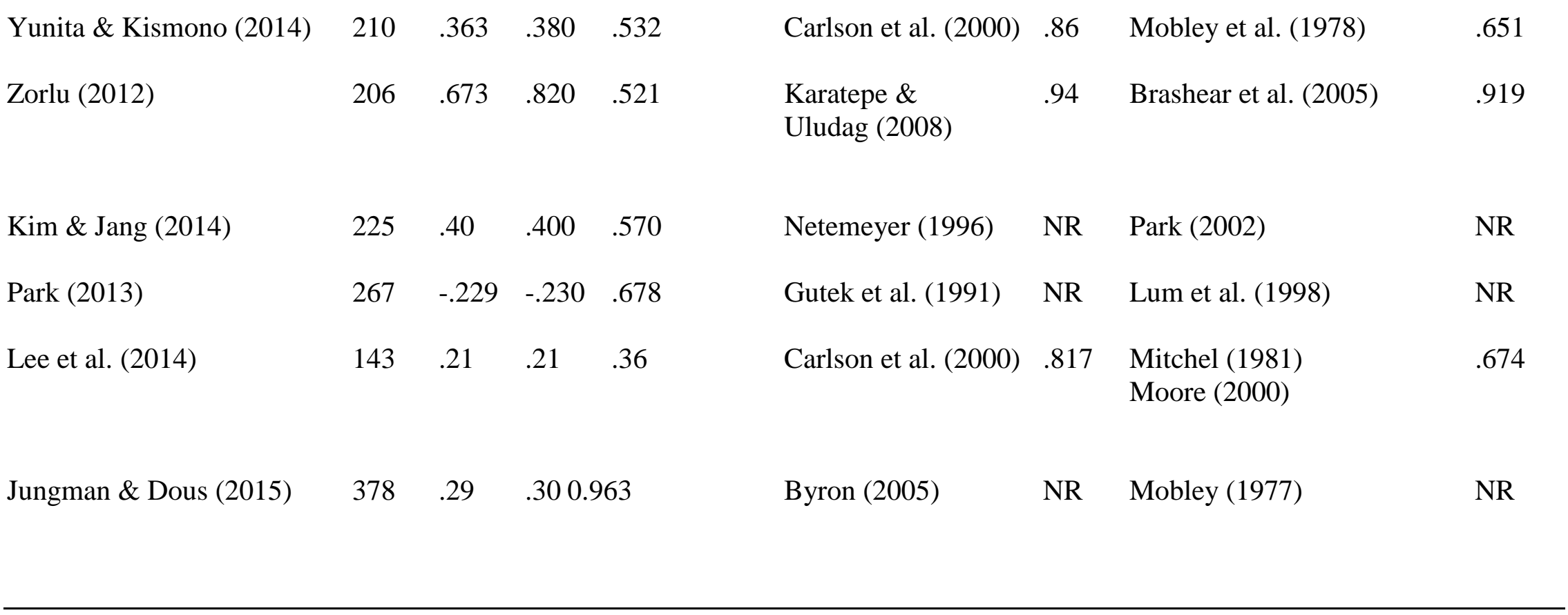

Note. $N=$ study sample size; $r=$ correlation coefficient. * = Netemeyer et al. (1996); \# = Yardley (1994) WFC measure developed from items on Gutek, B. A., Searle, S., \& Klepa, L. (1991). Kopelman, R. E., Greenhaus, J. H., \& Connolly, T. F. (1983) and Frome, Russel \& Cooper (1992). 
Table D-2

Employee Engagement/Intention to Turnover Study Information

\begin{tabular}{|c|c|c|c|c|c|c|c|c|}
\hline Author(s)/Year & $\mathrm{N}$ & $\mathrm{r}$ & $\begin{array}{c}\text { Fisher's } \\
\text { Z }\end{array}$ & $\begin{array}{l}\text { Study } \\
\text { Weight }\end{array}$ & $\begin{array}{l}\text { EE } \\
\text { Inst. }\end{array}$ & $\alpha$ & $\begin{array}{l}\text { TO } \\
\text { Inst. }\end{array}$ & $\alpha$ \\
\hline Alfes et al. (2013) & 328 & -.40 & -.42 & .905 & Rich, et al. (2010) & .88 & Boroff \& Lewin (1997) & .95 \\
\hline Appelbaum et al. (2013) & 17 & -.67 & -.81 & .039 & Saks (2006) & NR & Reychav \& Sharkie (2010) & NR \\
\hline bin Salahudin et al. (2016) & 170 & -.955 & -1.89 & .465 & Gallup (2006) & .815 & Mary (2014) & .718 \\
\hline $\begin{array}{l}\text { de Villiers \& } \\
\text { Stander (2011) }\end{array}$ & 278 & -.25 & -.26 & .765 & May et al. (2004) & .77 & Sjöberg \& Sverke (2000) & .83 \\
\hline Foster (2013) & 120 & .46 & .50 & .326 & Saks (2006) & .85 & Colarelli (1984) & .74 \\
\hline Gyensare et al. (2017) & 336 & -.21 & -.21 & .927 & Harter et al. (2002) & .72 & Colarelli (1984) & .79 \\
\hline Halliday et al. (2018) & 23439 & -.62 & -.73 & 65.234 & Rich, et al. (2010) & .89 & Self-developed & .83 \\
\hline Liss-Levinson et al. (2015) & 10246 & -.026 & -.03 & 28.511 & Self-developed & NR & Self-developed & NR \\
\hline Malinen \& Harju (2017) & 221 & .29 & .30 & .607 & Saks (2006) & .79 & Pearce (1983) & .65 \\
\hline Shuck, A. et al. (2013) & 241 & .61 & .71 & .662 & Rich, et al. (2010) & .96 & Colarelli (1984) & .91 \\
\hline Shuck, B. et al. (2011) & 283 & -.56 & -.63 & .779 & May et al. (2004) & .89 & Colarelli (1984) & .81 \\
\hline
\end{tabular}


Appendix E

\section{Additional Funnel Plots}

This appendix includes all four types of funnel plots available in the metafor package in R. Using Sterne \& Egger (2001) as a guide, as well as the metafor package website (found at http://www.metafor-project.org/doku.php/plots:funnel_plot_variations) all four funnel plot types: standard error, sampling variance, inverse standard error, and inverse sampling variance, were ran for the variable pairings of employee engagement/intent to turnover and work-family conflict/intent to turnover. Sterne \& Eggers (2001) suggest using the standard error plot in most cases. However, with smaller studies the inverse standard error plot is more precise (Sterne \& Egger, 2001). The plots are below. As indicated in chapters 4 and 5 the plots, given the low number of studies, similar weighting of studies, and high heterogeneity, suggest there is no evidence in bias. 
Figure E-1

Work-Family Conflict/Intent to Turnover Funnel Plots

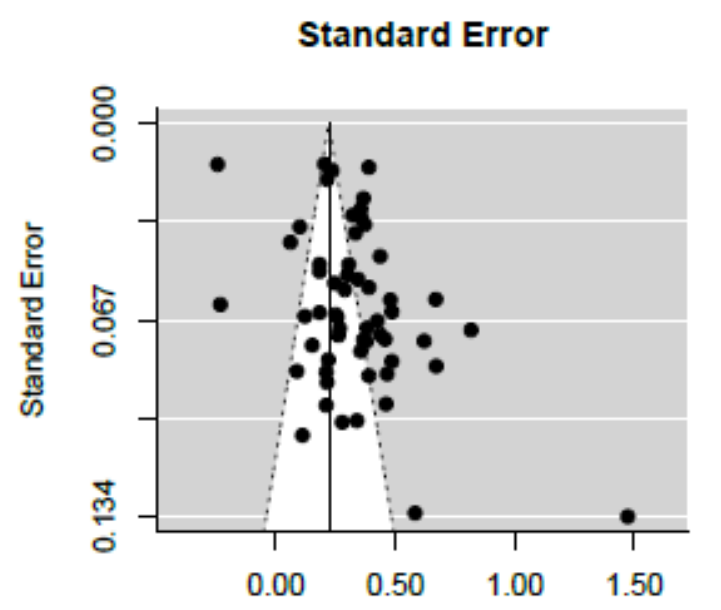

Fisher's z Transformed Correlation Coefficient

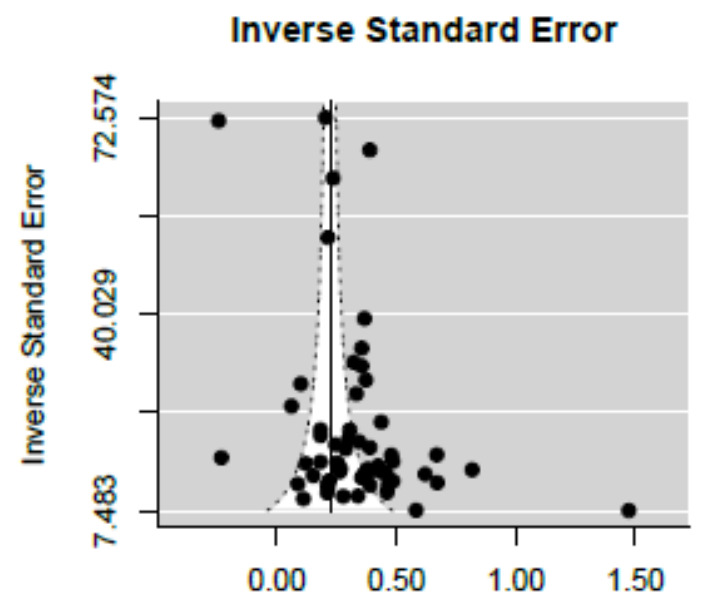

Fisher's z Transformed Correlation Coefficient

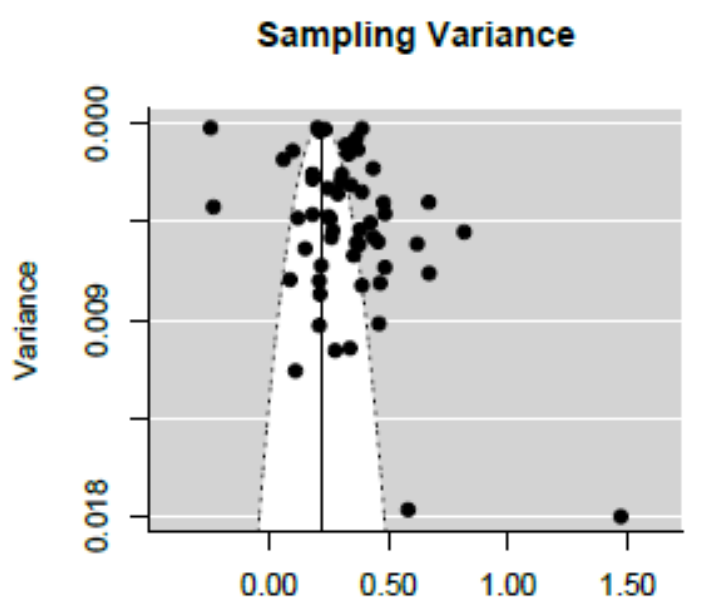

Fisher's z Transformed Correlation Coefficient

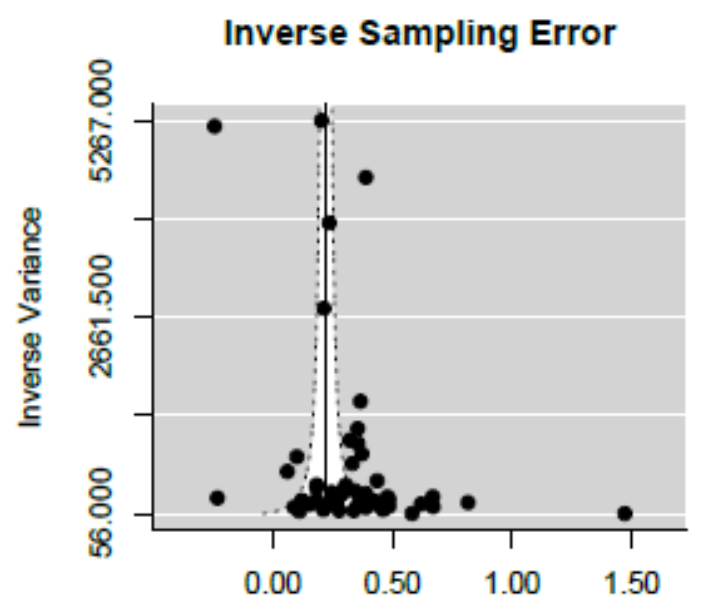

Fisher's z Transformed Correlation Coefficient 
Figure E-2

Employee Engagement/Intent to Turnover Funnel Plots

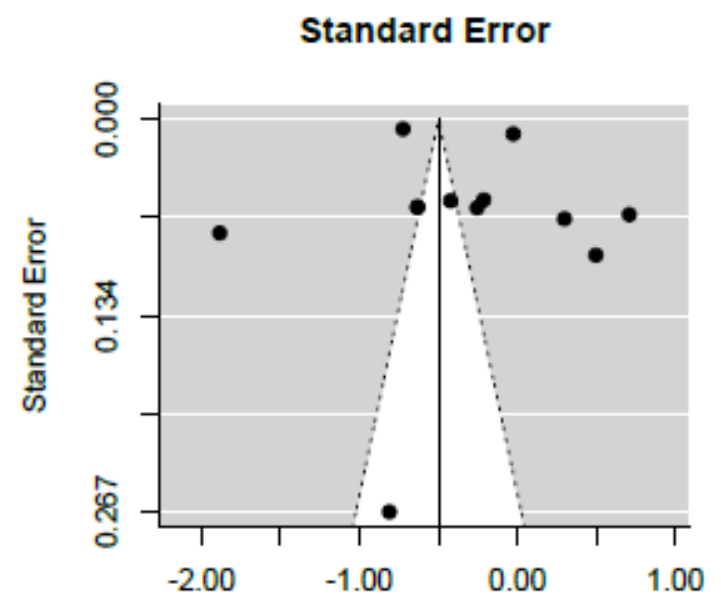

Fisher's z Transformed Correlation Coefficient

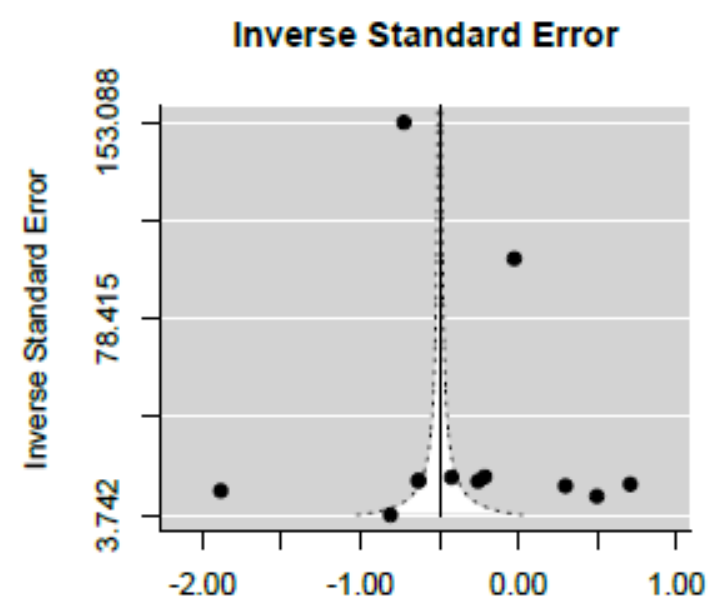

Fisher's z Transformed Correlation Coefficient

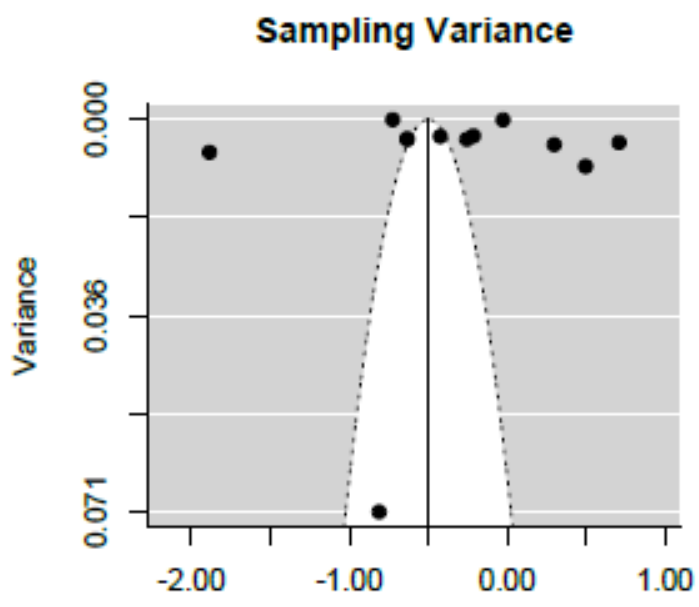

Fisher's z Transformed Correlation Coefficient

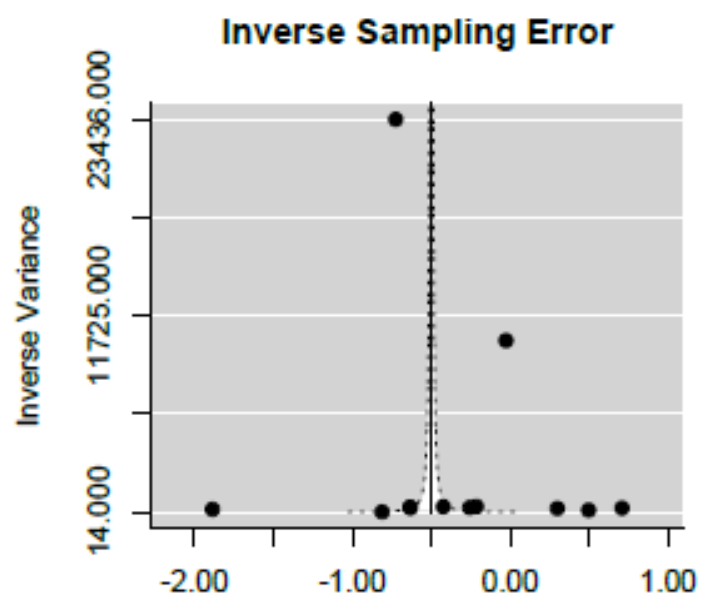

Fisher's z Transformed Correlation Coefficient 


\section{CURRICULUM VITAE}

Joshua Branden Jordan

\section{Education}

University Of Louisville, Louisville, Kentucky

expected 2019

Doctoral Candidate, Educational Leadership and Organization Development

\section{Concentration}

Human Resource Development

Dissertation: Meta-Engagement: An Examination of Employee Engagement Antecedent Variable Interactions and the Impact on Engagement Outcomes

Troy University, Troy, Alabama

2004

Master of Science in Management

Concentration

Leadership and Organizational Effectiveness

Purdue University, West Lafayette, Indiana

Bachelor of Arts, Political Science (major), Philosophy ( $1^{\text {st }}$ minor), Religious Studies $\left(2^{\text {nd }}\right.$ minor)

\section{Professional Certifications and Skills}

The International Society of Logistics (SOLE)

Demonstrated Master Logistician

United States Army, Washington D.C.

Lean Six Sigma Black Belt (ASI 1Y)

\section{Professional Employment Experience}

Haworth, Inc., Holland, MI

Supply Chain Project Leader

2017-2019

Continuous Improvement Champion (Lean Manufacturing Champion)

United States Army, Washington D.C.

Major, Logistics Corps

Instructor/Writer Support Operations Course

2013-2015

Doctoral Student, University of Louisville 
Captain, Logistics Corps

Assistant Executive Officer to Director, OPMD, HRC

2010-2011

Logistics Observer/Controller, Joint Readiness Training Center

2008-2010

Logistics Advisor, Military Transition Team, Baqubah, Iraq

2007-2008

Second Lieutenant - Captain, Ordnance Corps

Commander, Headquarters and Headquarters Detachment, $68^{\text {th }}$ CSB $\quad$ 2004-2006

Budget Officer, 43d Area Support Group 2004

Ammunition Platoon Leader \& Executive Officer, 60 ${ }^{\text {th }}$ Ordnance Co. $\quad 2002-2004$

United States Army Reserve, Washington D.C.

Automated Logistics Non-Commissioned Officer

1999-2001

United States Army, Washington D.C.

Automated Logistics Specialist

Land Combat Support Systems (LCSS) Test Specialist

1996-1998

1993-1996

\section{Professional Publications}

\section{Articles in Professional/Trade Publications}

Jordan, J. (2007). Preparing for a Transition Team Assignment in Iraq. Army Logistician, $39(4)$.

Jordan, J. (2014) Huntington's “The Clash of Civilizations?”: Is the clash still driving conflict? Small Wars Journal, 10(6). Retrieved from http://smallwarsjournal.com/jrnl/art/huntingtons-"the-clash-of-civilizations"-isthe-clash-still-driving-conflict

\section{Book Reviews}

Jordan, J. (2014). Book Review: All the Great Prizes: The Life of John Hay, from Lincoln to Roosevelt. Military Review 94(6), 140-141.

Jordan, J. (2015). Book Review: American General: The Life and Times of William Tecumseh Sherman, by John S.D. Eisenhower. Military Review 95(1), 127.

\section{Works in Progress}

Jordan, J. (manuscript in preparation), Meta-Analytic Examination of Employee Engagement Individual and Organization engagement antecedents on Organizational Outcomes [Submission target for 2020]

\section{Academic Teaching Experience}

Army Logistics University, Fort Lee, VA 
University Of Louisville, Louisville, Kentucky

ELFH 605 Leadership in HROD

Graduate Teaching Instructor; Assist Lead Instructor

\section{Presentations and Workshops}

\section{Workshops and Presentations, Non-Competitive}

Jordan, J. (2012). Army Talent Management: Comparisons to Current Research. Presented at the 2012 Spring Research Conference at University of Louisville, Louisville, KY

\section{Assessment \& Program Evaluation Experience}

University of Louisville, Louisville, Kentucky

Zero Waste Needs Assessment (Lee, E., Jordan, J., \& Fryrear, B.)

Yum Brands, Kentucky Fried Chicken, Louisville, KY

Chicken Mastery Program Evaluation (DeFerraro, D., \& Jordan, J.)

United States Army Human Resources Command, Fort Knox, KY

Officer Nominative Process Evaluation

\section{Professional Honors}

Awarded membership to the Honorable Order of Kentucky Colonels

\section{Non-Academic Community Service}

American Red Cross, Louisville, Kentucky, Volunteer

2012

Fort Polk Child and Youth Services, Youth Soccer Coach

2009

Fort Carson Child and Youth Services, Youth Soccer Coach

\section{Professional Affiliations}


American Educational Research Association

2011-2015

Society of Human Resource Management Professionals

2011-2013

United States Chess Federation

2009-Present

Veterans of Foreign Wars

2005-Present

Alpha Tau Omega Fraternity

2000-Present 